Aus dem Institut für Anatomie und Embryologie

(Prof. Dr. Christoph Viebahn)

der Medizinischen Fakultät der Universität Göttingen

Charakterisierung des Targetingverhaltens präsynaptischer Proteine

\author{
INAUGURAL-DISSERTATION \\ zur Erlangung des Doktorgrades \\ für Zahnheilkunde \\ der Medizinischen Fakultät der \\ Georg-August-Universität zu Göttingen
}

vorgelegt von

\title{
Donatus Riemann
}

aus

Osterode am Harz 
Dekan:

Referent/in:

Ko-Referent/in:

Drittreferent/in:

Datum der mündlichen Prüfung:
Prof. Dr. rer. nat. H. K. Kroemer

Prof. Dr. rer. nat. T. Dresbach 
Hiermit erkläre ich, die Dissertation mit dem Titel "Charakterisierung des Targetingverhaltens präsynaptischer Proteine" eigenständig angefertigt und keine anderen als die von mir angegebenen Quellen und Hilfsmittel verwendet zu haben. Göttingen, den 


\section{INHALTSVERZEICHNIS}

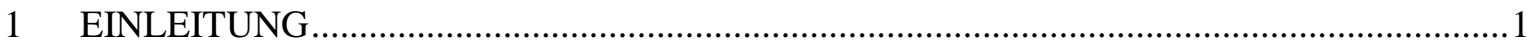

1.1 Die neuronale Synapse: Grundlagen und Struktur-Funktions-Beziehungen................... 1

1.2 Molekulare Organisation und Funktion der aktiven Zone/CAZ .................................... 5

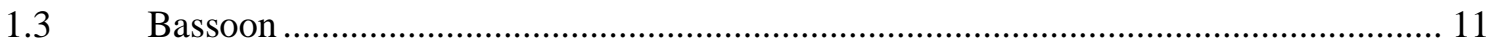

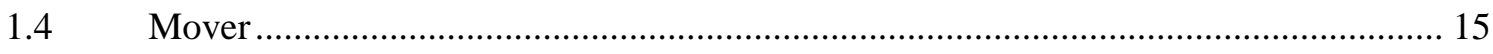

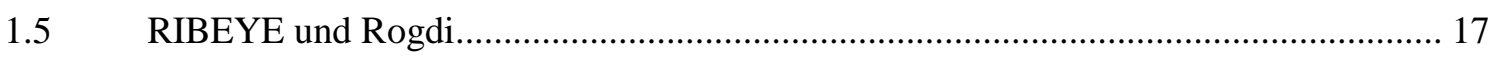

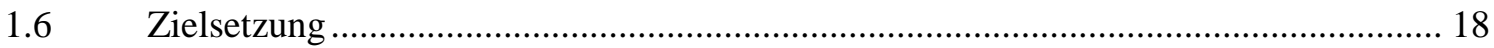

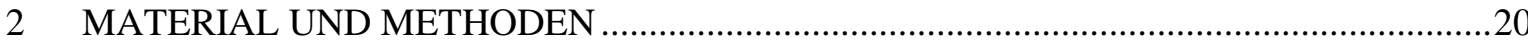

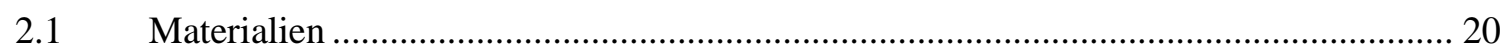

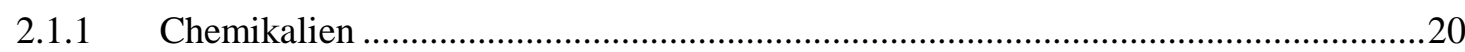

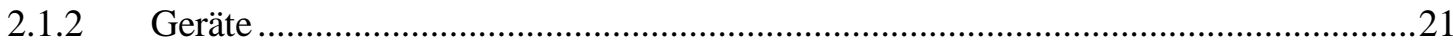

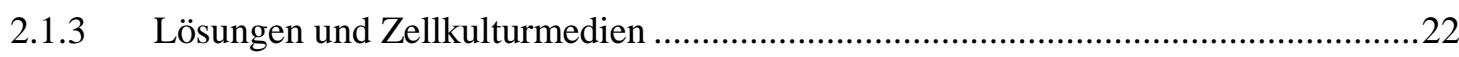

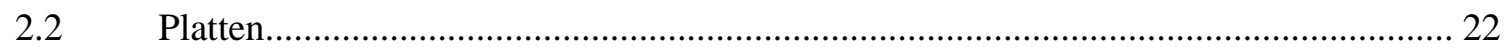

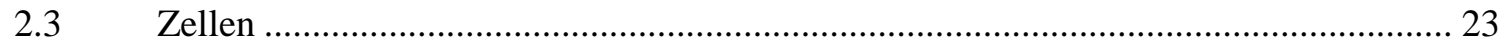

2.3.1 Hippocampale Neurone....................................................................................23

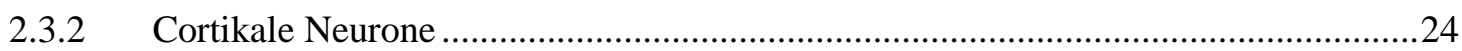

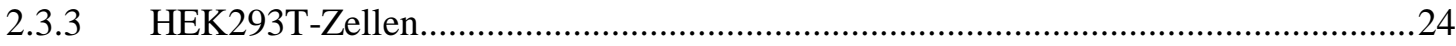

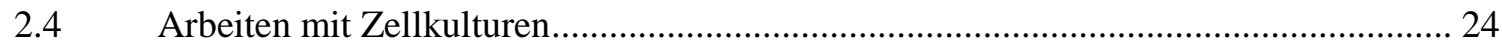

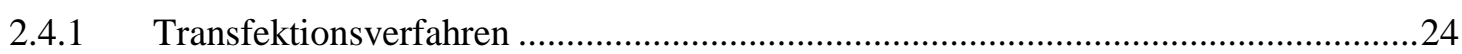

2.4.1.1 Calcium-Phosphat-Präzipitation........................................................................ 25

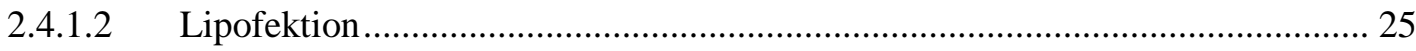

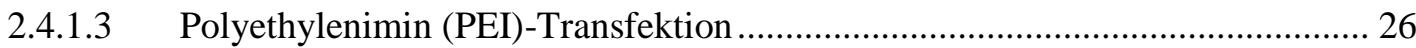

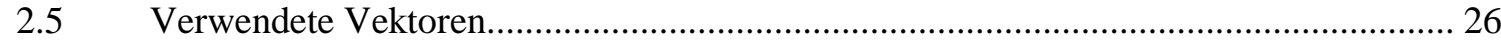

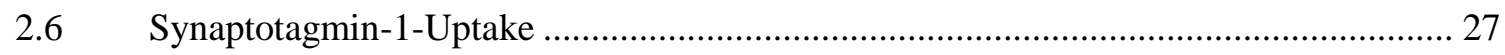

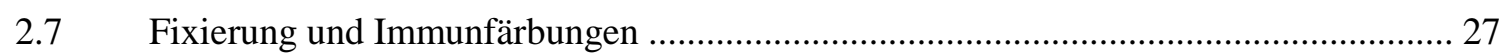

$2.8 \quad$ Fluoreszenzmikroskopie und Bildaufnahme/Fotografie ............................................... 29

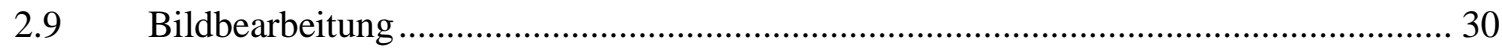

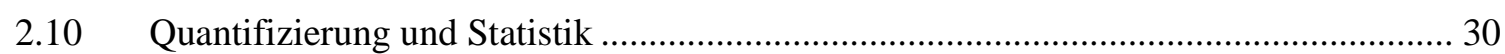

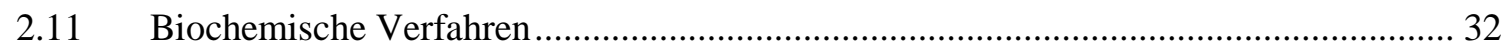

2.11.1 Verwendete Puffer und Lösungen.............................................................................32

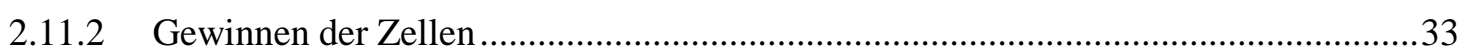

2.11.3 SDS-Polyacrylamid-Gelelektrophorese (PAGE) ………….........................................33

2.11.4 Western Blot.........................................................................................................34

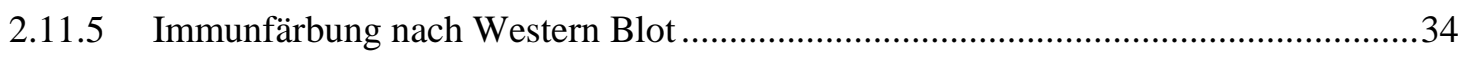

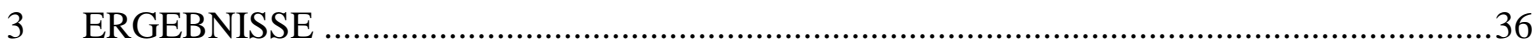

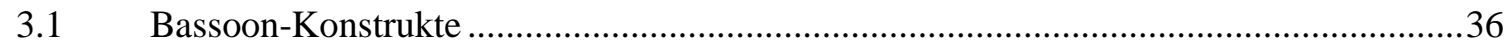


3.1.1 Verteilung und Fluoreszenzintensitäten der Konstrukte typischer präsynaptischer Proteine in den Somata junger Neurone .36

3.1.2 Verteilung und Intensität der rekombinanten Proteine in adulten Neuronen ............. 39

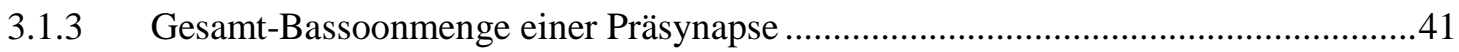

3.1.4 Bassoonmenge in starken Überexprimierern ...............................................................43

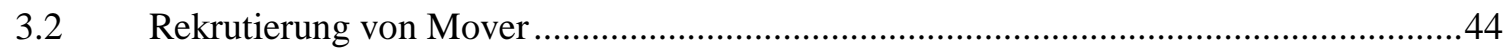

3.2.1 Verteilung und Fluoreszenzintensität von Mover in den Somata junger

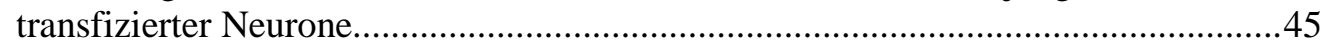

3.2.2 Anreicherung endogenen Movers in adulten transfizierten Neuronen........................47

3.2.3 Mover unter massiver Expression zweier Bassoon-Kontrukte ................................49

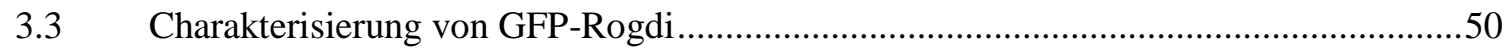

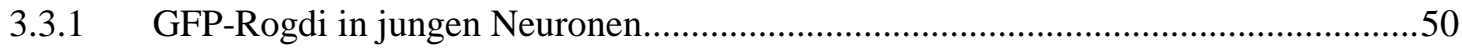

3.3.2 Untersuchung der Lokalisation des rekombinanten Rogdi .......................................51

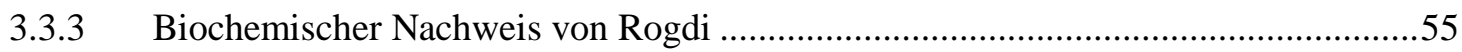

3.3.4 Synaptisches Targeting in adulten Neuronen...........................................................56

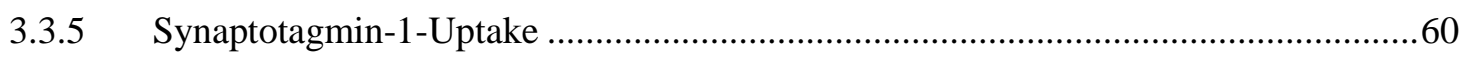

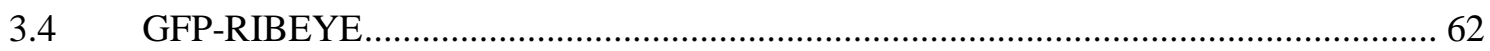

3.4.1 Expression von GFP-RIBEYE in jungen Kulturen ...............................................62

3.4.2 Rekombinantes RIBEYE in adulten Neuronen - qualitative und quantitative

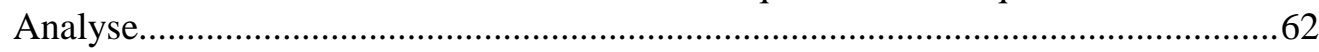

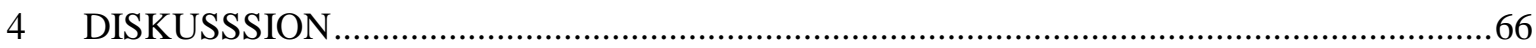

4.1 Bassoon: rekombinante Varianten und deren Einfluss auf die Mover-Rekrutierung.... 67

4.1.1 Subzelluläre Verteilung beider Bassoon-Varianten am Golgi-Apparat junger

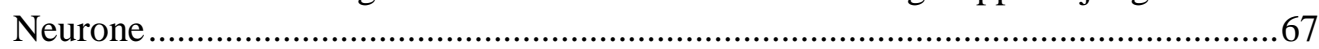

4.1.2 Mover: Bassoon als regulierender Faktor?.................................................................... 72

4.2 Rogdi: eine neue präsynaptische Komponente? ........................................................... 76

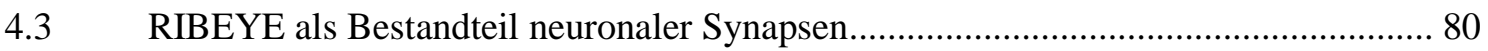

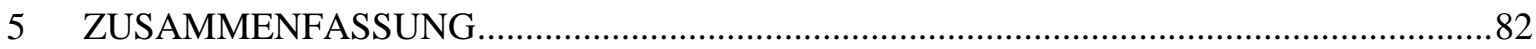

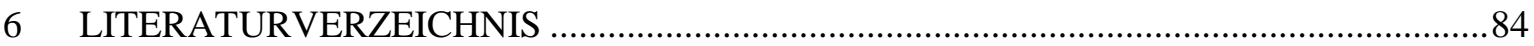




\section{Abkürzungsverzeichnis}

\begin{tabular}{|c|c|}
\hline ANOVA & einfaktorielle Varianzanalyse \\
\hline AP & Aktionspotential \\
\hline BAP & brain-specific angiogenesis inhibitor 1 (BAI1) -associated protein \\
\hline BARS & brefeldin A (BFA) adenosine diphosphate-ribosylated substrate \\
\hline BDNF & brain-derived neurotrophic factor \\
\hline BSA & Bovines Serumalbumin \\
\hline CA & Cornu Ammonis \\
\hline CASK & calcium/calmodulin dependent serine protein kinase \\
\hline CAST & CAZ-associated structural protein \\
\hline CAZ & Zytomatrix der aktiven Zone \\
\hline $\mathrm{CC}$ & coiled-coil \\
\hline CHAPS & 3-((3-cholamidopropyl) dimethylammonio)-1-propanesulfonate \\
\hline CRISPR/Cas & Clustered Regularly Interspaced Short Palindromic Repeats/ CRISPR-associated \\
\hline CtBP1 & C-terminal-binding protein1 \\
\hline CtBP2 & C-terminal-binding protein2 \\
\hline DABCO & 1,4-Diazabicyclo[2.2.2]octan \\
\hline DAO & D-amino acid oxidase \\
\hline DIV & days in vitro \\
\hline DLC & dynein light chain \\
\hline DMEM & Dulbecco`s Modified Eagle`s Medium \\
\hline DNA & Desoxyribonukleinsäure \\
\hline DPBS & Dulbecco's Phosphate-Buffered Saline \\
\hline ECL & Elektrochemilumineszenz \\
\hline EDTA & Ethylendiamintetraessigsäure \\
\hline EGFP & enhanced green fluorescent protein \\
\hline ELKS & eukaryotic-like protein kinases \\
\hline ERC & ELKS/Rab6-interacting protein 2/CAST \\
\hline EYFP & enhanced yellow fluorescent protein \\
\hline FCS & fetal calf serum \\
\hline GFP & green fluorescent protein \\
\hline GTP & Guanosintriphosphat \\
\hline HBSS & Hank’s Balanced Salt Solution \\
\hline HEK293 & human embryonic kidney 293 \\
\hline HEPES & 2-(4-(2-Hydroxyethyl)-1-piperazinyl) ethansulfonsäure \\
\hline KIF3A & kinesin family member 3A \\
\hline LAR & leukocyte common antigen-related protein \\
\hline LP & Lipoprotein \\
\hline MALS & mammalian LIN-7 \\
\hline MAP & microtubule-associated protein \\
\hline Mint1 & Munc18-1-interacting protein 1 \\
\hline Munc13 & mammalian homolog of unc- 13 \\
\hline NB & Neurobasal \\
\hline NMDA & N-Methyl-D-aspartat \\
\hline OPTM & Opti-MEM® \\
\hline PAGE & polyacrylamide gel electrophoresis \\
\hline PBS & phosphatgepufferte Salzlösung \\
\hline
\end{tabular}




$\begin{array}{ll}\text { Pclo } & \text { Piccolo } \\ \text { PDZ } & \text { PSD-95/DLG/ZO-1 } \\ \text { PEI } & \text { Polyethylenimin } \\ \text { Pen-Strep } & \text { Penicillin-Streptomycin } \\ \text { PFA } & \text { Paraformaldehyd } \\ \text { PSD } & \text { postsynaptische Dichte } \\ \text { PTV } & \text { Piccolo-Bassoon-Transportvesikel } \\ \text { PVDF } & \text { Polyvinylidendifluorid } \\ \text { Rabs } & \text { Ras-related proteins in brain } \\ \text { Rab6IP2 } & \text { Rab6-interacting protein 2 } \\ \text { RIM } & \text { Rab3 interacting molecule } \\ \text { RIM-BPs } & \text { RIM-binding proteins } \\ \text { RNA } & \text { Ribonukleinsäure } \\ \text { ROI } & \text { regions of interest } \\ \text { RP } & \text { Reservepool } \\ \text { RRP } & \text { readily releasable pool } \\ \text { SAM } & \text { sterile alpha motive } \\ \text { SDS } & \text { sodium dodecyl sulfate } \\ \text { SH3 } & \text { Src-Homologie 3 } \\ \text { Siah1 } & \text { seven in absentia homolog 1 } \\ \text { SNAP-25 } & \text { synaptosome-associated protein of 25 kDa } \\ \text { SNARE } & \text { soluble NSF attachement protein receptor } \\ \text { Svap30 } & \text { synaptic vesicle-associated protein of 30 kDa } \\ \text { syd } & \text { sunday driver } \\ \text { Syt-1 } & \text { Synaptotagmin-1 } \\ \text { TBS } & \text { Tris-buffered saline } \\ \text { TBST } & \text { Tris-buffered saline + Tween20 } \\ \text { TGN } & \text { trans-Golgi-Netzwerk } \\ \text { Tprgl } & \text { transformation related protein 63 regulated like } \\ \text { VAMP } & \text { vesicle associated membrane protein } \\ \text { VELIS } & \text { vertebrate homolog of LIN-7 } \\ \text { x g } & \text { Vielfaches der Erdbeschleunigung } \\ \text { Zn } & \text { Doppelzinkfinger } \\ \text { ZNS } & \text { Zentrales Nervensystem } \\ & \end{array}$




\section{Tabellenverzeichnis}

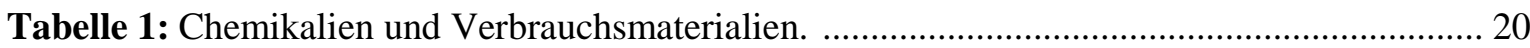

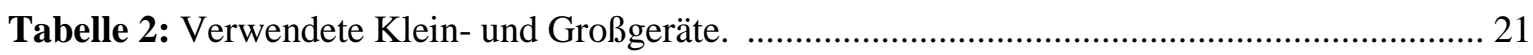

Tabelle 3: Verwendete Lösungen und Medien sowie deren Zusammensetzungen. ........................ 22

Tabelle 4: Tabellarische Übersicht der verwendeten DNAs inklusive Kurzbeschreibungen. ....... 26

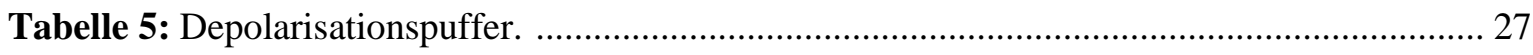

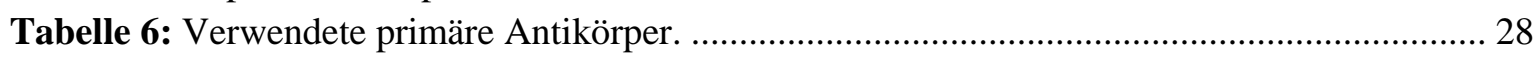

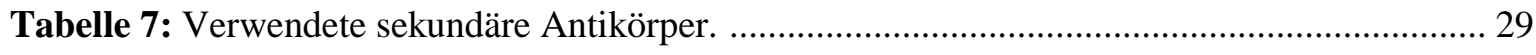

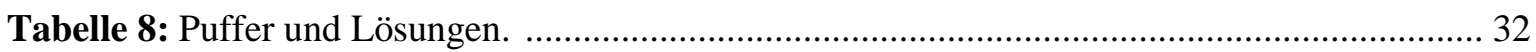

\section{Abbildungsverzeichnis}

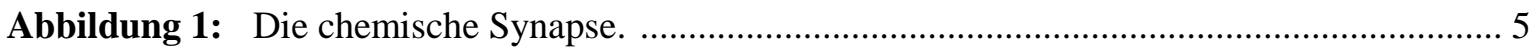

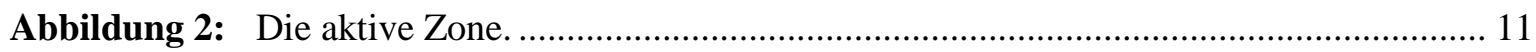

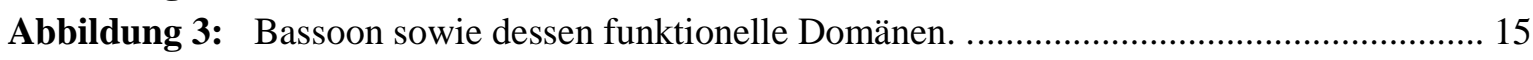

Abbildung 4: Konstrukte präsynaptischer Proteine in den Somata junger Neurone. .................... 38

Abbildung 5: Verteilung und Intensität dreier rekombinanter Proteine in adulten Neuronen...... 40

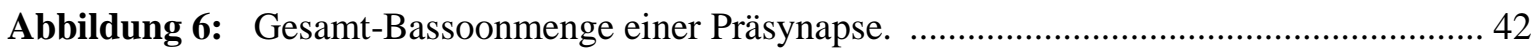

Abbildung 7: Gesamt-Bassoonmengen in starken Überexprimierern. ......................................... 44

Abbildung 8: Endogenes Mover in den Somata junger transfizierter Neurone. ............................ 46

Abbildung 9: Anreicherung endogenen Movers in adulten transfizierten Neuronen. .................. 48

Abbildung 10: Mover-Anreicherung unter massiver Expression zweier Bassoon-Kontrukte. ...... 49

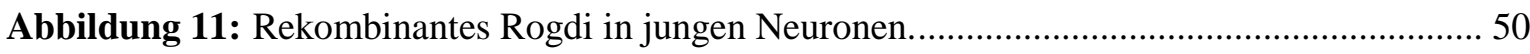

Abbildung 12: Subzelluläre Verteilung des monomeren GFP (m-GFP) ........................................ 51

Abbildung 13: Subzelluläre Verteilung des rekombinanten GFP-VAMP. ..................................... 52

Abbildung 14: Subzelluläre Verteilung des rekombinanten PSD95-GFP. ...................................... 53

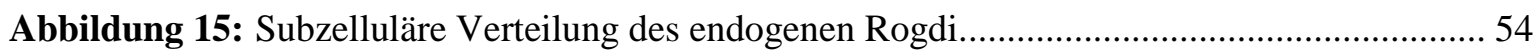

Abbildung 16: Subzelluläre Verteilung des rekombinanten GFP-Rogdi. ...................................... 55

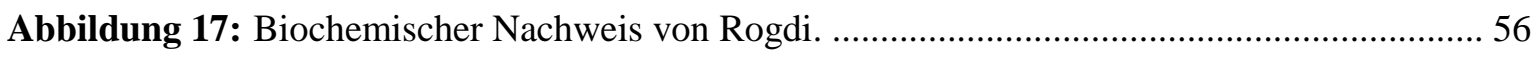

Abbildung 18: Colokalisation von GFP-Rogdi mit Synapsenmarkern. ........................................ 58

Abbildung 19: Colokalisation von GFP-Rogdi mit Synapsenmarkern II. .................................... 59

Abbildung 20: Synaptotagmin-1-Uptake in m-GFP- und GFP-Rogdi-transfizierten Neuronen.... 61

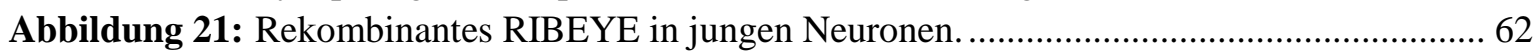

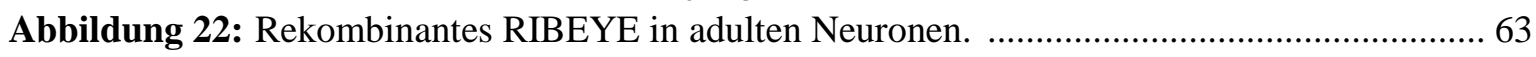

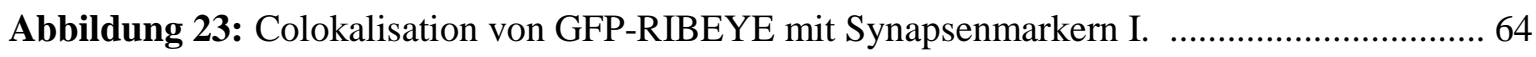

Abbildung 24: Colokalisation von GFP-RIBEYE mit Synapsenmarkern II. .................................. 65 


\section{EINLEITUNG}

\subsection{Die neuronale Synapse: Grundlagen und Struktur-Funktions- Beziehungen}

Durch einen vielschichtigen Prozess von inneren und äußeren Einflüssen, Vererbung und Zufall wurde die wohl komplexeste funktionelle Einheit unserer Erde geschaffen: das menschliche Gehirn. Als zentraler Bestandteil des Nervensystems übernimmt das Gehirn eine Vielzahl von Aufgaben. Die Verarbeitung von Reizen, welche von verschiedensten Rezeptoren sowohl auf der Körperoberfläche als auch im Körperinneren vermittelt werden, ist die Grundlage für die Kommunikation mit unserer Umgebung. Durch die Ermöglichung kognitiver Fähigkeiten einerseits sowie der Aufrechterhaltung der Körperfunktionen andererseits ermöglicht das Gehirn uns nicht nur das tägliche Über-, sondern auch ein Zusammenleben mit anderen Lebewesen. Trotz seines vergleichsweise geringen Gewichts kann das Gehirn den mannigfaltigen Anforderungen aufgrund seiner enormen Komplexität gerecht werden.

Das Gehirn setzt sich aus den Kernen sowie den Fortsätzen verschiedener Zelltypen zusammen. Man unterscheidet Neurone von Gliazellen, welche je nach Morphologie und Funktion mehreren Subtypen zugeordnet werden. Die Gliazellen übersteigen die Neurone in ihrer Anzahl deutlich um einen niedrigen zweistelligen Faktor. In der Summe geht man von rund 86 Milliarden Neuronen (Herculano-Houzel 2009) aus, welche unter- und miteinander jeweils bis zu 10.000 Synapsen, in Ausnahmefällen über 100.000, ausbilden. Neben der erstaunlichen Anzahl verblüffen Synapsen durch ihre Plastizität: die Eigenschaft, ihre Morphologie und Informationsverarbeitung nutzungsbedingt an die gegebenen Umstände anzupassen. Grundsätzlich werden zwei verschiedene Typen von Synapsen unterschieden. Bei dem phylogenetisch älteren und im reifen zentralen Nervensystem (ZNS) von Säugern deutlich weniger häufig vorkommenden Typ handelt es sich um die elektrische Synapse, bei der in der Regel eine direkte elektrische Kopplung zwischen zwei Neuronen vorliegt. Histologisch wird der Zellkontakt durch gap junctions vermittelt. Porenbildende Proteinkomplexe, sogenannte Connexone, sorgen für das unmittelbare Anliegen der Zellmembranen zweier Neurone. Der die Zellen trennende Spalt liegt in einer Größenordnung von 2-3,5 nm. Ein Connexon besteht aus sechs Connexinen, die sich zu einem Halbkanal zusammenlagern. Durch das End-zu-End-Aneinanderlagern jeweils zweier Halbkanäle wird die Verbindung zwischen Synapsen dieses Typs hergestellt. Aufgrund der 
Durchlässigkeit für niedermolekulare Stoffe und Ionen wird die Kommunikation ohne zeitliche Verzögerung ermöglicht. Durch ein eingehendes Aktionspotential (AP) wird die präsynaptische Zelle depolarisiert, und es entsteht ein Potentialgefälle zwischen ihr und der postsynaptischen Zelle, aufgrund dessen ein entsprechender Ionenstrom durch die Connexone erfolgt. Durch diese elektrische Verbindung kommt es zu einer unmittelbaren Depolarisation der nachgeschalteten Zelle und bei Überschreiten der Reizschwelle zur Ausbildung eines Aktionspotentials, welches bei entsprechender Häufigkeit und/oder Amplitude seine Wirkung auf eine nachgeschaltete Zelle entfaltet.

Die chemische Synapse (Abbildung 1) unterscheidet sich in Struktur und Wirkungsweise deutlich von der elektrischen. Sie besitzt einen asymmetrischen Aufbau aus Prä- und Postsynapse, welche voneinander durch den synaptischen Spalt getrennt sind. Diese ca. 20-50 nm breite Zone enthält eine proteinreiche extrazelluläre Matrix. Die Kommunikation der beiden Teile wird durch Neurotransmitter, die Boten- oder Überträgerstoffe des Nervensystems, gewährleistet. Zu dieser Gruppe zählt man Stoffe wie biogene Amine, Aminosäuren, Neurohormone, -modulatoren und -peptide. Diese Botenstoffe befinden sich auf präsynaptischer Seite in zahlreichen membranumschlossenen Containern, den synaptischen Vesikeln und werden nach deren Reifung bei Bedarf in den synaptischen Spalt abgegeben. Die ca. $40 \mathrm{~nm}$ großen synaptischen Vesikel werden klassischerweise drei Gruppen, sogenannten Pools, zugeordnet, auch wenn die Grenzen zwischen den Pools fließend sind. Bei dem fusionsbereiten Pool, auch readily releasable pool (RRP) genannt, handelt es sich im Vergleich zur Gesamtmenge der synaptischen Vesikel um eine recht kleine Ansammlung (1-2 \%), die aufgrund ihrer unmittelbaren Lage an der präsynaptischen Membran und vorangegangenen Reifungsschritten sehr schnell freigesetzt werden kann, aber auch nach wenigen elektrischen Stimulationen erschöpft ist. Bei moderater Stimulation wird die weitere Neurotransmitterfreisetzung innerhalb weniger Sekunden durch die mobilen Vesikel des recycling pools gewährleistet. Erst bei unphysiologisch starker Stimulation und mit zeitlicher Verzögerung wird auf den 80-90 \% der Vesikel umfassenden Reservepool (RP) zurückgegriffen (Denker und Rizzoli 2010; Rizzoli und Betz 2005). Der Vorgang der Neurotransmitterausschüttung ist ein Prozess, der einer gewissen Koordination bedarf und nur in bestimmten Bereichen der Präsynapse, den sogenannten aktiven Zonen, möglich ist. Zu Beginn des Vorgangs trifft ein AP in die präsynaptische Endigung ein und bewirkt dort eine Depolarisation. Durch die Veränderung des Membranpotentials öffnen sich in der Zellmembran befindliche spannungsabhängige $\mathrm{Ca}^{2+}$-Kanäle. Das einströmende $\mathrm{Ca}^{2+}$ bindet an Synaptotagmin, ein Vesikelprotein. Die Verschmelzung der Vesikel- mit der Plasma- 
membran des Boutons und damit die Transmitterausschüttung werden durch sogenannte SNARE (soluble NSF attachement protein receptor)-Proteine vermittelt. Bei diesen handelt es sich um Synaptobrevin, Syntaxin und SNAP-25 (synaptosome-associated protein of 25 $\mathrm{kDa}$ ). Man unterscheidet eine vollständige Verschmelzung von einer kurzzeitig bestehenden Porenbildung, die entweder als kiss-and-run- oder kiss-and-stay-Ausschüttung bezeichnet wird, je nachdem, ob das Vesikel den Ausschüttungsort verlässt oder dort verbleibt (Breckenridge und Almers 1987; Ceccarelli et al. 1972; Zimmerberg et al. 1987). Die in den synaptischen Spalt freigesetzten Überträgerstoffe diffundieren zur Postsynapse und können dort durch die Bindung an spezifische Rezeptoren ihre Wirkung entfalten. Zu den Wirkungen von Neurotransmittern gehören die Beeinflussung von Ionenkanälen und G-Proteinen. So kann auf das postsynaptische Neuron ein erregender, hemmender oder modulierender Einfluss mit einer resultierenden postsynaptischen Potentialänderung genommen werden. G-Protein-gekoppelte Rezeptoren dienen der Aktivierung verschiedener Signaltransduktionskaskaden im Rahmen der Informationsverarbeitung.

Potentialänderungen im postsynaptischen Neuron werden elektrotonisch, also mit exponentiellem Amplitudenabfall zum Axonhügel weitergeleitet. In der Summe wird somit eine elektrische Information zunächst in eine chemische und anschließend wieder in eine elektrische umgewandelt. Dabei kommt es im postsynaptischen Teil nur zu einer erneuten Umsetzung in einen elektrischen Impuls, wenn das eintreffende Signal bzw. die Summe der Signale das Überschreiten eines Schwellenwerts ermöglicht. Diese Form der Informationsverarbeitung bezeichnet man auch als Alles-oder-nichts-Prinzip, da im Falle unterschwelliger Reizung keine Aktionspotentiale am Axonhügel der nachgeschalteten Zelle gebildet werden.

Im Anschluss an die Transmitterfreisetzung kommt es auf der präsynaptischen Seite zu einer Wiederaufnahme der Vesikel. Im Rahmen von Maturierungsschritten werden sie entsprechend dem synaptischen Vesikelzyklus wieder aufgefüllt und stehen erneut zur Exozytose bereit (Südhof 1995). Um eine dauerhafte Wirkung der Überträgerstoffe und damit eine Desensitisierung zu vermeiden, werden diese enzymatisch abgebaut oder von der Präsynapse sowie benachbarten Gliazellen wieder aufgenommen. Durch Diffusion werden sie ebenfalls aus dem synaptischen Spalt entfernt.

Ultrastrukturell sind die Orte der Neurotransmission und -rezeption durch Verdichtungen auf beiden Seiten einer Synapse gekennzeichnet. Der präsynaptische Ort, an dem mehrere hundert transmittergefüllte Vesikel (Schikorski und Stevens 1997) andocken und calciumabhängig fusionieren wird als Zytomatrix der aktiven Zone (CAZ) bezeichnet 
(Couteaux und Pecot-Dechavassine 1970). Deren Aufgaben sind so grundlegend wie vielfältig und unabdingbar für die synaptische Funktionalität. Sowohl Andocken, Priming und Entleerung als auch Recycling der Vesikel erfolgen in dieser aktiven Zone. Bei einem Durchmesser von bis zu 500 nm (Siksou et al. 2007) enthält die aktive Zone eine Vielzahl dicht gepackter Proteine. Elektronenmikroskopische Aufnahmen von Säugern zeigen, dass dieser komplexen Struktur elektronendichte, kegelförmige Bereiche von jeweils ca. $50 \mathrm{~nm}$ zugrunde liegen (Phillips et al. 2001), die untereinander durch Filamente des Zytoskeletts verbunden sind (Zhai 2004).

Der durch den synaptischen Spalt von der Präsynapse getrennte postsynaptische Teil wird aufgrund seines elektronenmikroskopischen Erscheinungsbildes als postsynaptische Dichte (PSD) bezeichnet und besteht neben der postsynaptischen Membran aus verschiedenen Rezeptoren, Ionenkanälen und weiteren Proteinen, die mit assoziierten Signaltransduktionskomponenten in Verbindung stehen (Sheng und Hoogenraad 2007).

Sonderformen stellen neben neuromuskulären Synapsen, welche als Kontaktstellen zwischen Motoneuronen und Skelettmuskelfasern dienen, sogenannte Bandsynapsen in sensorischen Zellen wie Fotorezeptoren und inneren Haarzellen dar. Bei diesen bis zu 500 nm messenden Strukturen finden sich präsynaptische bandförmige Bereiche, welche als ribbons bezeichnet werden und von Vesikeln gesäumt sind. Die gegen Zelllyse resistente und damit feste Anbindung der synaptischen Vesikel an den jeweiligen bandförmigen Abschnitt erfolgt über etwa $20 \mathrm{~nm}$ messende Filamente. Auch innerhalb dieser synaptischen Sonderform wird in morphologisch unterschiedliche Typen differenziert. Im Frosch findet man beispielsweise sphärisch geformte Bandsynapsen, während es im Rochen zur Ausbildung eines abgeflachten Subtyps kommt (Lenzi et al. 1999; Lenzi und Von Gersdorff 2001). 

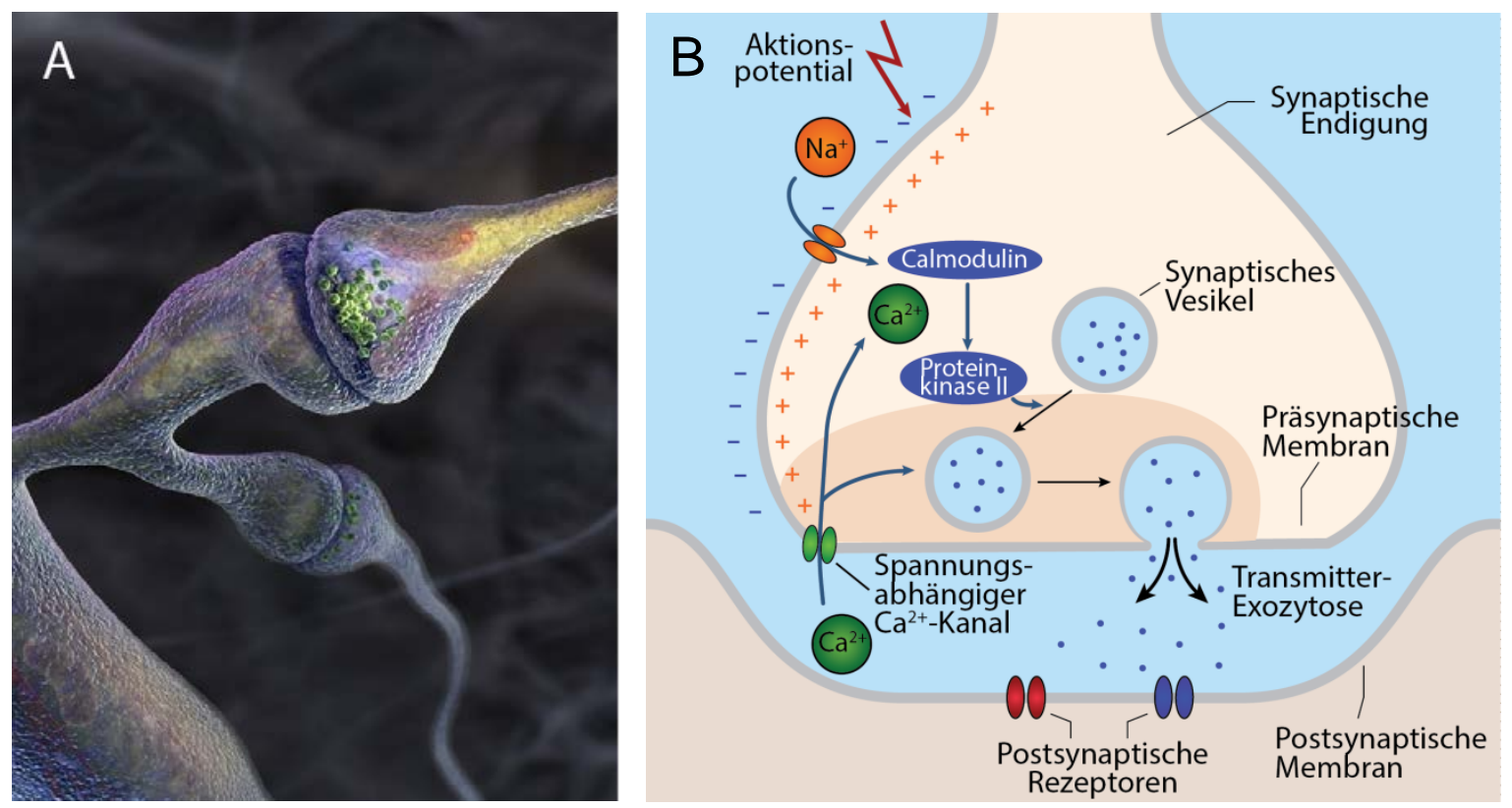

Abbildung 1: Die chemische Synapse. Darstellungen einer chemischen Synapse, welche aus einem prä- sowie einem postsynaptischen Anteil besteht. Beide Abschnitte sind durch den dazwischen liegenden synaptischen Spalt voneinander getrennt (A). In (B) ist der physiologische Ablauf der neuronalen Informationsübertragung schematisch dargestellt. Ein einströmendes Aktionspotential bewirkt die $\mathrm{Ca}^{2+}$-abhängige Neurotransmitterexozytose. Die Botenstoffe entfalten ihre Wirkung an nachgeschalteten Rezeptoren der postsynaptischen Membran. Quellen: (A) Die Abbildung wurde von Herrn Graham Johnson für HHMI (C2004 erstellt; die Verwendung erfolgt mit deren freundlicher Genehmigung, (B) Die Verwendung der Abbildung erfolgt mit freundlicher Genehmigung von Herrn Hermes Pofantis.

\subsection{Molekulare Organisation und Funktion der aktiven Zone/CAZ}

Der 1970 von Couteaux und Pecot-Dechavassine geprägte Begriff „aktive Zone“ bezeichnet scheibenähnliche, im Durchmesser ca. 200-500 nm messende, hochspezialisierte Bereiche der präsynaptischen Nervenendigungen (Abbildung 2), an denen eine Freisetzung von Neurotransmittern und somit eine Kommunikation zwischen Neuronen erfolgen kann (Siksou et al. 2007). Bei der Zytomatrix der aktiven Zone handelt es sich um einen vergleichsweise dynamischen Bereich. Diese Dynamik wird durch den Austausch einzelner Komponenten, vor allem aber durch den Verbrauch und die Erzeugung synaptischer Vesikel bestimmt. Diese Vorgänge erfordern eine präzise molekulare Organisation, welche unter anderem anhand des synaptischen Vesikelzyklus ersichtlich wird. Innerhalb dieses Zyklus durchlaufen synaptische Vesikel verschiedene Reifungsstufen. Nach der Befestigung an der aktiven Zone, dieser Schritt wird auch als tethering bezeichnet, lagern sich die Vesikel an die Plasmamenbran an (docking), durchlaufen einen weiteren Schritt, welcher sie fusionsbereit macht (priming) und sind damit in der Lage, ihren Inhalt in den synaptischen Spalt abzugeben. Verbrauchte Vesikel werden durch Endozytose wiedergewonnen und erneut mit Neurotransmittern befüllt, sodass sie dem Zyklus weiterhin erhalten bleiben (Südhof 2004). Neben der Vesikelreifung muss die aktive Zone nutzungsbedingte Änderungen reibungslos durchlaufen können (Kurz- und Langzeitplastizität). 
Obwohl wahrscheinlich noch weitere Komponenten und Eigenschaften der aktiven Zone unbekannt sind, muss davon ausgegangen werden, dass sie für die Funktionalität einer Synapse unentbehrlich ist. Neben der Stabilisierung und Organisation der Präsynapse werden durch die regulierte Reifung synaptischer Vesikel und die Rekrutierung spannungsabhängiger $\mathrm{Ca}^{2+}$-Kanäle neben der Neurotransmitterfreisetzung auch die Kurz- sowie Langzeitplastizität der Synapse ermöglicht. Dabei gehen die Funktionen der aktiven Zone mit bestimmten morphologischen Eigenschaften einher. Zu diesen gehören das aufgrund der proteinreichen Bestandteile bestehende elektronendichte Erscheinungsbild, das Vorhandensein von Vesikelgruppen sowie die unmittelbare räumliche Nähe zur PSD. Aufgrund der Morphologie unterscheidet man die aktive Zone in unterschiedliche Abschnitte: (1) die präsynaptische Membran, welche der PSD gegenüberliegt und an welcher die Ausschüttung von Neurotransmittern erfolgt, (2) die sich anschließende Zytomatrix, in der das Andocken der Vesikel statt findet sowie (3) das Zytoplasma, in welches elektronendichte Ausläufer hineinragen. Zusätzlich zu den ubiquitär vorkommenden und das Zytoskelett bildenden Proteinen Actin, Myosin, Spektrin (Burns und Augustin 1995), Tubulin, Cadherin, ß-Catenin (Hirokawa et al. 1989; Missler und Südhof 1998; Phillips et al. 2001), Syndekan (Hsueh et al. 1998) sowie der weiteren bereits bekannten Proteine sind im Laufe der letzten Jahre weitere Komponenten der Zytomatrix identifiziert worden. Fünf sowohl struktur- als auch funktionsgebende Proteine waren gehäuft Gegenstand wissenschaftlicher Arbeiten. CAST (CAZ-associated structural protein, (Ohtsuka et al. 2002))/ELKS (eukaryotic-like protein kinases (Nakata et al. 1999))/Rab6IP2 (Rab6-interacting protein 2 (Monier et al. 2002)), Munc13 (mammalian homolog of unc-13 (Betz et al. 2001; Brose et al. 1995)), RIM (Rab3 interacting molecule (Betz et al. 2001; Wang et al. 1997)) und die beiden homologen und außergewöhnlich großen Proteine Bassoon und Piccolo/Aczonin (Cases-Langhoff et al. 1996; tom Dieck et al. 1998; Fenster et al. 2000; Limbach et al. 2011, Wang et al. 1999) mit Massen von 420 und 550 kDa. Diese Proteine kommunizieren untereinander und auch mit weiteren Proteinen der präsynaptischen Zytomatrix sowie peripheren, integralen und Transmembranproteinen, zu denen auch RIM-binding proteins, kurz RIM-BPs (Wang et al. 2000), $\alpha$-Liprine (Serra-Pagès et al. 1998), der CASK/VELIS-/Mint1 (calcium/calmodulin dependent serine protein kinase/vertebrate homolog of LIN-7/Munc18-1-interacting protein 1)-Komplex (Butz et al. 1998), die verschiedenen Typen der $\mathrm{Ca}^{2+}$-Kanäle und Rezeptorproteintyrosinphosphatasen gehören. Es konnte nachgewiesen werden, dass der Aufbau von aktiven Zonen mithilfe sogenannter Piccolo-Bassoon-Transportvesikel (PTVs) erfolgt, welche mit einer Geschwindigkeit von bis zu $5 \mu \mathrm{m}$ pro Sekunde in Richtung sich entwi- 
ckelnder Synapsen transportiert werden und unter anderem die Proteine Aczonin/Piccolo und Bassoon enthalten (Ahmari et al. 2000; Shapira et al. 2003; Zhai et al. 2001). Untersuchungen deuten an, dass auf diese Weise bereits 25-30 min nach dem ersten Zell-ZellKontakt funktionsfähige aktive Zonen entstehen (Friedman et al. 2000). Nach dem Zusammenstellen übernehmen die oben genannten Proteine verschiedene, jedoch eng miteinander verknüpfte Funktionen.

\section{Munc13}

Bei Munc13 (mammalian homolog of unc-13) handelt es sich um die in Säugetieren vorkommenden Homologe zu dem in Nematoden (Caenorhabditis elegans) beschriebenen unc-13 Gen, welches für das Vesikelpriming, also die Bereitstellung fusionsbereiter Vesikel, unerlässlich ist (Augustin et al. 1999; Brose et al. 2000). Die entsprechenden Munc13Gene codieren für eine Proteinfamilie, die sich aus mindestens fünf Mitgliedern zusammensetzt, die sich lediglich N-terminal voneinander unterscheiden und einerseits hauptsächlich im Gehirn vorkommen (Munc13-1, Munc13-3, BAP (brain-specific angiogenesis inhibitor 1 (BAI1) -associated protein 2)), andererseits ubiquitär exprimiert werden (Munc13-2 und Munc13-4). Dabei werden aus Munc13-2 promotorabhängig entweder das ubiquitär vorkommende ubMunc13 oder das gehirnspezifische bMunc13-2 exprimiert (Augustin et al. 1999; Brose et al. 1995; Koch et al. 2000). Unter anderem konnten neben RIMs (Betz et al. 2001; Dulubova et al. 2005; Lu et al. 2006), Rabs (Ras-related proteins in brain) (Wang et al. 2009), Aczonin/Piccolo, Bassoon und CAST (Wang et al. 2009) auch SNARE-Proteine als Interaktionspartner nachgewiesen werden (Guan et al. 2008), wobei Munc13 zusammen mit RIM1 $\alpha$ und Rab3A einen heterotrimeren Komplex bildet (Dulubova et al. 2005). Das Vesikelpriming erfolgt in Abhängigkeit von der MUNDomäne der Munc13-Proteine (Basu et al. 2005; Stevens et al. 2005) und einer Konformationsänderung von Syntaxin-1 (Gerber et al. 2008), wodurch eine anschließende SNAREKomplex-bildung (Ma et al. 2011; Richmond et al. 2001) bewirkt wird. Es konnte nachgewiesen werden, dass die MUN-Domäne durch Homodimerisierung der Muncs über ihre Nterminalen C2A-Domänen ihre Wirksamkeit verliert (Deng et al. 2011). Dabei nimmt Munc13 nicht nur Einfluss auf die Verschmelzung von Vesikel- und präsynaptischer Membran einerseits, sondern möglicherweise auch auf die Befestigung der Vesikel an der Plasmamembran andererseits (Siksou et al. 2009). Darüber hinaus übt Munc13 vermutlich einen regulierenden Einfluss auf die Neurotransmitterexozytose und damit auf die Plastizität der Synapse aus (Rhee et al. 2002; Rosenmund et al. 2002). 


\section{RIM}

Ein weiterer zentraler Bestandteil der Zytomatrix der aktiven Zone ist das Multidomänenprotein RIM, welches für das Docken und Priming synaptischer Vesikel (Deng et al. 2011; Koushika et al. 2001), die Rekrutierung von $\mathrm{Ca}^{2+}$-Kanälen (Han et al. 2011) und sowohl die Kurz- (Schoch et al. 2002) als auch die Langzeitplastizität der Synapse sowohl über Cannabinoid- als auch NMDA (N-Methyl-D-aspartat)-Rezeptoren zuständig ist (Castillo et al. 2002; Chevaleyre et al. 2007; Fourcaudot et al. 2008; Huang et al. 2005; Lachamp et al. 2009; Pelkey 2008). Über seine verschiedenen Bindungsstellen steht es im Mittelpunkt der komplexen Vesikelexozytosemaschinerie. N-terminal besteht über einen Zinkfinger eine Verbindung zur jeweiligen C2A-Domäne von Munc 13-1 und ubMunc 13-2 (Betz et al. 2001; Dulubova et al. 2005). Über die den Zinkfinger umgebenden $\alpha$-Helices wird eine GTP (Guanosintriphosphat)-abhängige Bindung zu Rab-Proteinen der funktionellen Gruppen III und VIII (Dulubova et al. 2005; Fukuda 2003; Wang et al. 2000; Wang et al. 1997) und somit indirekt zu den synaptischen Vesikeln hergestellt (Von Mollard et al. 1990). Durch die Bindung an die C2A-Domäne von Munc13 werden die inaktiven Munc13Homodimere in eine aktive Form überführt und zu einem Bestandteil eines heterodimeren Komplexes aus RIM und Munc13 (Deng et al. 2011; Dulubova et al. 2005). Bei der zentral gelegenen PDZ-Domäne, deren Name sich vom Vorkommen in den Proteinen PSD95/SAP90, Discs large und Zonula occludentes-1 ableitet, handelt es sich um eine bedeutende Interaktionsdomäne. Diese bindet ELKS (Ohtsuka et al. 2002; Wang et al. 2002) und einige Typen der $\mathrm{Ca}^{2+}$-Kanäle (N- und P/Q-Typ, aber nicht L-Typ) und trägt damit zu deren Rekrutierung bei (Han et al. 2011; Kaeser et al. 2011). Mit ihren zwischen den C2Aund C2B-Domänen liegenden prolinreichen Sequenzen sind sie in der Lage, an SH3 (SrcHomologie 3)-Domänen der RIM-BPs zu binden (Wang et al. 2000), welche wiederum mit $\mathrm{Ca}^{2+}$-Kanälen in Verbindung stehen. Die C2B-Domäne stellt den Kontakt mit $\alpha$-Liprinen her. Es konnte gezeigt werden, dass die synaptischen Vesikel in Caenorhabditis elegans Rab3- und UNC-10-abhängig an die aktive Zone gebracht werden (Gracheva et al. 2008) und in Zusammenhang mit Zelladhäsionsmolekülen stehen. Die mit den RIM-Proteinen interagierenden RIM-BPs, von denen in Säugern drei Gene nachgewiesen wurden, in Drosophila hingegen nur ein Gen identifiziert werden konnte (Liu et al. 2011; Mittelstaedt und Schoch 2007; Wang et al. 2000), stehen über ihre drei SH3-Domänen mit N-, P/Q- und auch L-Typ-Ca ${ }^{2+}$-Kanälen (Hibino et al. 2002; Kaeser et al. 2011) in Beziehung. Diese funktionellen Abschnitte stellen gleichzeitig die Verknüpfung zu den RIMs dar (Wang et al. 2000). Mutationen der entsprechenden Proteine riefen in Drosophila eine Reduktion der 
$\mathrm{Ca}^{2+}$-Kanäle und infolgedessen eine deutlich reduzierte Freisetzungswahrscheinlichkeit der synaptischen Vesikel hervor (Liu et al. 2011). Daher kann vermutet werden, dass die RIMBPs entscheidend an der Rekrutierung von $\mathrm{Ca}^{2+}$-Kanälen beteiligt sind.

\section{ELKS und CASK}

Ein weiteres Protein der aktiven Zone, ELKS, welches auch durch seine vielfältigen Bezeichnungen wie CAST (Ohtsuka et al. 2002), ERC (ELKS/Rab6-interacting/CAST (Wang et al. 2002)) oder Rab6IP2 (Rab6-interacting protein 2 (Monier et al. 2002)) auffällt, wurde ursprünglich in einem papillären Thyroidea-Karzinom gefunden (Nakata et al. 1999). Durch das Vorhandensein von Genen mit alternativen N-terminalen Promotorregionen und C-terminalen Spleißsequenzen treten in Säugern zwei Mitglieder der ELKS-Familie auf: CAST1 und CAST2 (Wang et al. 2002). Diese interagieren mit Bassoon (Takao-Rikitsu et al. 2004), $\alpha$-Liprinen (Ko et al. 2003), Piccolo/Aczonin (Wang et al. 2009), Rab6 (Monier et al. 2002), RIM und Munc (Ohtsuka et al. 2002; Wang et al. 2002). Untersuchungen in Drosophila ergaben, dass diese in T-förmigen Bereichen („T-bars“) ihrer neuromuskulären Verzweigungsstellen ein zum Teil homologes Protein besitzt, welches am Aufbau der aktiven Zone, an der $\mathrm{Ca}^{2+}$-Kanalrekrutierung und der Vesikelfreisetzung beteiligt ist (Kittel et al. 2006). Verminderte Expression des Proteins führte dabei unter anderem zum Verlust der T-bars, teilweisem Fehlen synaptischer Komponenten und einem instabilen Flug der Fliegen, weshalb es den Namen „Bruchpilot“ erhielt (Wagh et al. 2006). Das Protein CASK, welches sowohl in prä- als auch postsynaptischen Endigungen zu finden ist (Hsueh et al. 1998), bildet zusammen mit VELIS/MALS (mammalian LIN-7) und Mint1/Lin-10 einen heterotrimeren Komplex (Butz et al. 1998; Kaech et al. 1998). Dieser ist wiederum in der Lage sowohl mit $\alpha$-Liprinen als auch mit Munc18-1 zu interagieren, wodurch Rekrutierung und Befestigung weiterer Bestandteile der aktiven Zone ermöglicht werden (Okamoto und Südhof 1997; Olsen et al. 2005). Mutationen von CASK führen in Drosophila zu einer verringerten Anzahl neuromuskulärer Synapsen, einer veränderten synaptischen Übertragung und damit zu einer funktionellen Einschränkung betroffener Synapsen (Chen und Featherstone 2011). Neben der Interaktion mit den oben genannten Proteinen ist CASK in der Lage, über seine PDZ-Domäne fest an Adhäsionsmoleküle wie Neurexin und Syndekan zu binden und damit zu der transsynaptischen Befestigung der Zytomatrix der aktiven Zone beizutragen (Hata et al. 1996; Hsueh et al. 1998). 


\section{a-Liprine und Synapsine}

Bisher sind einige homologe Varianten der $\alpha$-Liprine bekannt, nämlich syd (sunday driver)-2 in Caenorhabditis elegans, Dliprin in Drosophila sowie vier weitere in Säugetieren (Liprin- $\alpha 1-4)$. Das Vorkommen von Liprin- $\alpha 2$ und Liprin- $\alpha 3$ beschränkt sich auf das Nervensystem, während die beiden anderen auch außerhalb des Gehirns zu finden sind (SerraPages et al. 1998). Die Interaktionen mit andern Proteinen sind vielfältig: unter anderem Cterminal über drei SAM (sterile alpha motive)-Domänen mit CASK und ß-Liprinen und LAR-Typ (leukocyte common antigen-related protein)-Rezeptorphosphotyrosinphosphatasen, N-terminal über eine coiled-coil-Domäne mit RIM, ELKS und Piccolo (Schoch und Gundelfinger 2006; Spangler und Hoogenraad 2007; Stryker und Johnson 2007). Unter anderem tragen sie über ihre Bindung zu LAR-Typ-Rezeptorphosphotyrosinphosphatasen zur Bildung von Synapsen bei (Ackley et al. 2005; Serra-Pagès et al. 1998). In Caenorhabditis elegans und Drosophila riefen Mutationen der entsprechenden Homologe der $\alpha$-Liprinen strukturelle Veränderungen der aktiven Zonen und eine Störung von Transport sowie Akkumulation der synaptischen Vesikel hervor (Dai et al. 2006; Kaufmann et al. 2002; Miller et al. 2005; Zhen und Jin 1999).

Eine weitere Proteinfamilie, die Synapsine, nimmt einen modulierenden Einfluss auf die Verfügbarkeit von synaptischen Vesikeln sowie die neuronale Plastizität (Cesca et al. 2010; Tarelli et al. 1992). Bis heute konnten 10 homologe Mitglieder bestimmt werden (Ia, Ib, IIa, IIb, IIIa-f; (Porton et al.1999a; Porton et al. 1999b; Südhof 1989)) die durch alternatives Spleißen der drei in Säugern vorkommenden Gene (SYN1, SYN2, SYN3) erzeugt werden (Übersichtsartikel in Cesca et al. 2010). Die Synapsine interagieren nicht nur miteinander (Hosaka und Südhof 1999), sondern stehen mit nahezu allen Zytoskelettbestandteilen in Verbindung (Übersichtsartikel in Cesca et al. 2010). Da sie des Weiteren auf synaptischen Vesikeln der verschiedenen Vesikelpools (RP, RRP und recycling pool) gefunden wurden (Bloom et al. 2003; Hilfiker et al. 1998) kann von einer generellen strukturellen Funktion, dem Verbinden der synaptischen Vesikel mit dem präsynaptischen Zytoskelett, ausgegangen werden (Hirokawa et al. 1989). Diese Annahme sieht sich durch Experimente an knock-out-Mäusen bestätigt, bei denen es zu einer signifikanten Abnahme an synaptischen Vesikeln kam (Siksou et al. 2007).

\section{Bassoon und Piccolo}

Als strukturgebende Komponenten bzw. Gerüstproteine fungieren die beiden außergewöhnlich großen Proteine Bassoon und Piccolo, welche insgesamt 10 homologe Regionen aufweisen. Daneben sind sie am Wiederbeladen synaptischer Vesikel beteiligt, jedoch ohne 
die Vesikelexozytose direkt zu beeinflussen (Hallermann et al. 2010; Mukherjee et al. 2010). Mithilfe von knock-out-Versuchen konnte deren Einfluss auf das Überleben von Mäusen und die Neurotransmitterfreisetzung in kultivierten Neuronen studiert werden. Das Fehlen eines der beiden Proteine allein wirkte sich dabei weniger stark negativ aus, wohingegen das gleichzeitige Abhandensein beider strukturgebender Komponenten bei sonst gleich bleibender Zusammensetzung der synaptischen Endigungen deutliche Veränderungen der Ultrastruktur der CAZ und der PSD einerseits und dem Zusammenlagern und Docken der synaptischen Vesikel andererseits bewirkte (Altrock et al. 2003; Angenstein et al. 2008; Mukherjee et al. 2010).

In den vergangenen Jahren konnten somit viele Komponenten sowie Funktionen der Zytomatrix der aktiven Zone identifiziert werden. Dennoch liegt die Vermutung nahe, dass nur ein Teil dieser komplexen Struktur vollständig verstanden ist und weitere Bestandteile sowie deren Bedeutung bislang unbekannt sind.
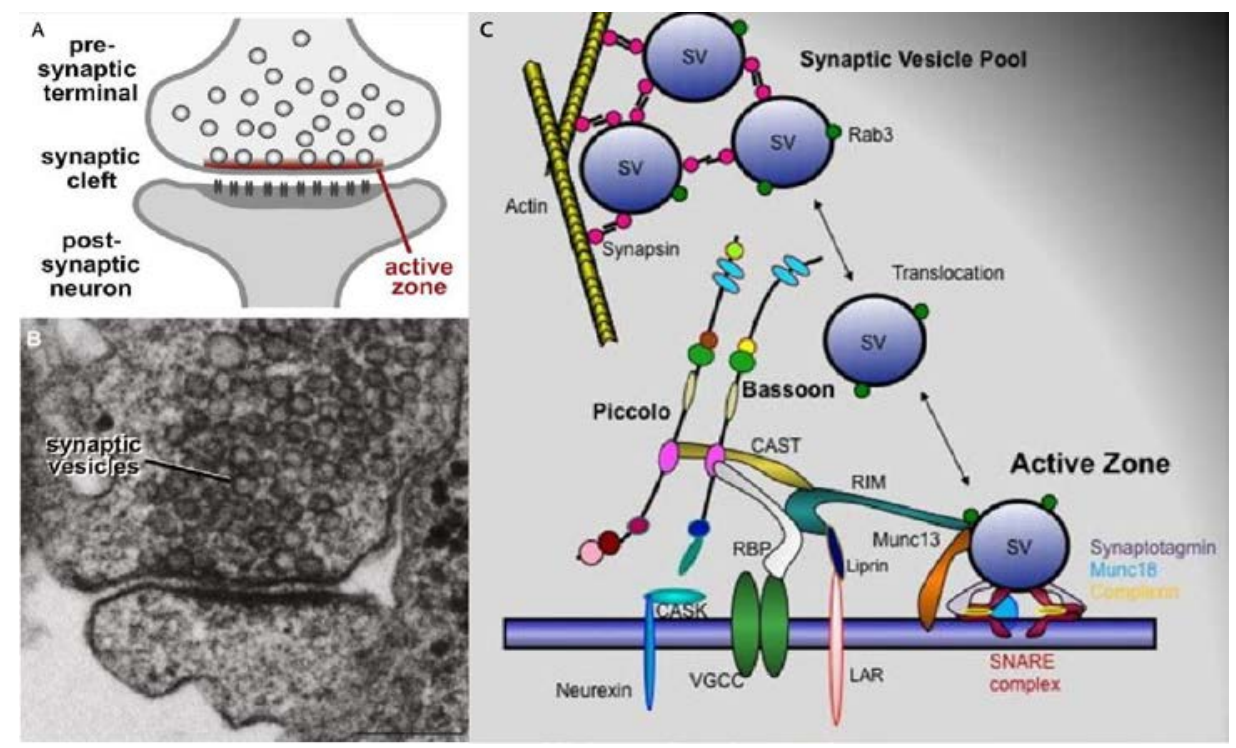

Abbildung 2: Die aktive Zone. Lokalisation und Komponenten der Zytomatrix der aktiven Zone. Die schematische (A) und elektronenmikroskopische (B) Darstellung einer Synapse veranschaulicht die Lokalisation der CAZ nahe der präsynaptischen Membran. Die bedeutendsten Bestandteile der molekularen Architektur sind in (C) dargestellt. Quellen (modifiziert): (A) und (B) Südhof 2012 (die Verwendung der Abbildung erfolgt mit freundlicher Genehmigung des Elsevier Verlags), (C) Gundelfinger et al. 2015 (die Verwendung der Abbildung erfolgt entsprechend der Creative CommonsLizenzen mit freundlicher Genehmigung der Frontiers Research Foundation sowie der Autoren Gundelfinger, Reissner und Garner).

\subsection{Bassoon}

Das Protein Bassoon ist eine der bisher bekannten Komponenten der aktiven Zone und in weiten Teilen des Gehirns nachweisbar. Besonders hohe Konzentrationen wurden dabei im Hippocampus, dem Zerebellum und dem Bulbus olfactorius nachgewiesen (tom Dieck et al. 1998; Richter et al. 1999) und deuten auf eine besondere Funktion des Proteins bei der 
neuronalen Informationsverarbeitung hin. Es scheint vor allem als Gerüst zu fungieren und somit die aktive Zone zusammen mit anderen Proteinen strukturell zu organisieren (Dresbach et al. 2003). Diese Annahme wird dadurch bekräftigt, dass sich Bassoon mit seiner außerordentlich geringen Austauschrate von $>8 \mathrm{~h}$ als relativ stabile Komponente der Zytomatrix der aktiven Zone erweist (Tsuriel et al. 2009). Neben dessen struktureller Bedeutung fällt auf, dass Bassoon eines der am frühesten in aufkeimenden Synapsen auftretenden Proteine ist (Friedman et al. 2000; Zhai et al. 2000). Dagegen scheint es bei der Neurotransmitterfreisetzung in Zellkulturen keinen direkten Einfluss zu haben (Mukherjee et al. 2010), obwohl es die Wiederbeladung synaptischer Vesikel beschleunigt (Hallermann et al. 2010). Es fällt auf, dass das Protein vom Nager bis zum Menschen mit einem identischen Anteil von ca. 88 \% weitestgehend konserviert ist (Winter et al. 1999). Da es nicht in Invertebraten zu finden ist, scheint es sich um ein evolutionär junges Protein zu handeln (Mukherjee et al. 2010).

Bassoon fällt vor allem durch seine Größe von 420 kDa bei 3938 bzw. 3942 Aminosäuren in Ratte und Maus auf (tom Dieck et al. 1998) und ist damit die zweitgrößte Komponente der Zytomatrix der aktiven Zone. Es ist, ebenso wie das noch größere Protein Piccolo/Aczonin (Cases-Langhoff et al. 1996) und RIM (Wang et al. 1997), ein sogenanntes Multidomänenprotein (Abbildung 3). Die N-terminalen Aminosäuren 162-223 und 457518 codieren in der Ratte die beiden Doppelzinkfinger Zn-1 und Zn-2 (tom Dieck et al. 1998; Fenster et al. 2000; Winter et al. 1999). Doppelzinkfinger sind grundsätzlich für Protein-Nu-kleinsäure- oder Protein-Protein-Interaktionen zuständig (Sánchez-García und Rabbitts 1994). Darüber hinaus weist das Protein drei coiled-coil-Domänen (CC1-CC3) auf, welche ebenfalls eine bedeutende Rolle bei der inter- und intramolekularen ProteinProtein-Interaktion einnehmen (Lupas 1996). Dresbach et al. konnten 2003 zeigen, dass die in den Aminosäuren 1692 bis 3263 enthaltenen Domänen CC2 und CC3 für die Verankerung des Proteins in der aktiven Zone zuständig sind. In den C-terminalen Aminosäuren 3775-3799 fällt eine Reihe von Polyglutaminen auf, die durch multiple CAG-Tripletts ist. Bei dem CAG-Triplett handelt es sich um die Nukleotidsequenz, welche für die Aminosäure Glutamin codiert. Im Zusammenhang mit dem Auftreten von Polyglutaminen stehen Erkrankungen wie Chorea Huntington und Ataxie (Reddy und Housman 1997; Ross 1997). Aufgrund der im Vergleich zu Nagern deutlich verringerten Anzahl an Glutaminen im menschlichen Bassoon ist eine Korrelation mit der Ausbildung entsprechender Krankheitssymptome allerdings unwahrscheinlich (Winter et al. 1999).

Die N-terminale Myristoylierungssequenz (MGNEASLEG) ist an der gerichteten Bewe- 
gung von Bassoon in Richtung Golgi-Apparat (Dresbach et al. 2006) sowie der präsynaptischen Anordnung und der Befestigung des Proteins beteiligt (Dresbach et al. 2003). Bassoon tritt früh während der neuronalen Differenzierung zusammen mit synaptischen Vesikeln und auch Komponenten der PSD, aber auch während der gesamten weiteren Synaptogenese auf (Zhai et al. 2001). Dieses zeitliche Auftreten könnte dafür sprechen, dass Bassoon, welches sowohl in exzitatorischen Typ1-Synapsen als auch in inhibitorischen Typ2-Synapsen gefunden wurde (Richter et al. 1999; Zhai et al. 2001), an der Ausbildung der aktiven Zone im Bereich der präsynaptischen Membran beteiligt ist. Die genaue Lokalisierung des Proteins konnte durch verschiedene Versuche und Methoden bestimmt werden. Durch Immunogoldfärbungen konnte zunächst die Lage des Bassoons zwischen synaptischen Vesikeln bestimmt werden (tom Dieck et al. 1998). Über den Nachweis mit Antikörpern konnte im Jahr 2000 gezeigt werden, dass das Gerüstprotein in unmittelbarer Nähe zu Synaptotagmin, also an Orten des aktiven Vesikelrecyclings, vorliegt (Zhai et al. 2001). Die Verbindung zur präsynaptischen Membran konnte mithilfe von Auswaschversuchen nachgewiesen werden. Weder unter hochsalzhaltigen Bedingungen, noch durch nichtionische Detergenzien wie Triton X-100 oder Octyglucosid und zwitterionische Detergenzien wie CHAPS (3-((3-cholamidopropyl) dimethylammonio)-1-propanesulfonate ) konnte Bassoon von der aktiven Zone abgelöst werden. Nur unter alkalischen Bedingungen, unter denen periphere Membranproteine gelöst werden können, wird Bassoon als nicht integrales, sondern der Membran (indirekt z.B. über Spektrin) angelagertes, Protein herausgelöst (Cases-Langhoff et al. 1996; tom Dieck et al. 1998).

Beim Transport dieses Gerüstproteins vom Soma zu den Synapsen handelt es sich um einen komplexen Prozess. Aufgrund der Colokalisation von Bassoon mit TGN38, einem trans-Golgi-Netzwerk (TGN)-Marker, konnte dessen juxtanukleäre Lokalisierung nachgewiesen werden. Hier tritt es zusammen mit dem ihm verwandten Piccolo/Aczonin auf (Dresbach et al. 2006). Extrasomatisch wurde Bassoon zusammen mit Piccolo und Synaptophysin auf $80 \mathrm{~nm}$-großen Transportorganellen, den Piccolo-Bassoon Transportvesikeln (PTVs), gefunden (Shapira et al. 2003; Zhai et al. 2001). Versuche zeigten, dass der Transport vom Soma zu den aufkeimenden Synapsen von einem funktionierenden GolgiApparat abhängig ist (Dresbach et al. 2006). Über die Aminosäuren 1-97 erfolgt eine gerichtete Bewegung, jedoch nicht die Bindung, von Basson an den Golgi-Apparat via NMyristoylierung. Die Verpackung in PTVs und der anschließende Transport von Bassoon innerhalb dieser Vesikel innerhalb des Axons zu den aufkeimenden Synapsen hin hängen entscheidend von vorausgehender Assoziation mit dem Golgi-Apparat und Durchquerung 
desselbigen ab. Eine Einschränkung oder Ausschaltung der Golgi-Aktivität führen hierbei zur Bildung von intrazellulären Aggregaten (Dresbach et al. 2006). Das Protein selbst besitzt aufgrund seines DLC (dynein light chain)-bindenden Abschnitts die Fähigkeit mit den Dyneinleichtketten (DLCs) DLC1 und DLC2 zu interagieren und somit PTVs mit den Motorproteinen zu verbinden. Eine Defizienz des DLC-bindenden Abschnitts resultiert in einer deutlichen Geschwindigkeitsabnahme sowohl des antero- als auch des retrograden Transports von Bassoon (Fejtova et al. 2009).

Als ein zentraler Bestandteil der Zytomatrix der aktiven Zone interagiert Bassoon mit einer Vielzahl von Bindungspartnern, zu denen neben den oben genannten DLCs auch die Cterminalen Bindungsproteine CtBP1/BARS (C-terminal-binding protein1/brefeldin A (BFA) adenosine diphosphate-ribosylated substrate ) und CtBP2/RIBEYE (Hübler et al. 2012; Ivanova et al. 2015; Jose et al. 2008) sowie eine Reihe weiterer Proteine des Kernkomplexes zählen. Zu diesen gehören das verwandte Multidomänenprotein Piccolo/Aczonin (Fenster et al. 2000; Wang et al. 1999), mit welchem Bassoon 10 homologe Regionen teilt, ERC/ELKS/CAST, Munc13 (Wang et al. 2009) sowie RIM-BPs (Davydova et al. 2014). CtBP1 und -2, welche ursprünglich als Corepressoren identifiziert wurden (Furusawa et al. 1999), konnten später als Komponenten sogenannter Bandsynapsen in sensorischen Zellen beschrieben werden. Darüber hinaus wird ihnen (sowie CtBP3) ein Einfluss auf die Abschnürung synaptischer Vesikel sowie deren Zyklus zugeschrieben (Bonazzi et al. 2005; Schmitz et al. 2000).

Auf ultrastruktureller Ebene konnten in loss-of-function-Studien an Synapsen des ZNS keine Veränderungen der Zytomatrix der aktiven Zone festgestellt werden. Jedoch zeigten die Mäuse, welche die entsprechende Mutation aufwiesen, eine Erhöhung der Sterblichkeit, bedingt durch vermehrtes Auftreten von epileptischen Anfällen. Es wird vermutet, dass einige Funktionen von Bassoon und Piccolo redundant sind, weshalb der Verlust nur eines der beiden Proteine weniger schwerwiegende Folgen als das Nichtvorhandensein beider strukturgebender Komponenten nach sich zieht. Bei einem Verlust von funktionsfähigem Bassoon in konventionellen Synapsen scheint es durch eine Erhöhung der Gesamtmenge von Piccolo zu einer Kompensation dieses Ausfalls zu kommen (Altrock et al. 2003). Ganz anders wirkt sich eine Mutation des Bassoon-Gens in sensorischen Zellen von Vertebraten aus. In Fotorezeptorzellen verbindet Bassoon bandförmige synaptische Strukturen mit dem sogenannten arciformen Kompartiment. In Bassoon-Mausmutanten gehen diese Bindung und damit die Möglichkeit zur Informationsübertragung verloren (Dick et al. 2003; tom Dieck et al. 2005). Bei der Anbindung der Bandstrukturen an die Zytomatrix 
der aktiven Zonen sensorischer Zellen sind auch RIBEYE und ERC/ELKS/CAST beteiligt (Magupalli et al. 2008; Takao-Rikitsu et al. 2004; tom Dieck et al. 2005). In Bandsynapsen konnte gezeigt werden, dass Bassoon auch einen Einfluss auf die Amplitude von $\mathrm{Ca}^{2+}$ Strömen, die Anzahl von Freisetzungsstellen und die Größe des readily releasable pools nimmt (Frank et al. 2010). Zumindest indirekt scheint Bassoon darüber hinaus an der Freisetzung des Wachstumsfaktors BDNF (brain-derived neurotrophic factor) beteiligt zu sein (Heyden et al. 2011).

Bei dem Multidomänenprotein Bassoon handelt es sich damit um eine strukturgebende und funktionell bedeutende Komponente der Zytomatrix der aktiven Zone, welche über verschiedenste Bindungsstellen mit den sie umgebenden Bestandteilen der präsynaptischen Endigung in reger Wechselwirkung steht und deren Fehlen in Abhängigkeit von der Zellart unterschiedlich schwere Folgen nach sich zieht.

\title{
Bassoon
}

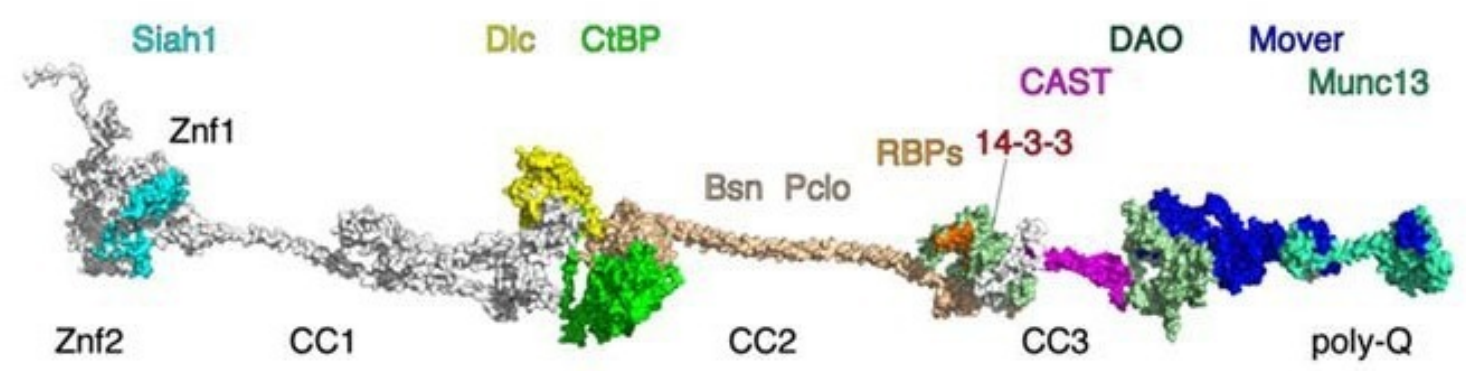

\begin{abstract}
Abbildung 3: Bassoon sowie dessen funktionelle Domänen. In silico Darstellung des präsynaptischen Proteins Bassoon mit dessen funktionellen Domänen und Bindungsstellen. Neben den beiden Doppelzinkfingern (Znf1 und Znf2), den drei coiled-coil-Domänen (CC1-CC3) und einer Reihe von Polyglutaminen (poly-Q), fallen farblich markiert die entsprechenden Bindungsstellen für die verschiedenen Proteine auf. Als zentraler Bestandteil interagiert es unter anderem mit Komponenten der CAZ. Weitere Abkürzungen: Bsn $=$ Bassoon, Pclo $=$ Piccolo, CtBP $=$ C-terminal-binding protein 1 , Dlc = Dynein light chains, Siah1 $=$ seven in absentia homolog 1, RBPs $=$ RIM binding proteins, CAST $=$ CAZ-associated structural protein, DAO = D-amino acid oxidase. Quelle (modifiziert): Gundelfinger et al. 2016 (die Verwendung der Abbildung erfolgt entsprechend den Creative Commons-Lizenzen mit freundlicher Genehmigung der Autoren Gundelfinger, Reissner und Garner) .
\end{abstract}

\subsection{Mover}

Bei Mover handelt es sich um ein 2007 erstmals beschriebenes vertebratenspezifisches (vertebrate-specific) Protein, welches unter anderem an den Endigungen von hippocampalen Moosfasern (mossy fibers) zu finden ist und auch unter den Namen Svap30 (synaptic vesicle-associated protein of $30 \mathrm{kDa}$ (Burré und Volknandt 2007)) und Tprgl (transformation related protein 63 regulated like (Antonini et al. 2008)) bekannt ist. In Wirbeltieren wurden Homologe des aus 266 Aminosäuren bestehenden Proteins identifiziert. In der Held'schen Calyx, einer außergewöhnlich großen Synapsenart konnte Mover im präsynaptischen Kompartiment nachgewiesen werden. Diese Ergebnisse konnten in anschließenden 
Colokalisierungsstudien sowie biochemisch verifiziert werden. Dazu wurden rekombinante Versionen von Mover, unter anderem Mover-myc, genutzt. Bei myc handelt es sich um ein Polypeptid, welches sich von dem c-myc-Gen ableitet und vom entsprechenden Antikörper erkannt werden kann. Dies stellt einen Vorteil dar, wenn noch kein spezifischer Antikörper gegen das zu untersuchende Protein (z.B. Mover zum damaligen Zeitpunkt) verfügbar ist. Die Lokalisationen der verwendeten Varianten wurden mit der Verteilung verschiedener rekombinanter prä- und postsynaptischer Proteine verglichen. Während Mover-myc eine identische Verteilung zu Synaptophysin-GFP (green fluorescent protein) und endogenem Synapsin aufwies, zeigte sich keine Colokalisation mit dem rekombinanten postsynaptischen PSD-95-GFP. Diese Ergebnisse sprechen für eine präsynaptische Anreicherung von Mover-myc. Bei den untersuchten Synapsen handelte es sich um voll funktionsfähige synaptische Terminalen.

Den Beweis hierfür lieferten Synaptotagmin-Wiederaufnahmeversuche.

Darunter versteht man eine Antikörperfärbung, mit welcher funktionsfähige Freisetzungsstellen von Neurotransmittern dargestellt werden können. Dabei wird die luminale Domäne des in Depolarisationspuffer gelösten und anschließend in die synaptischen Vesikel aufgenommenen primären Antikörpers vom sekundären erkannt. Im Hefe-2-Hybrid-System, welches zur Identifikation von Protein-Protein-Interaktionen genutzt wird, konnte ein Cterminaler Anteil des präsynaptischen Proteins Bassoon als Bindungspartner identifiziert werden. Dieses Ergebnis wird durch Untersuchungen an HEK293 (human embryonic kidney 293)-Zellen gestützt, in welchen eine Co-Aggregation von rekombinanten Mover- mit Bassoon-Konstrukten nachgewiesen werden konnte. Mover ist nicht nur im Gehirn, sondern auch in Hoden sowie in geringerer Menge in Herz, Milz und Leber nachweisbar. Innerhalb des Gehirns scheint Mover eine Funktion sowohl an inhibitorischen als auch an exzitatorischen Synapsen zu erfüllen. Während es in der hippocampalen CA (Cornu Ammonis )3-Region ausschließlich in erregenden Endigungen gefunden wurde, kann es im zerebellären Cortex in hemmenden nachgewiesen werden. Das Protein weist weder eine Transmembranregion noch andere Möglichkeiten zur Verankerung an der präsynaptischen Membran auf. Da es darüber hinaus im Western Blot in der Fraktion synaptischer Vesikel (Lipoprotein2 (LP2)-Fraktion) nachgewiesen wurde, lag bereits früh die Vermutung nahe, dass es sich um ein vesikelassoziiertes Protein handeln muss (Kremer et al. 2007). Dabei scheint jedoch nur eine Untergruppe von knapp 1/ 5 der synaptischen Vesikel Mover aufzuweisen. Darüber hinaus konnte Mover als homophiles Phosphoprotein identifiziert werden. Die Phosphorylierung, unter welcher man das Übertragen von Phosphat- oder Pyro- 
phosphat-Gruppen versteht, ist grundsätzlich ein Prozess, welcher einen regulierenden Einfluss auf die Aktivität von Proteinen und Signaltransduktionskaskaden nimmt. Im Falle von Mover resultierte die Dephosphorylierung mittles Phosphatase in einer Dissoziation von den synaptischen Vesikeln und damit in einem Verlust des Proteins in der Präsynapse. Für die oben genannte Homomerisation sind dabei sowohl das N-terminale als auch das C-terminale Ende unerlässlich. Das konnte mittels Hefe-2-Hybrid-System gezeigt werden (Ahmed et al. 2013).

Mithilfe von knock-down-Versuchen in der Held'schen Calyx konnten keine morphologischen Veränderungen innerhalb des readily releasable pools festgestellt werden, wohingegen elektrophysiologisch bei sonstiger Unauffälligkeit eine erhöhte Freisetzungswahrscheinlichkeit nachweisbar war. Daher scheint das Vorhandensein von Mover zumindest in den untersuchten Synapsen einen negativen regulatorischen Einfluss zu besitzen (Körber et al. 2015). Als präsynaptisch nachweisbares, vesikelassoziiertes Phosphoprotein scheint Mover alle Voraussetzungen zu erfüllen, um als modulierender Faktor in die synaptische Transmission einzugreifen. Warum es jedoch nur in einem kleinen Teil synaptischer Vesikel vorzukommen scheint und wie groß dessen Einfluss innerhalb der entsprechenden Synapsen ist, bleibt weiterhin ungeklärt.

\subsection{RIBEYE und Rogdi}

Bei dem Protein handelt es sich um eine bedeutende Komponente vertebratenspezifischer Bandsynapsen. Diese Sonderform der Synapsen vermittelt in verschiedenen sensorischen Zellen eine kontinuierliche Neurotransmitterfreisetzung. Es konnte nachgewiesen werden, dass das ca. 1000 Aminosäuren messende RIBEYE aus einer individuellen aggregatbildenden A-Domäne und einer B-Domäne, die mit dem Transkriptionsrepressor CtBP2 nahezu identisch ist, besteht. Das Fusionsprotein besitzt wie auch CtBP2 die Fähigkeit, $\mathrm{NAD}^{+}$zu binden. Damit könnte es möglicherweise einen regulierenden Einfluss auf die synaptische Aktivität nehmen (Schmitz et al. 2000).

In den Bandsynapsen von Photorezeptoren wird die strukturelle Bedeutung von RIBEYE ersichtlich: als ein zentraler Bestandteil der aktiven Zone fungiert das Protein über seinen Aktionspartner Bassoon als Bindeglied zwischen einem bandassoziierten Komplex aus CtBP1, RIBEYE/CtBP2, KIF3A (Kinesin Family Member 3A) und einem membranassoziierten Komplex, der aus Bassoon, RIM2, Munc13-1, CAST1 und Calciumkanälen besteht (tom Dieck et al. 2005).

Um ein besseres Verständnis für die Funktion des Proteins zu gewinnen, wurde es zunächst 
teilweise, später vollständig inaktiviert. Im Zebrabärbling verursachte ein knock-down lediglich eine signifikante Verringerung des Proteins ohne schwerste morphologische Veränderungen der Bandsynapsen (Wan et al. 2005, Lv et al. 2012).

In knock-out-Mäusen konnte die Rolle von RIBEYE genauer untersucht werden. Massive morphologische und funktionelle Einschränkungen führten zu der Erkenntnis, dass es essentiell für die Bildung von Bandsynapsen in Photorezeptoren von Vertebraten, die $\mathrm{Ca}^{2+}$ getriggerte Neurotransmitterfreisetzung und die Anbindung von L-Typ-Ca ${ }^{2+}$-Kanälen an Bereiche fusionsbereiter Vesikel ist (Maxeiner et al. 2016).

Das im Falle des menschlichen Homologs 287 Aminosäuren messenden Protein Rogdi wurde zunächst in einer synaptischen Vesikelfraktion nachgewiesen (Boyken et al. 2013). Bisher wurde es ausschließlich in Zusammenhang mit dem Kohlschütter-Tönz-Syndrom, einer Erkrankung, bei welcher die Mutation des Rogdi-Gens Amelogenesis imperfecta, Epilepsie sowie psychomotorische Einschränkungen verursacht, untersucht (Kohlschütter et al. 1974; Schossig et al. 2012). Es könnte sich um eine bisher nahezu unbekannte Komponente der neuronalen Entwicklung und/oder Informationsverarbeitung handeln, deren Bedeutung hinterfragt werden muss.

\subsection{Zielsetzung}

Mithilfe der Untersuchungen soll ein besseres Verständnis für die Eigenschaften der beschriebenen Proteine geschaffen werden. Zu diesem Zweck wurden die Eigenschaften rekombinanter Varianten dieser Proteine in neuronalen Zellkulturen untersucht. Die grundlegenden Gedanken hinter diesen Experimenten sind einerseits die anzustrebende Verwendung zumindest eines der Bassoon-Konstrukte in gentechnisch veränderten höheren Lebewesen wie z.B. Labormäusen, andererseits die Charakterisierung bisher in hippocampalen Neuronen nicht beschriebener Proteine. Darüber hinaus soll die potentielle Bindung von Bassoon und Mover mittels verschiedener Ansätze verifiziert werden. Die im Rahmen der Versuche genutzten Konstrukte sind in dem Teil „Material und Methoden“ tabellarisch dargestellt. Von großer Bedeutung für den erstgenannten Teil waren die Bestimmung der Intensität der Protein-Tags sowie die Überprüfung der Möglichkeit, dass die Lokalisierung des Protein-Tags von großer Bedeutung sein kann. Des Weiteren stellen die Identifikation bisher unbekannter Bestandteile sowie das Hinterfragen weiterer Eigenschaften bekannter Komponenten der Synapsen einen wichtigen Faktor für die Grundlagenforschung dar. Bei den bisher in hippocampalen Neuronen noch nicht charakterisierten rekombinanten Proteinen handelt es sich um GFP-Rogdi und GFP-RIBEYE. Während die Eigenschaften des 
erstgenannten nahezu gänzlich unbekannt sind, ist das endogene Pendant zu GFPRIBEYE, nämlich RIBEYE/CtBP2 bereits in sensorischen Zellen näher untersucht worden.

Daher stelle ich bekannte, aber auch neue Merkmale der Konstrukte in qualitativer und quantitativer Form vor. Die Vorgehensweise ist dabei für die verschiedenen Versuche ähnlich. Zunächst werden die Verteilung und gegebenenfalls Besonderheiten in jungen Neuronen, anschließend in adulten Zellen präsentiert. In Abhängigkeit von der jeweiligen Fragestellung erfolgt die Beschreibung der Eigenschaften auch in quantitativer Form.

Insgesamt werden drei übergeordnete Fragen gestellt:

1) Unterscheiden sich die Bassoon-Varianten in ihrer subzellulären Verteilung und nehmen sie einen Einfluss auf die Rekrutierung des Proteins Mover?

2) Handelt es sich bei dem Protein Rogdi um eine bisher unbeschriebene präsynaptische Komponente?

3) Wird das Protein RIBEYE, welches Bestandteil von Sinneszellen ist, auch in den Synapsen hippocampaler Neurone angereichert und führt es dort zur Bildung von Bandsynapsen? 


\section{MATERIAL UND METHODEN}

\subsection{Materialien}

\subsubsection{Chemikalien}

Tabelle 1: Chemikalien und Verbrauchsmaterialien.

\begin{tabular}{|c|c|}
\hline Bezeichnung & Hersteller \\
\hline Blotting Filterpapier & Omni Lab \\
\hline $\mathrm{B} 27$ & Invitrogen \\
\hline Calciumchlorid & Sigma-Aldrich \\
\hline CheLuminate HRP FemtoDetect Plus & AppliChem \\
\hline Destilliertes Wasser & Invitrogen \\
\hline DMEM (Dulbecco`s Modified Eagle`s Medium) & Invitrogen \\
\hline DPBS (Dulbecco's Phosphate-Buffered Saline) & Gibco \\
\hline Eppendorfgefäße (2 ml) & Eppendorf \\
\hline Falcon multiwell 24 well (Zellkulturschale) & Falcon \\
\hline Falconröhrchen & Greiner Bio-One \\
\hline Fetales Kälberserum & Invitrogen \\
\hline $\begin{array}{l}\text { HEPES (2-(4-(2-Hydroxyethyl)-1- } \\
\text { piperazinyl) ethansulfonsäure) }\end{array}$ & Sigma-Aldrich \\
\hline Kaliumchlorid & Sigma-Aldrich \\
\hline Glucose & Applichem \\
\hline Glycerin & Applichem \\
\hline Immunoblot PVDF (Polyvinylidendifluorid) Membran & Bio-Rad \\
\hline L-Glutamin & Gibco \\
\hline HBSS (Hank’s Balanced Salt Solution) & Invitrogen \\
\hline Lipofektamin 2000 & Invitrogen \\
\hline Magnesiumchlorid & Sigma-Aldrich \\
\hline Menzel Gläser & Thermoscientific \\
\hline Methanol & Applichem \\
\hline Milchpulver & Applichem \\
\hline $\mathrm{NaCl}$ & BioFroxx \\
\hline Neurobasal Medium (NB) & Invitrogen \\
\hline NuPAGE $\AA$ Bis Tris mini gels & Thermoscientific \\
\hline $\begin{array}{l}\text { NuPAGETM MES SDS (sodium dodecyl sulfate) Run- } \\
\text { ning Buffer }(20 \mathrm{x})\end{array}$ & Thermoscientific \\
\hline OptiMEM® (OPTM) & Invitrogen \\
\hline
\end{tabular}




\begin{tabular}{|l|l|}
\hline PEI (Polyethylenimin) für Transfektionen & Sigma-Aldrich \\
\hline Pen-Strep (Penicillin-Streptomycin) & Gibco \\
\hline PFA (Paraformaldehyd) & Applichem \\
\hline Pipetten & Eppendorf \\
\hline Pipettenspitzen & Eppendorf \\
\hline Ponceau- Lösung & Qiagen \\
\hline See Blue Pre Stained Standard & Thermoscientific \\
\hline Sucrose & Applichem \\
\hline TC-Platte 6 Well,Standard,F (Zellkulturschale) & Sarstedt \\
\hline Tris & Applichem \\
\hline Triton-X-100 & Applichem \\
\hline Trypsin-EDTA (Ethylendiamintetraessigsäure ) & Sigma-Aldrich \\
\hline Trypan Blue Stain 0,4 \% & Gibco \\
\hline Tween 20 & Applichem \\
\hline 10x PBS (phosphatgepufferte Salzlösung) & Roche \\
\hline
\end{tabular}

\subsubsection{Geräte}

Tabelle 2: Verwendete Klein- und Großgeräte.

\begin{tabular}{|l|l|}
\hline Gerät & Hersteller \\
\hline Centrifuge 5702 (Zentrifuge) & Eppendorf \\
\hline CoolSNAP HQ2 & Photometrics \\
\hline Fluor Chem E & Protein Simple \\
\hline Hera Cell 150 (Inkubator) & ThermoElectron Corporation \\
\hline Sicherheitswerkbank & ThermoElectron \\
\hline TB2 Thermoblock & Biometra \\
\hline $\begin{array}{l}\text { Trans-Blot SD Semi-Dry Transfer Cell } \\
\text { (Western Blot-Kammer) }\end{array}$ & Bio Rad \\
\hline Vortex Genius 3 & IKA \\
\hline Waage ExtendED4202S & CW Sartorius \\
\hline $\begin{array}{l}\text { XCellSureLock Elektrophorese System } \\
\text { (Elektrophoresekammer) }\end{array}$ & Thermo Fisher Scientific \\
\hline Zeiss Observer. Z1 & Zeiss \\
\hline Zentrifuge & Mikro200R Hettich \\
\hline
\end{tabular}




\subsubsection{Lösungen und Zellkulturmedien}

Tabelle 3: Verwendete Lösungen und Medien sowie deren Zusammensetzungen.

\begin{tabular}{|c|c|}
\hline Reagenz & Zusammensetzung \\
\hline HEK293T-Gefriermedium & $\begin{array}{l}\text { DMEM High Glucose, } 20 \% \text { fetales Kälberserum } 5 \\
\text { ml, } 10 \% \text { DMSO }\end{array}$ \\
\hline HEK293T-Transfektionsmedium & $\begin{array}{l}\text { DMEM High Glucose, } 10 \% \text { fetales Kälberserum, } \\
1 \% \text { Penicillin/Streptomycin }\end{array}$ \\
\hline HEK293T-Zellkulturmedium & $\begin{array}{l}\text { DMEM High Glucose, } 10 \% \text { fetales Kälberserum, } \\
1 \% \text { Penicillin/Streptomycin, } 1 \% \text { L-Glutamat }\end{array}$ \\
\hline Komplettmedium $50 \mathrm{ml}$ & $\begin{array}{l}\text { 48,875 ml NB, } 1 \mathrm{ml} \mathrm{B27,} \\
125 \mu \mathrm{l} \mathrm{L-Glutamin}\end{array}$ \\
\hline $\begin{array}{l}\text { Mowiol+DABCO } \\
\text { (1,4-Diazabicyclo[2.2.2]octan) }\end{array}$ & $\begin{array}{l}\text { Mowiol, Glycerin, 0,2 M Tris-Cl (pH: 8,5), 2,5 \% } \\
\text { DABCO, } \mathrm{dH}_{2} \mathrm{O}\end{array}$ \\
\hline PEI-Lösung & $2 \mathrm{ml}$ PEI in $50 \mathrm{ml} \mathrm{dH}_{2} \mathrm{O}$ \\
\hline Primärer Antikörperpuffer & $\begin{array}{l}10 \% \text { FBS, } 5 \% \text { Sucrose, } 2 \% \text { BSA (Bovines Serum- } \\
\text { albumin ), 0,3 \% Triton X-100 in PBS }\end{array}$ \\
\hline Sekundärer Antikörperpuffer & 5 \% Sucrose, 2 \% BSA, 0,3 \% Triton X-100 in PBS \\
\hline $\begin{array}{l}\text { Transfektionspuffer für Calcium- } \\
\text { Phosphat-Präzipitation }\end{array}$ & 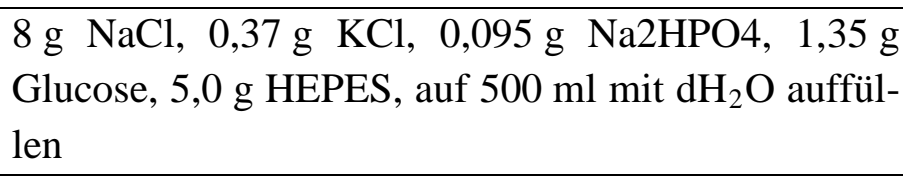 \\
\hline $\begin{array}{l}\text { Zellkulturmedium für die Präparati- } \\
\text { on hippocampaler Neurone }\end{array}$ & $\begin{array}{l}10 \text { \% fetales Kälberserum, } 1 \text { \% Penicillin/Streptomy- } \\
\text { cin, } 2 \text { mM L-Glutamin in DMEM }\end{array}$ \\
\hline $\begin{array}{l}\text { Zellkulturmedium für hippocampale } \\
\text { Neurone }\end{array}$ & $\begin{array}{l}\text { NB-Medium, } 2 \% \text { B27, } 1 \% \text { Penicillin/Strepto- } \\
\text { mycin, 0,25\% L-Glutamin }\end{array}$ \\
\hline
\end{tabular}

\subsection{Platten}

Die Mikrotiterplatten wurden mit Deckgläschen bestückt, indem jeweils ein Deckgläschen mit einer an einer Vakuumpumpe befestigten Glaspipettenspitze angesaugt und in ein Well gegeben wurde. Anschließend wurden je 0,5 ml DPBS pro Well hinzugegeben und mindestens über Nacht, besser länger, belassen. Dieser Schritt erfolgte, da die Deckgläschen zu Beginn hydrophob sind und anschließende Arbeitsschritte durch schwimmende Deckgläschen verhindert worden wären. Daraufhin wurde das DPBS abgesaugt und durch 0,5 ml Polyethylenimin (PEI)-Lösung ersetzt, welche nach frühestens mehreren Stunden durch dreimaliges Waschen mit DPBS entfernt wurde. PEI ermöglichte das Festsetzen der hippocampalen Neurone auf den Deckgläschen. 


\subsection{Zellen}

\subsubsection{Hippocampale Neurone}

Bei den verwendeten Säugetierzellen handelte es sich um hippocampale Neurone (E19Zellen) aus Rattenembryonen. Die Präparationsart zur Herstellung der Primärkulturen entsprach weitestgehend der von Goslin und Banker aus dem Jahr 1998. Nach dreimaligem Waschen der gewonnenen Neurone mit HBSS wurde der Überstand bis auf ein Restvolumen von $2 \mathrm{ml}$ entfernt, anschließend mit 0,25\% Trypsin versetzt und für $20 \mathrm{~min}$ im auf $37^{\circ} \mathrm{C}$ vorgewärmten Wasserbad inkubiert, um die Dissoziation der E19-Zellen zu erreichen. Im Anschluss an die Inkubation und Überführung in ein 2-ml-Eppendorfgefäß erfolgte zunächst das dreimalige Waschen mit HBSS, um die Trypsinierung zu beenden sowie eine mechanische Dissoziation, indem die Suspension mehrfach durch zwei Kanülen verschiedener Durchmesser in eine Spritze aufgenommen und anschließend wieder abgegeben wurde. Durch ein zuvor benetztes Sieb wurde die Suspension in ein 50-mlEppendorfgefäß überführt. Das Benetzen und spätere Durchspülen des Siebs erfolgte mit einer zuvor angesetzten und auf $37^{\circ} \mathrm{C}$ vorgewärmten Lösung, welche aus DMEM, 10 \% fetalem Kälberserum, welches unter anderem Wachstumsfaktoren enthält, sowie 1 \% PenStrep und 1 \% 20 mM Glutamin bestand. Neben einem ausgewogenen Verhältnis an Nährstoffen ermöglicht dieses Medium auch einen Schutz gegen die Kontamination mit sowohl aeroben als auch anaeroben Bakterien. Zur Ermittlung der Zelldichte wurden die Zelllösung und Tryptanblau im Verhältnis 1:1 gemischt und $20 \mu \mathrm{l}$ dieser Mischung in eine Zellkammer gegeben. Unter mikroskopischer Betrachtung erfolgte anschließend das Zählen der Zellen. Das Ausplattieren der Zellen auf 24-Well-Mikrotiterplatten erfolgte auf mit PEI beschichteten Deckgläschen, wobei pro Well jeweils $500 \mu \mathrm{l}$ der die Zellen enthaltenden Lösung abgegeben wurden. Für alle durchgeführten Experimente wurde eine Zelldichte von 50.000 Zellen pro Well gewählt. Im Anschluss an das Ausplattieren wurden die Zellen bei $37{ }^{\circ} \mathrm{C}$, $95 \%$ Luftfeuchtigkeit und $5 \% \mathrm{CO}_{2}$ inkubiert. Im Regelfall erfolgte ein Mediumwechsel noch am selben, gegebenenfalls erst am folgenden Tag. Bei diesem Nährmedium handelte es sich um eine Mischung aus Neurobasalmedium, Pen-Strep, Glutamin und B27. Letztgenanntes wird auch als Komplettmedium bezeichnet. Die Mikrotiterplatten wurden lediglich zur Transfektion und zur Fixation aus dem Inkubator entnommen. 


\subsubsection{Cortikale Neurone}

Für die biochemischen Untersuchungen wurden auch cortikale Neurone verwendet. Die Präparation entsprach weitestgehend der oben genannten mit dem Unterschied, dass statt der Hippocampi das gesamte cortikale Gewebe exklusiv der zuvor gewonnenen Hippocampi entnommen wurde. Hierbei war darauf zu achten, dass die Hemisphären von den gesamten Meningen einschließlich aller begleitenden Gefäße befreit wurden. Vor der Trypsinierung erfolgte darüber hinaus noch eine mechanische Zerkleinerung, um die anschließende chemische Dissoziation zu vereinfachen. Das Ausplattieren der Neurone erfolgte in 6-Well Schalen. Es wurde eine Dichte von 500.000 Neuronen pro Deckglas gewählt, um eine ausreichende Zellmenge für die biochemische Untersuchung zu erhalten. Die Neurone wurden bei $37^{\circ} \mathrm{C}$, $95 \%$ Luftfeuchtigkeit und $5 \% \mathrm{CO}_{2}$ für die folgenden 10 Tage inkubiert.

\subsubsection{HEK293T-Zellen}

Die bei $-80{ }^{\circ} \mathrm{C}$ aufbewahrten HEK293T-Zellen wurden im Wasserbad bei $37^{\circ} \mathrm{C}$ innerhalb weniger Minuten aufgetaut und anschließend in $10 \mathrm{ml}$ Lösung aus DMEM, 10 \% FCS (fetal calf serum ) und $1 \%$ Pen-Strep gegeben. Nach dem 5 minütigen Zentrifugieren bei $200 \mathrm{~g}$ wurde der Überstand entfernt und das Pellet in $5 \mathrm{ml}$ des oben genannten Mediums aufgelöst. Die Zellen einschließlich Medium wurden in $100 \mathrm{~mm}$ im Querschnitt messende Zellkulturschalen überführt und bei $37{ }^{\circ} \mathrm{C}$ und $5 \% \mathrm{CO}_{2}$ inkubiert. Am darauf folgenden Tag wurde das Medium gewechselt. Die sich vermehrenden Zellen wurden regelmäßig bei hoher Konfluenz passagiert und wenige Tage vor einer geplanten Transfektion auf 24Well-Mikrotiterplatten gegeben.

\subsection{Arbeiten mit Zellkulturen}

\subsubsection{Transfektionsverfahren}

Unter einer Transfektion versteht man das Einbringen fremder DNA (Desoxyribonukleinsäure) oder RNA (Ribonukleinsäure) in eine Wirtszelle, wobei im Rahmen dieser Dissertation eine transiente, also vorübergehende, Transfektion der Plasmide in Wirtszellen durchgeführt wurde. Im Falle der hippocampalen Neurone erfolgte das Einschleusen der DNAs in Abhängigkeit vom Transfektionsverfahren am dritten oder sechsten Tag in vitro, von nun an als days in vitro/DIV bezeichnet, bei einer Zelldichte von 50.000 pro Deckglas. Die 
HEK293T-Zellen wurden mittels Polyethy-lenimin bei einer Konfluenz von ca. 50-75 \% wie unten beschrieben behandelt.

An dieser Stelle sollte erwähnt werden, dass die Effektivität einer Transfektion entscheidend von einer Vielzahl von Faktoren abhängt (Jordan und Wurm 2004), welche nahezu zwangsläufig zumindest minimal von Ansatz zu Ansatz schwanken. Vor allem der durch die vorausgegangene Präparation beeinflusste physiologische Zustand der gewonnenen Primärkulturen scheint einen enormen Einfluss zu haben: Wachstum und definitive Zelldichte schwanken und könnten daher einen Einfluss auf die Ergebnisse nehmen. Es ist jedoch davon auszugehen, dass dieser Einfluss innerhalb bestimmter Grenzen liegt und für alle betrachteten Teilexperimente nahezu gleich groß ist. Diese Annahme wird durch die oftmals geringen Standardabweichungen der Mittelwerte bekräftigt.

\subsubsection{Calcium-Phosphat-Präzipitation}

Bei der Calcium-Phosphat-Präzipitation handelt es sich um ein Verfahren zum Einbringen der DNA in junge Zellen (am DIV 3). Zunächst wurde die Transfektionslösung bestehend aus destilliertem Wasser, $2 \mathrm{M} \mathrm{CaCl}_{2}$ und der entsprechenden DNA angesetzt, wobei für 3 Deckgläschen ein Gesamtvolumen von $45 \mu$ l genutzt wurde. Erfahrungsgemäß findet man mehr transfizierte Zellen vor, wenn zusätzlich für ein weiteres Deckglas kalkuliert, der bodenständige Rest der Lösung allerdings verworfen wird. Zuerst wurden das destillierte Wasser und die DNAs gemischt, danach das $2 \mathrm{M} \mathrm{CaCl}_{2}$ hinzugegeben. Zusätzlich wurde eine der bisher angesetzten Lösung entsprechende Menge Transfektionspuffer (pH 7,047,05) auf dem Vortex tröpfchenweise ergänzt. Die nun vollständige Transfektionslösung wurde für 20 min schwingungsfrei neben der Sicherheitswerkbank aufbewahrt. Während dieser Zeit wurde das Zellkulturmedium entnommen, separat aufbewahrt und durch $500 \mu \mathrm{l}$ Opti-MEM® ersetzt. Nach Ablaufen der 20 min wurden pro Deckglas jeweils $30 \mu \mathrm{l}$ der Transfektionslösung zugefügt und für $60 \mathrm{~min}$ bei $37^{\circ} \mathrm{C}$ und $5 \% \mathrm{CO}_{2}$ inkubiert. Nach Entnehmen des Opti-MEM® erfolgte das Waschen der Zellen, indem zunächst $1 \mathrm{ml}$ Neurobasalmedium zugegeben wurde und anschließend jeweils $750 \mu$ l dieses Mediums hinzu- und abgeführt wurden. Nach dem Waschen wurde das Neurobasalmedium durch das aufbewahrte Zellkulturmedium ersetzt.

\subsubsection{Lipofektion}

Das Ansetzen der Transfektionslösung pro Deckglas erfolgte durch das Vermischen von $25 \mu \mathrm{l}$ Opti-MEM ${ }^{\circledR}$ und $1 \mu \mathrm{l}$ Lipofectamine ${ }^{\circledR} 2000$ mit $25 \mu$ l Opti-MEM ${ }^{\circledR}$ und $1 \mu \mathrm{g}$ der zu 
übertragenden DNA, wobei das kleinste hergestellte Volumen für 3 Deckgläschen ausreichend war und die Lösung für 20 min bei Raumtemperatur inkubiert wurde. Während der Wartezeit wurde das Zellkulturmedium aus den Wells entnommen, separat aufbewahrt und durch das Komplettmedium ersetzt. Nach der 20-minütigen Inkubationszeit wurde pro Deckglas eine Menge von $50 \mu \mathrm{l}$ Transfektionslösung hinzugegeben und für 1:15 h bei $37{ }^{\circ} \mathrm{C}$ und $5 \% \mathrm{CO}_{2}$ inkubiert. Anschließend wurde das Komplettmedium entnommen, durch $1 \mathrm{ml}$ Neurobasalmedium ersetzt und dieser Arbeitsschritt durch das dreimalige Entnehmen und erneute Hinzugeben von $750 \mu$ l frischem Neurobasalmedium abgeschlossen. Letztlich wurde das Medium nach dem Waschen abgesaugt und das aufbewahrte Zellkulturmedium wieder hinzugegeben.

Diese Vorgehensweise eignet sich sehr gut, um Plasmide in DIV 6-Zellen einzubringen.

\subsubsection{Polyethylenimin (PEI)-Transfektion}

Für die Transfektion von HEK293T-Zellen wurde ein Verfahren verwendet, bei dem eine Transfektionslösung bestehend aus dem entsprechenden Vektor bzw. den entsprechenden Vektoren bei Co-Transfektionen, OPTM und PEI hergestellt und auf die HEK293T-Zellen gegeben wurde. Pro Deckglas wurde ein Gesamtvolumen von $30 \mu l$ kalkuliert. Dieses bestand aus $15 \mu \mathrm{l}$ OPTM, $1 \mu \mathrm{g}$ DNA bzw. zweimal $1 \mu \mathrm{g}$ DNA bei Co-Transfektionen und einem entsprechenden Restvolumen PEI. Die angesetzte Lösung verblieb für $30 \mathrm{~min}$ bei Raumtemperatur, bevor sie auf die Zellen pipettiert wurde. Nach 48 h erfolgte die Fixierung der Zellen mit 4 \% PFA in PBS.

\subsection{Verwendete Vektoren}

Tabelle 4: Tabellarische Übersicht der verwendeten DNAs inklusive Kurzbeschreibungen. Abkürzung: VAMP: vesicle associated membrane protein.

\begin{tabular}{|l|l|}
\hline Plasmid & Position und Art des Protein-Tags \\
\hline GFP-Rogdi & $\begin{array}{l}\text { N-terminales monomeres EGFP (enhanced green fluorescent protein)- } \\
\text { Tag }\end{array}$ \\
\hline GFP-VAMP & N-terminales EGFP-Tag \\
\hline Bassoon-GFP & C-terminales monomeres EGFP-Tag (C-terminal von AS 3938) \\
\hline GFP-Bassoon & Monomeres EGFP-Tag innerhalb des Konstrukts (zw. AS 97 und 98) \\
\hline GFP-RIBEYE & N-terminales EGFP- Tag \\
\hline PSD95-GFP & C-terminales EGFP-Tag \\
\hline m-GFP & Monomeres EGFP-Tag (mit A207K-Mutation) \\
\hline Synaptophysin-phluorin- & C-terminales monomeres Orange-Tag \\
\hline
\end{tabular}


mOrange

\subsection{Synaptotagmin-1-Uptake}

Tabelle 5: Depolarisationspuffer.

\begin{tabular}{|l|l|}
\hline Bestandteil & Konzentration [mM] \\
\hline $\mathrm{NaCl}$ & $64 \mathrm{mM}$ \\
\hline $\mathrm{KCL}$ & $70 \mathrm{mM}$ \\
\hline $\mathrm{MgCL}_{2}$ & $1 \mathrm{mM}$ \\
\hline $\mathrm{CaCl}_{2}$ & $2 \mathrm{mM}$ \\
\hline $\mathrm{HEPES}$ & $20 \mathrm{mM}$ \\
\hline Glucose & $30 \mathrm{mM}$ \\
\hline
\end{tabular}

Dieses Verfahren wurde zur Überprüfung der synaptischen Aktivität transfizierter Neurone genutzt. Der molekulare Ablauf dieser Methode besteht in der Aufnahme des zugegebenen Synaptotagmin-1-Antikörpers in die synaptischen Endigungen. Dieser kann im Anschluss mithilfe eines sekundären Antikörpers sichtbar gemacht werden. Die Voraussetzung für die Aufnahme ist eine vorausgehende Depolarisation und Entleerung der synaptischen Vesikel. Dazu wurden der Antikörper in einer Verdünnung von 1:600 in dem Depolarisationspuffer (1x) verdünnt, pro Well $200 \mu \mathrm{l}$ der Mischung auf die Neurone gegeben und für 5 min bei $37^{\circ} \mathrm{C}$ und $5 \% \mathrm{CO}_{2}$ inkubiert. Nach dreimaligem Waschen mit Neurobasalmedium wurden die Zellen wie unten beschrieben fixiert und mit dem sekundären Antikörper gefärbt.

\subsection{Fixierung und Immunfärbungen}

Zur Fixierung wurden die Zellen für 20 min mit auf $4{ }^{\circ} \mathrm{C}$ gekühltem 4-prozentigen PFA in PBS versetzt. Daraufhin folgten drei 5-minütige Waschschritte mit 1x PBS, bevor die Immunfluoreszenzfärbungen durchgeführt wurden. Vor dem Färben wurden die 1x PBSLösung entfernt und die Zellen für 30 min mit der Erstantikörperblockierungspuffer inkubiert. Hierbei wurden pro Deckglas ca. $150 \mu \mathrm{l}$ zur Bedeckung der Zellen verwendet. Das in dem Erstantikörperpuffer vorhandene Triton X-100 bewirkt als Detergens das Herauslösen von Proteinen aus der neuronalen Membran. Die Inkuba-tionszeit wurde für die Verdünnung der Erstantikörper in Blockierungspuffer genutzt, wobei $200 \mu$ l pro Deckglas kalkuliert wurden. Nach Hinzufügen der Erstantikörper-Puffer-Lösung wurden die Zellen über Nacht bei $4{ }^{\circ} \mathrm{C}$ auf einer kippenden Platte gelagert. Am nächsten Vormittag wurden 
die Zellen erneut dreimal für 5 min mit 1x PBS gewaschen, die Zweitantikörper in einem entsprechenden Puffer verdünnt und nach Zugabe zu den Zellen für 60 min dunkel auf einem Schüttler inkubiert. Ein letztes Mal folgten drei weitere Waschgänge mit 1x PBS bevor die Deckgläschen jeweils mit $7 \mu$ l Mowiol auf Menzelgläsern fixiert wurden. Nach mehrstündiger Lagerung unter dem Abzug erfolgte die Lagerung der Proben im Kühlschrank bei $4{ }^{\circ} \mathrm{C}$.

Die

Grundlage für die Färbungen besteht in der Verwendung von spezifischen Primärantikörpern, welche gegen die exprimierten präsynaptischen Proteine gerichtet sind. Nach Zugabe der Antikörper kommt es zur Bindung dieser an die Epitopregion der zu markierenden Proteine im Sinne einer Antigen-Antikörper-Reaktion. Die Fc-Region des jeweiligen aufgetragenen unmarkierten primären Antikörpers wird daraufhin von einem Sekundärantikörper erkannt, welcher seinerseits mit einem Fluoreszenzfarbstoff markiert ist. Die verwendeten und unten genannten Primärantikörper stammen aus Maus, Meerschweinchen und Kaninchen.

Tabelle 6: Verwendete primäre Antikörper. Abkürzungen: $\mathrm{ch}=$ Huhn, gp = Meerschweinchen, $\mathrm{ms}=$ Maus, $r b=$ Kaninchen; $\mathrm{m}$ = mono-, $\mathrm{p}=$ polyklonal; MAP: microtubule-associated protein, BDB: BD Biosciences, SA: SIGMA-ALDRICH, SYSY: Synaptic Systems; Syt-1: Synaptotagmin-1

\begin{tabular}{|l|l|l|l|l|l|l|}
\hline Antigen & $\begin{array}{l}\text { Spe- } \\
\text { zies }\end{array}$ & Typ & Hersteller & IF & $\begin{array}{l}\text { Syt-1- } \\
\text { Uptake }\end{array}$ & $\begin{array}{l}\text { Western } \\
\text { Blot }\end{array}$ \\
\hline Bassoon & ms & m & Enzo & $1: 1000$ & & \\
\hline Bassoon & rb & p & SYSY & $1: 500$ & & \\
\hline Bassoon & gp & p & SYSY & $1: 500$ & & \\
\hline GFP6556 & rb & p & Abcam & $1: 3000$ & & \\
\hline GFP & ch & p & Abcam & $1: 1000$ & & \\
\hline MAP & gp & p & SYSY & $1: 1000$ & & \\
\hline Mover & rb & p & SYSY & $1: 1000$ & & \\
\hline Ribeye & rb & p & SYSY & $1: 10000$ & & $1: 1000$ \\
\hline Rogdi & rb & p & SA & $1: 500$ & & \\
\hline Synapsin & ms & m & SYSY & $1: 500$ & & \\
\hline Synaptophysin & ms & m & SYSY & $1: 500$ & & \\
\hline Synaptotagmin-1 & ms & p & SYSY & & $1: 600$ & \\
\hline TGN38 & ms & m & BDB & $1: 1000$ & & \\
\hline VAMP2 & rb & p & SYSY & $1: 500$ & & \\
\hline
\end{tabular}


Tabelle 7: Verwendete sekundäre Antikörper. Abkürzungen: $\mathrm{Ch}=$ Huhn, $\mathrm{Dk}=$ Esel, $\mathrm{Gp}=$ Meerschweinchen, Gt = Ziege, Ms = Maus, Rb = Kaninchen; $\mathrm{m}$ = mono-, $\mathrm{p}=$ polyklonal; JIR: Jackson ImmunoResearch, MP: MolecularProbes; Emax: Exzitationsmaximum, Syt-1: Synaptotagmin

\begin{tabular}{|l|l|l|l|l|l|l|l|}
\hline Antigen & Spezies & Typ & Hersteller & $\mathbf{E}_{\max }$ & IHC & $\begin{array}{l}\text { Syt-1- } \\
\text { Uptake }\end{array}$ & $\begin{array}{l}\text { Western } \\
\text { Blot }\end{array}$ \\
\hline Ch & Gt & IgG & JIR & 488 & $1: 1000$ & & \\
\hline Ch & Gt & IgG & JIR & CY3 & $1: 1000$ & & \\
\hline $\mathrm{Ms}$ & Dk & IgG & MP & 488 & $1: 1000$ & & \\
\hline $\mathrm{Ms}$ & Dk & IgG & JIR & CY3 & $1: 1000$ & & \\
\hline $\mathrm{Ms}$ & Gt & IgG & JIR & CY5 & & $1: 1000$ & \\
\hline $\mathrm{Gp}$ & Gt & IgG & MP & 546 & $1: 1000$ & & \\
\hline $\mathrm{Gp}$ & Gt & IgG & JIR & 647 & $1: 1000$ & & \\
\hline $\mathrm{Rb}$ & Dk & IgG & JIR & CY3 & $1: 1000$ & & \\
\hline $\mathrm{Rb}$ & Dk & IgG & MP & 647 & $1: 1000$ & & \\
\hline $\mathrm{Rb}$ & Dk & IgG & JIR & & & & $1: 10000$ \\
\hline $\mathrm{Rb}$ & Gt & IgG & MP & 488 & $1: 1000$ & & \\
\hline $\mathrm{Rb}$ & Gt & IgG & MP & 546 & $1: 1000$ & & \\
\hline $\mathrm{Rb}$ & Gt & IgG & MP & 647 & $1: 1000$ & & \\
\hline
\end{tabular}

Da der Antikörper „AffiniPureDonkey Anti-rabbit“ nicht mit einem Fluorophor gekoppelt ist, verbleibt die Spalte $\mathrm{E}_{\max }$ in diesem Falle leer.

\subsection{Fluoreszenzmikroskopie und Bildaufnahme/Fotografie}

Die fluoreszenzmikroskopische Betrachtung der Zellen erfolgte bei 20-facher Vergrößerung oder mit hochauflösenden Öl-Immersions-Objektiven des inversen Mikroskops Zeiss Observer. Z1 welche 40- bis 100-fache Vergrößerungen ermöglichten. Für die Fotografie wurde als Aufnahmegerät eine PhotometricsCoolSNAP HQ2 verwendet. 


\subsection{Bildbearbeitung}

Die anschließende Bildbearbeitung mithilfe des Programms Photoshop CS6 beschränkte

sich auf dezente Änderungen in Helligkeit und Kontrast, um die Rohdaten möglichst wenig zu modifizieren und wurde nur zur Darstellung verwendet. Quantitative Analysen wurden ausschließlich an Rohdaten vorgenommen. Für das Zusammenfügen der Aufnahmen in Form der endgültigen Abbildungen wurde das Grafik- und Zeichenprogramm Adobe Illustrator CC genutzt.

\subsection{Quantifizierung und Statistik}

Für die quantitativen Analysen der Datensätze wurden verschiedene Herangehensweisen verfolgt. Das aus den DIV 6-Zellen erhaltene Datenmaterial wurde durch die kombinierte Anwendung der Programme ImageJ und Microsoft Excel ausgewertet. Die erstgenannte Anwendung ermöglichte hierbei zunächst das Erstellen sogenannter regions of interest (ROI), also klar definierter Bereiche, welche in einem weiteren Schritt analysiert werden konnten. Da im Falle der untersuchten Proteine in der Regel eine Akkumulation am GolgiApparat nachweisbar war, wurden dessen sich scharf abzeichnende Begrenzungen als Rahmen der ROI genutzt. Dabei wurden alle in der Fokusebene befindliche Bereiche des Zellorganells ausgewertet. Darüber hinaus notwendig war das Erzeugen von Quadraten definierter Größe (50 x 50 Pixel), welche frei platziert werden konnten, um Hintergrundintensitäten subtrahieren zu können. Dazu wurden die Intensitäten dieser quadratischen Flächen, welche innerhalb des jeweiligen Zellkerns und damit wiederum in der Zellebene platziert wurden, berechnet. Zur Auswertung der aus DIV 10-Zellen gewonnenen Daten zum Intensitätsvergleich und für Colokalisationsanalysen verschiedener Proteine wurde die Software OpenView angewendet. Das Programm ermittelt durchschnittliche Pixelwerte von 4 x 4 Pixel messenden Quadraten innerhalb der zuvor ausgewählten punktförmigen Regionen (Fisher-Lavie und Ziv 2013). Hierbei konnten alle Intensitäten eines Kanals, welche einen definierten Schwellenwert überschritten, als Maske genutzt und in einen weiteren Kanal zu Analysezwecken übertragen werden. Der jeweilige Schwellenwert wurde per Augenmaß so bestimmt, dass die gesamte in den Rohdaten befindliche relevante Information berücksichtigt werden konnte. Der für ein Teilexperiment gewählte Schwellenwert wurde für alle bestehenden Aufnahmen konstant gehalten. Von großer Bedeutung war das sehr unterschiedlich stark ausfallende Hintergrundsignal, welches von den Rohdaten abgezogen werden musste. Dazu wurden pro Aufnahme drei Bereiche, welche augenscheinlich typische Hintergrundsignale darstellten, ausgewählt und gemittelt. Der resultie- 
rende Mittelwert wurde daraufhin von den jeweiligen Rohdaten subtrahiert. Um eine möglichst hohe Ähnlichkeit der Hintergrundbereiche zu gewährleisten, müssen diese selbst dem aus ihnen errechneten Mittelwert \pm 10 (willkürliche Einheit des Programms OpenView) entsprechen. Anderenfalls wurden die Werte verworfen und neue gewählt. Im Fall der Experimente an adulten Neuronen wurden die weiteren der Auswertung dienenden Schritte in Microsoft Excel durchgeführt. Dazu wurden die zuvor in OpenView bestimmten Fluoreszenzintensitäten der jeweils betrachteten Proteine nur unter bestimmten Voraussetzungen der definitiven Analyse zugeführt. Verschiedene Proteine wurden als colokalisierend angenommen, wenn das Protein von Interesse, welches für das Erstellen der Maske genutzt wurde, mit am selben Ort vorliegendem Synapsenmarker, dessen Intensität dem 1,33-fachen Wert des bestimmten Hintergrundes entsprach, nachweisbar war.

Für die Ergebnisse eines jeden Experiments wurden mithilfe des Programms IBM SPSS statistics 21 die Standardabweichung von Mittelwert bestimmt sowie auf Signifikanzen geprüft. Dazu wurde in Abhängigkeit von der jeweiligen Fragestellung im Falle von Intensitätsvergleichen von zwei Werten ein t-Test, bei mehr als zwei zu vergleichenden Werten eine einfaktorielle Varianzanalyse (ANOVA) in Kombination mit einem Post-hoc-Test und im Falle der Colokalisationsanalysen ein Chi-Quadrat-Test durchgeführt. Während im Rahmen der vergleichenden Fluoreszenzintensitätsanalysen die Intensitätswerte der diversen Konstrukte direkt miteinander verglichen werden konnten, mussten bei den Colokalisationsanalysen zwei Zustände, nämlich „positive Colokalisation“ und „,negative Colokalisation“ definiert und den Werten 1 und 0 zugeordnet werden. Entsprechende Dia-gramme wurden mit Microsoft Excel erstellt und anschließend in ImageJ angeordnet.

\section{Beispiel 1:}

Für die Fluoreszenzintensitätsanalysen wurden jeweils drei Sätze, also Präparationen mit anschließender Kultivierung und Transfektion der Neurone, durchgeführt. Aus jedem Satz wurden dabei zehn ROI ausgewählt, welche von drei Deckgläschen derselben Präparation stammen. Jede dieser Regionen wies wiederum im Falle der jungen Neurone punktförmige oder aufgrund der Assoziation einiger Proteine mit dem Golgi-Apparat schollenförmige und im Falle aller adulten Zellen aufgrund der synaptischen Anreicherung punktförmige Signale auf. Die Anzahl der Signale hing dabei stark von der subzellulären Verteilung des jeweiligen gefärbten endogenen oder rekombinanten Proteins ab. Somit wurden je nach Fragestellung hunderte bis tausende Werte pro Protein (-konstrukt) in die Analyse einbezogen. Aus allen Signalen, die nach den oben beschriebenen Auswahlkriterien verblieben, 
wurde pro Region ein Mittelwert bestimmt. So ergaben sich pro Konstrukt und Fragestellung jeweils 30 Durchschnittswerte aus 30 Regionen. Zur Überprüfung einer möglicherweise vorhandenen signifikanten Abweichung zwischen z.B. den Fluoreszenzintensitäten der Konstrukte wurden jeweils die sich ergebenden 30 Durchschnittswerte miteinander verglichen. Die in den Säulendiagrammen gezeigten Werte entsprechen dabei dem jeweiligen gesamten Durchschnittswert aller zuvor bestimmten 30 Werte.

\subsection{Biochemische Verfahren}

\subsubsection{Verwendete Puffer und Lösungen}

Tabelle 8: Puffer und Lösungen.

\begin{tabular}{|c|c|}
\hline Puffer bzw. Lösung & Zusammensetzung \\
\hline Blocklösung für die Immunfärbung & $\begin{array}{l}2 \mathrm{~g} \text { Milchpulver, } 50 \mathrm{ml}(1 \mathrm{x}) \text { TBST (Tris-buffered } \\
\text { saline + Tween20) }\end{array}$ \\
\hline Homogenisierungspuffer/HEPES-Puffer & $\begin{array}{l}320 \mathrm{mM} \text { Sucrose, } 4 \mathrm{mM} \text { HEPES-KOH, } \mathrm{pH} 7,4 \text {, in } \\
\mathrm{dH}_{2} \mathrm{O}\end{array}$ \\
\hline NuPAGE®-Laufpuffer & 20x NuPAGE® MES SDS-Laufpuffer, in $\mathrm{dH}_{2} \mathrm{O}$ \\
\hline SDS-Probenpuffer/-Ladepuffer & $\begin{array}{l}100 \mathrm{mM} \text { Tris (pH 6,8), } 25 \% \text { Glyzerin, } 2 \% \text { SDS, } \\
0,01 \% \text { Bromphenolblau, } 10 \% \beta \text {-Mercaptoethanol, } \\
\text { in } \mathrm{dH}_{2} \mathrm{O}\end{array}$ \\
\hline TBS (Tris-buffered saline) & $90 \mathrm{~g} \mathrm{NaCl}, 60 \mathrm{~g}$ Trisbase, in $1000 \mathrm{ml} \mathrm{d \textrm {H } _ { 2 } \mathrm { O }}$ \\
\hline TBST & $\begin{array}{l}100 \mathrm{ml}(10 \mathrm{x}) \mathrm{TBS}, 2,5 \mathrm{ml} \text { Tween }{ }^{\circledR} 20 \text {, in } 1000 \mathrm{ml} \\
\mathrm{dH}_{2} \mathrm{O}\end{array}$ \\
\hline Transferpuffer & 30,3 g Tris, 144 g Glyzerin, in $1000 \mathrm{ml} \mathrm{dH_{2 } \mathrm { O }}$ \\
\hline Western Blot Puffer & 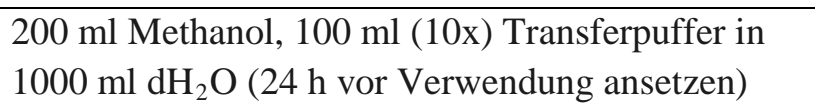 \\
\hline
\end{tabular}




\subsubsection{Gewinnen der Zellen}

Das Weiterverarbeiten der hippocampalen und cortikalen Neurone kann nach dem Ausplattieren und entsprechend langer Inkubation (in den beschriebenen Fällen 10 Tage) auf zwei Arten erfolgen. Die erste Möglichkeit sieht vor, dass die Zellen nach Entnahme des Zellkulturmediums mit DPBS gewaschen werden, mithilfe eines Zellschabers von den Mikrotiterplatten gelöst und anschließend in einer möglichst geringen Menge Homogenisierungspuffer resuspendiert werden. Dazu wurden im Falle der 6-Well Platte $200 \mu \mathrm{l}$, im Falle der 24-Well Platte $80 \mu$ in den ersten Schacht gegeben, die Zellen abgekratzt, mithilfe einer Pipette entnommen und daraufhin ohne weitere Flüssigkeitszugabe in das nächste Well überführt. Dieser Vorgang wurde dann zwecks Erhöhung der Zellzahl mehrfach wiederholt. Die anschließende Zentrifugation bei 1000 g für 5 min ermöglicht die Auftrennung der Suspension in den Überstand und das Pellet, welches verworfen wird. Der Überstand wird 1:1 mit 2x SDS-Puffer versetzt, 5 min im TB2 Thermoblock bei $95{ }^{\circ} \mathrm{C}$ erhitzt und erneut bei $1000 \mathrm{~g}$ für 5 min zentrifugiert.

Die zweite Möglichkeit sieht das direkte Versetzen der gewaschenen Zellen mit 1x SDSPuffer vor. Dazu wird in Abhängigkeit von der Beschaffenheit der Platte eine möglichst geringe Menge Puffer in das erste Well gegeben (vergleiche oben) und nach $5 \mathrm{~min}$ in das nächste überführt. Dieser Vorgang wird mehrfach wiederholt. Nach 5-minütigem Erhitzen bei $95^{\circ} \mathrm{C}$ erfolgt die Zentrifugation bei $1000 \mathrm{~g}$ für $5 \mathrm{~min}$. Das gewonnene Material kann bei $-20^{\circ} \mathrm{C}$ gelagert werden, muss aber vor jeder Gelelektrophorese erneut erhitzt und zentrifugiert werden.

\subsubsection{SDS-Polyacrylamid-Gelelektrophorese (PAGE)}

Bei der SDS-Polyacrylamid-Gelelektrophorese (SDS-PAGE) handelt es sich um ein analytisches Verfahren zur Auftrennung von Proteinen anhand ihres Stokes-Radius und damit nach ihrem Molekulargewicht. Dabei wandern die Polypeptide im vertikal stehenden Gel in Richtung der Anode und können nach Auftrennung im Gel anschließend weiterverarbeitet werden. Die Gelelektrophoresekammer XCellSureLock ${ }^{\circledR}$ wurde nach Herstellerangabe mit 1x NuPAGE®-MES SDS Laufpuffer befüllt, wobei die obere Kammer 200 ml, die untere $600 \mathrm{ml}$ fasste. Bei den verwendeten Gelen handelte es sich um gebrauchsfertige NuPAGE® 4 - 12\%ige Bis-Tris-Gele. Zur Überwachung des Gellaufs wurde die erste Kammer mit $10 \mu \mathrm{l}$ des Markes SeeBlue ${ }^{\circledR}$ Pre-Stained Standard befüllt. Die anderen Kammern wurden mit jeweils $20 \mu \mathrm{l}$ der Proben oder bei wenigen Proben abwechselnd mit dem SDSProbenpuffer beladen. Die Laufzeit betrug bei einer Spannung von 200 V etwa 40 min. Um 
zu überprüfen, ob die Proben Proteine enthielten wurde das Gel entnommen und mit PageBlue $^{\mathrm{TM}}$ Protein Staining Solution für wenige Minuten gefärbt und anschließend begutachtet. Die verwendete Färbelösung leitet sich von kolloidalem Coomassie G-250 ab und kann bis zu dreimal verwendet werden.

\subsubsection{Western Blot}

Bei dem Western Blot handelt es sich um ein molekularbiologisches Verfahren. Zum Nachweis von Proteinen kommt es dabei zu deren Übertragung, dem Blotting, von einem Elektrophoresegel auf eine PVDF- oder Nitrocellulosemembran. Das elektrische Feld ist hierbei senkrecht zu dem Gel und der Membran ausgerichtet. Nach der Übertragung sind die Proteine fest in der Membran verankert und können auf verschiedene Arten, zumeist über Antikörperfärbungen, nachgewiesen werden.

Vor dem Blotten wurden das Elektrophoresegel, die PVDF-Membran und das Blottingpapier vorbereitet. Zunächst wurden der untere verstärkte Rand des verwendeten Gels abgetrennt und sowohl die Membran als auch das Papier auf die nötige Größe zurechtgeschnitten. Zur späteren Wiedererkennung der Orientierung wurde zusätzlich jeweils die untere linke Ecke entfernt. Während die Membran für wenige Sekunden in reinem Methanol und anschließend für weitere 5 min im Western Blot-Puffer gelagert wurde, wurden das Gel und das Papier lediglich 5 min mit dem Puffer benetzt.

Alle Lagen wurden von unten nach oben wie folgt in der Western Blot-Kammer geschichtet: zwei Lagen Blotting Papier- PVDF-Membran- Elektrophoresegel- zwei Lagen Blotting Papier. Nach dem Auftragen jeder Schicht wurden eventuell vorhandene Luftblasen mit einer Pasteurpipette ausgestrichen. Das Blotting erfolgte daraufhin für ein Gel bei $150 \mathrm{~mA}$ für $1 \mathrm{~h}$, für zwei Gele bei $300 \mathrm{~mA}$ für $1 \mathrm{~h}$.

\subsubsection{Immunfärbung nach Western Blot}

Im Anschluss an das Blotting wird die PVDF-Membran nach zweimaligem Waschen (für jeweils 5 min) mit $\mathrm{dH}_{2} \mathrm{O}$ in eine Blotschale gelegt und für 2 min mit Ponceau-Lösung gefärbt. Bei dieser Lösung handelt es sich um einen roten Azofarbstoff, der die übertragenen Proteine reversibel färbt, also anzeigt, ob der zuvor durchgeführte Western Blot erfolgreich war. Die Banden können dann markiert und fotografiert werden. Durch das Spülen mit destilliertem Wasser entfärbt sich die Membran wieder. Vor Zugabe des primären Antikörpers werden $10 \mathrm{ml}$ Blocklösung für $1 \mathrm{~h}$ auf die Membran gegeben. Die Lagerung in der Blotschale erfolgte auf einer rotierenden Platte. Nach der Inkubationszeit wurde die Block- 
lösung verworfen, die Membran mit PBS gespült und der verdünnte primäre Antikörper hinzugegeben. Die Verdünnung des primären Antikörpers erfolgte 1:1000 in der Blocklösung bei einem Gesamtvolumen von $10 \mathrm{ml}$. Die Färbung erfolgte kippend über Nacht bei $4{ }^{\circ} \mathrm{C}$. Am folgenden Vormittag wurde die Membran dreimal für $10 \mathrm{~min}$ mit TBST gewaschen und daraufhin für $1 \mathrm{~h}$ mit dem sekundären Antikörper versetzt. Dieser wurde zuvor 1:10 000 in PBS verdünnt $(\mathrm{V}=10 \mathrm{ml})$. Nach dreimaligem Waschen mit TBST für je 10 min wurde die Membran mit CheLuminate-HRP FemtoDetect Plus, einer 1:1 Peroxidund Luminolmischung, zur Vermeidung eines zu starken Hintergrundsignals für höchstens 5 min inkubiert. Die verwendete Konzentration der Mischung lag bei 0,1 ml Lösung/ $\mathrm{cm}^{2}$ Membranfläche. Zuletzt erfolgte die Visualisierung der gefärbten Proteine im Fluor ChemE, der digitalen Belichtungskammer. Von größter Bedeutung ist hierbei die Handhabung der gefärbten Membran. Diese sollte man nach der Inkubation mit dem Elektrochemilumineszenzreagenz (ECL-Reagenz) gründlich abtropfen lassen und in eine Folie geben. Die Entwicklung in der Belichtungskammer erfolgt dabei am gleichmäßigsten, wenn die Membran feucht ist und blasenfrei aufliegt. 


\section{ERGEBNISSE}

\subsection{Bassoon-Konstrukte}

\subsubsection{Verteilung und Fluoreszenzintensitäten der Konstrukte präsynap- tischer Proteine in den Somata junger Neurone}

Zur Darstellung der zu untersuchenden Proteine wurden junge Neurone (DIV 3) mittels Calcium-Phosphat-Präzipitation transfiziert und am DIV 6 für 20 min mit PFA in DPBS fixiert. Für diesen Versuch wurden die Vektoren Bassoon-GFP, GFP-Bassoon, m-GFP und GFP-VAMP verwendet. Die zentrale Fragestellung ist dabei, ob sich die Verteilung der rekombinanten Proteine mit derjenigen der jeweiligen endogenen Proteine deckt. Bekannt ist, dass Bassoon und VAMP wie auch viele weitere Proteine zwecks ihres subzellulären Transports am Golgi-Apparat angereichert vorkommen. Diese Lokalisation lässt sich besonders gut in jungen Entwicklungsstadien der Neurone nachweisen, in welchen bisher nur geringe Anteile der Proteine in die sich entwickelnden Fortsätze bewegt wurden. Neben der grünen Autofluoreszenz der oben genannten Proteinkonstrukte interessierte daher die Lage des Golgi-Apparates in der jeweiligen transfizierten Zelle. Diese wurde mittels Antikörperfärbung von TGN38, einem integralen Membranprotein des Zellorganells, sichtbar gemacht. Die Ergebnisse der Untersuchung sind in Abbildung 4 zusammengefasst. Während das monomere grün fluoreszierende Protein (m-GFP) im Bereich des Soma und sogar im Nucleus diffus verteilt ist, findet man Bassoon-GFP, GFP-Bassoon und GFP-VAMP angereichert und mit TGN38 colokalisiert, jedoch vollkommen abwesend vom Zellkern. Mit Ausnahme von m-GFP, welches bewusst als Vergleich zu den anderen gewählt wurde, entsprechen sich die Proteine in ihrer Lokalisation innerhalb der Somata junger Neurone. Bei der Betrachtung der Signale fiel die unterschiedliche Fluoreszenzintensität der Konstrukte auf, welche es anschließend zu untersuchen galt (Abbildung 4).

Um diese Vermutung überprüfen zu können, wurden die Fluoreszenzintensitäten von jeweils 30 Zellen aus drei verschiedenen Präparationen miteinander verglichen. Mithilfe des Programms ImageJ wurden aus 16-Bit-Bildern nach Abzug der jeweiligen Hintergrundintensität die mittleren Intensitäten der rekombinanten Proteine in Form von Graustufen angegeben. Mit einem Mittelwert von -43,36 £ 3,83 war m-GFP am Golgi-Apparat am wenigsten hell wahrzunehmen (Abbildung 4A-D und nicht gezeigte Quantifizierung). Das negative Vorzeichen lässt sich aufgrund der Vorgehensweise erklären. Nach Bestimmung der Intensität des jeweiligen Proteins im Bereich des Golgi-Apparates wurde die Helligkeit des Hintergrundes subtrahiert. Bei dieser Vorgehensweise wurde ein 50 mal 50 Pixel 
messendes Quadrat innerhalb des Nucleus als Hintergrund definiert, um in derselben Fokusebene zu bleiben, in welcher zuvor die Intensität des jeweiligen Proteins bestimmt wurde. Aufgrund der Tatsache, dass m-GFP keine Akkumulation im genannten Zellorganell aufwies und stattdessen sogar in den Zellkern diffundierte, wies der als Hintergrund festgelegte Bereich sogar eine intensivere Färbung auf. Mit 110,82 \pm 4,15 von 255 Graustufen leuchtete GFP-VAMP am Golgi-Apparat signifikant heller als die übrigen Proteine. Im Vergleich lagen die beiden Bassoon-Konstrukte mit Mittelwerten von 53,45 \pm 2,90 für GFP-Bassoon und 36,29 \pm 2,53 für Bassoon-GFP zwischen dem diffus verteilten m-GFP und dem sehr hellen und am Golgi-Apparat angereicherten GFP-VAMP. Zwischen den Fluoreszenzintensitäten aller Proteine, also auch der beiden Bassoon-Konstrukte, bestanden signifikante Unterschiede ( $\mathrm{P}<0,001)$. Die Ergebnisse sind in Abbildung 4 in Form eines Säulendiagramms dargestellt.

Dieses Experiment zeigt also, dass alle Proteine am erwarteten Ort angereichert sind bzw. mGFP diffus verteilt ist und GFP-Bassoon eine signifikant höhere Fluoreszenzintensität als Bassoon-GFP besitzt. Dieses könnte auf eine stärkere Anreicherung oder eine günstigere Faltung zurückzuführen sein. 

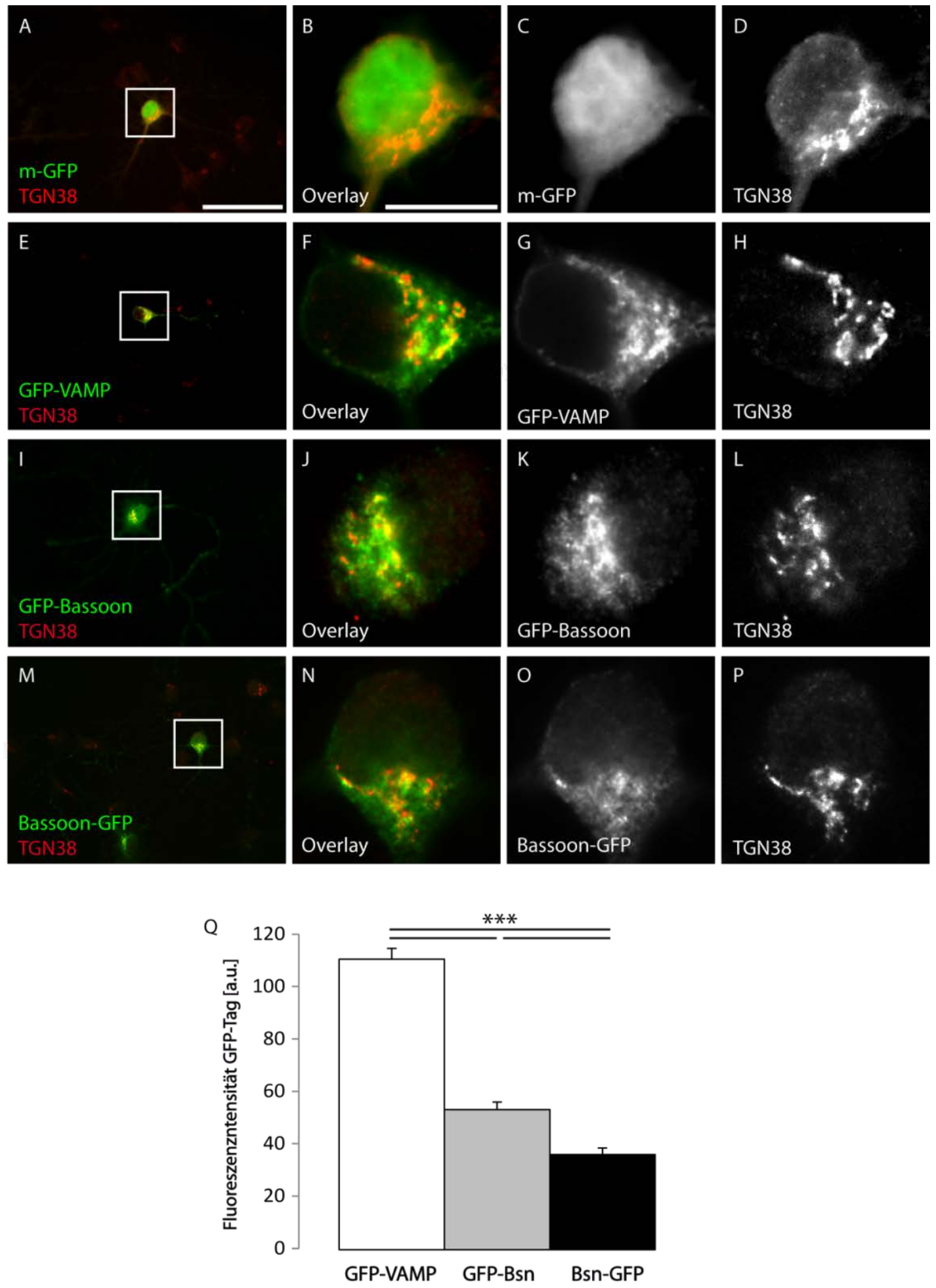

Abbildung 4: Konstrukte präsynaptischer Proteine in den Somata junger Neurone. Immunfluoreszenzfärbung von TGN38 als Golgi-Marker in Kombination mit der Autofluoreszenz der rekombinanten Proteine am DIV 6. Die Abbildungen (A), (E), (I) und (M) zeigen Übersichtsaufnahmen bei 40-facher, die restlichen die Somata bei 63-facher Vergrößerung. In Rot ist die Golgi-Färbung, in Grün die Autofluoreszenz der GFP-Tags dargestellt. Rechts neben den Übersichtsaufnahmen sind zunächst die überlagerten, dann die einzelnen Kanäle zu sehen. (Q): Quantitative Auswertung der Fluoreszenzintensitäten der Konstrukte am Golgi-Apparat der DIV 6-Neurone. Am intensivsten wahrnehmbar war GFPVAMP. Die Intensitäten der Bassoon-Konstrukte lagen zwischen denen der anderen Proteine. Der Vergleich aller Proteine untereinander fiel signifikant aus. Die am geringsten ausfallende Intensität des m-GFP ist nicht im Säulendiagramm gezeigt. Abkürzungen: GFP-Bsn: GFP-Bassoon; Bsn-GFP: Bassoon-GFP. Maßstäbe: (A) 50 m, (B) $10 \mu \mathrm{m}$. 


\subsubsection{Verteilung und Intensität der rekombinanten Proteine in adulten Neuronen}

Um festzustellen, ob ein Transport entlang der Fortsätze und eine Anreicherung der Konstrukte an präsynaptischen Endigungen vorliegt, wurde überprüft, ob punktförmige Signale zu erkennen sind und mit dem Präsynapsenmarker Synaptophysin colokalisieren. Bei Synaptophysin handelt es sich um ein integrales Membranprotein synaptischer Vesikel. Der Abbildung 5 ist zu entnehmen, dass sowohl GFP-VAMP als auch die Bassoon-Konstrukte Bassoon-GFP und GFP-Bassoon punktförmige Signale entlang von Zellfortsätzen zeigen und zusammen mit Synaptophysin vorliegen. Diese Ergebnisse entsprechen denen vorheriger Untersuchungen der Arbeitsgruppe sowie der Literatur (Ahmari et al. 2000; Dresbach et al. 2003; Dresbach et al. 2006). Für die DIV 10-Neurone wurde die Fluoreszenzintensität an den präsynaptischen Endigungen bestimmt. Als Präsynapsen wurden Bereiche definiert, an welchen die GFP-Fusionsproteine mit synaptophysinpositiven Punkten, welche eine mindestens 33 \% höhere Intensität als der jeweilige Hintergrund aufwiesen, colokalisierten. Die Analyse erfolgte mithilfe der Programme OpenView und MicrosoftExcel. Für die quantitative Analyse in adulten Zellen wurden erneut jeweils die Signale von 30 Bereichen aus drei unterschiedlichen Sätzen miteinander verglichen. Mit einem Mittelwert von 564,69 \pm 20,32 wies GFP-VAMP auch in adulten Zellen die höchste Intensität auf und war signifikant heller als Bassoon-GFP und GFP-Bassoon $(\mathrm{P}<0,0001)$.

Der relative Unterschied der Signalstärken von Bassoon-GFP $(114,91 \pm 4,38)$ und GFPBassoon $(117,34 \pm 5,69)$ fiel im Vergleich zu den jungen Neuronen nicht mehr signifikant aus $(\mathrm{P}=0,998)$.

Diese Daten legen nahe, dass die beiden rekombinanten Bassoon-Versionen eine sehr ähnliche synaptische Anreicherung erfahren. 

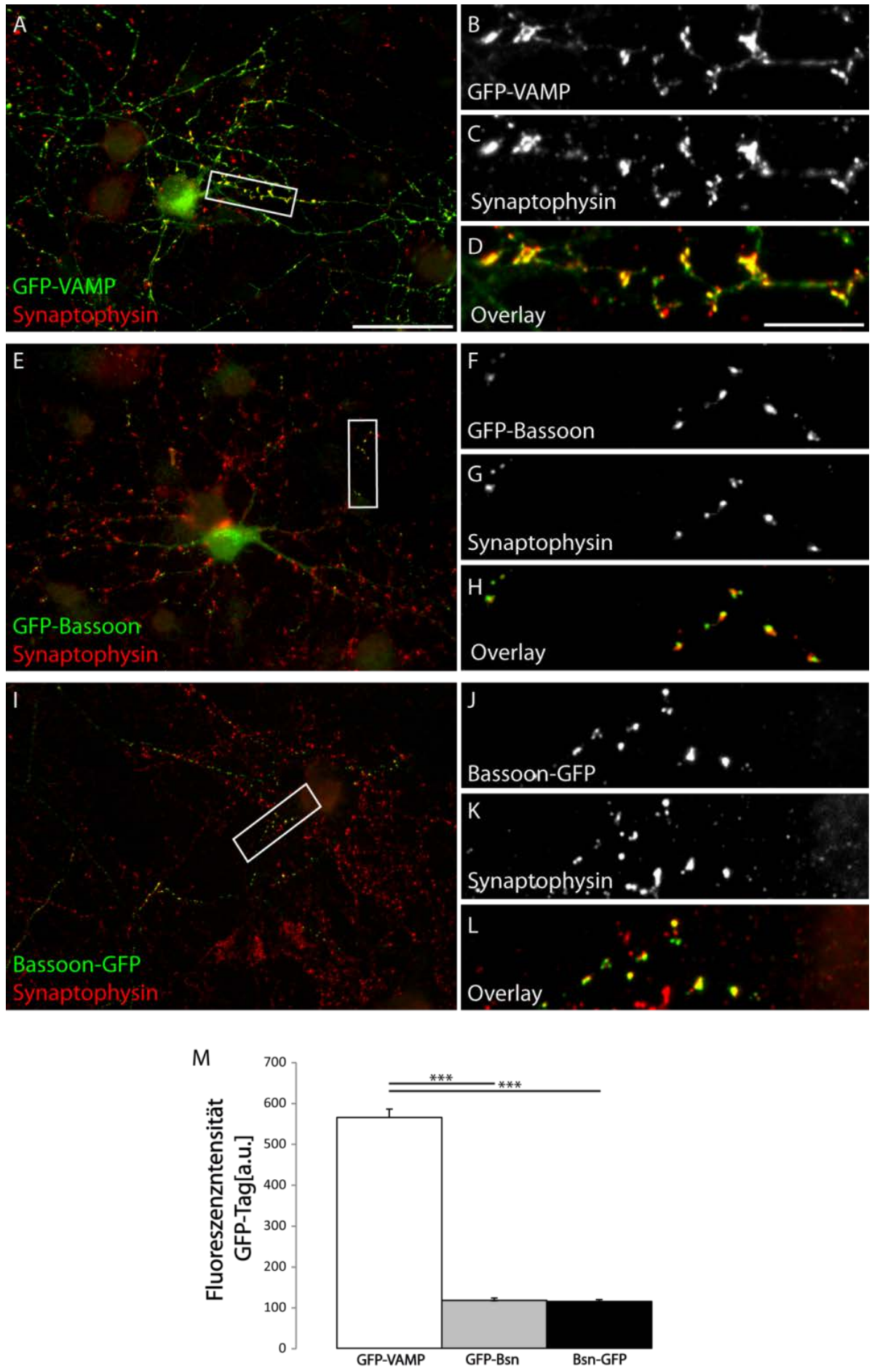

Abbildung 5: Verteilung und Intensität dreier rekombinanter Proteine in adulten Neuronen. (A), (E) und (I) zeigen die drei untersuchten rekombinanten Proteine in transfizierten Zellen am DIV 10 bei einer Vergrößerung von 40x. Während Synaptophysin in Rot dargestellt ist, zeigen sich die GFP-Tags in Grün. Die Felder (B)-(D), (F)-(H) und (J)-(L) zeigen die Ausschnitte aus den 40x-Übersichtsbildern bei 63-facher Vergrößerung und veranschaulichen die Colokalisation der rekombinanten Proteine mit dem endogenen Synaptophysin. Dazu werden zunächst die voneinander getrennten Kanäle und jeweils darunter die Überlagerungen (Overlays) gezeigt. Die kräftige Gelbfärbung einzelner Punkte repräsentiert die Colokalisation. Maßstäbe: $10 \mu \mathrm{m}$. (M) gibt das Ergebnis der Quantifizierung der Fluoreszenzintensitäten der Konstrukte wieder. Mit Mittelwerten von 117,34 \pm 5,69 (GFP-Bassoon) und 114,91 \pm 4,38 (Bassoon-GFP) unterschieden sich die Helligkeiten der Bassoon-Konstrukte nicht deutlich voneinander, jedoch signifikant von dem mit einem Mittelwert von 564,69 \pm 20,32 etwa 4-fach helleren GFP-VAMP. Abkürzungen: GFP-Bsn: GFP-Bassoon; Bsn-GFP: Bassoon-GFP. Maßstäbe: (A) $50 \mu \mathrm{m}$, (D) $10 \mu \mathrm{m}$. 


\subsubsection{Gesamt-Bassoonmenge einer Präsynapse}

Um zu überprüfen, wie stark die Zusammensetzung der Bestandteile der Präsynapse unter der Überexpression von rekombinantem Bassoon variieren kann, wurde die Gesamtbassoonmenge in transfizierten und nicht-transfizierten Zellen miteinander verglichen. Zur Überprüfung wurden erneut Überexpressionen von Bassoon-GFP und GFP-Bassoon durchgeführt und ein Bassoon-Antikörper genutzt, wodurch also zusätzlich endogenes Bassoon gefärbt wurde. Wichtig war hierbei der Vergleich der sich ergebenden Fluoreszenzintensitäten des Bassoon-Antikörpers. Hierzu wurden insgesamt jeweils 30 Regionen aus drei Präparationen mittels OpenView und Microsoft Excel miteinander verglichen. Die Auswertung ergab signifikante Unterschiede zwischen den Intensitäten der Bassoonpositiven Punkte in transfizierten und nicht-transfizierten Zellen. Mit Fluoreszenzintensitäten von 245,40 \pm 17,97 (GFP- Bassoon) und 284,14 \pm 23,01 (Bassoon-GFP) unterschieden sich Bassoon-positive Punkte, die sowohl endogenes als auch rekombinantes Protein enthielten, nicht signifikant voneinander $(\mathrm{P}=0,258)$. Im Vergleich zu untransfizierten Kulturen $(183,61 \pm 6,67)$ fielen jedoch beide Werte signifikant höher aus (Abbilddung 6). Die Transfektion führte also im Falle beider Bassoon-Konstrukte zu einer Erhöhung der Bassoonmenge von ca. 45 \%. Die Kulturen, in denen es zu einer Expression von BassoonGFP kam, unterschieden sich dabei stärker von den untransfizierten $(P<0,001)$ als die, in denen GFP-Bassoon exprimiert wurde ( $\mathrm{P}=0,035)$.

Die Ergebnisse zeigen, dass es aufgrund der Transfektion zu einer signifikanten, aber geringen Erhöhung der Bassoonmenge kommt. 

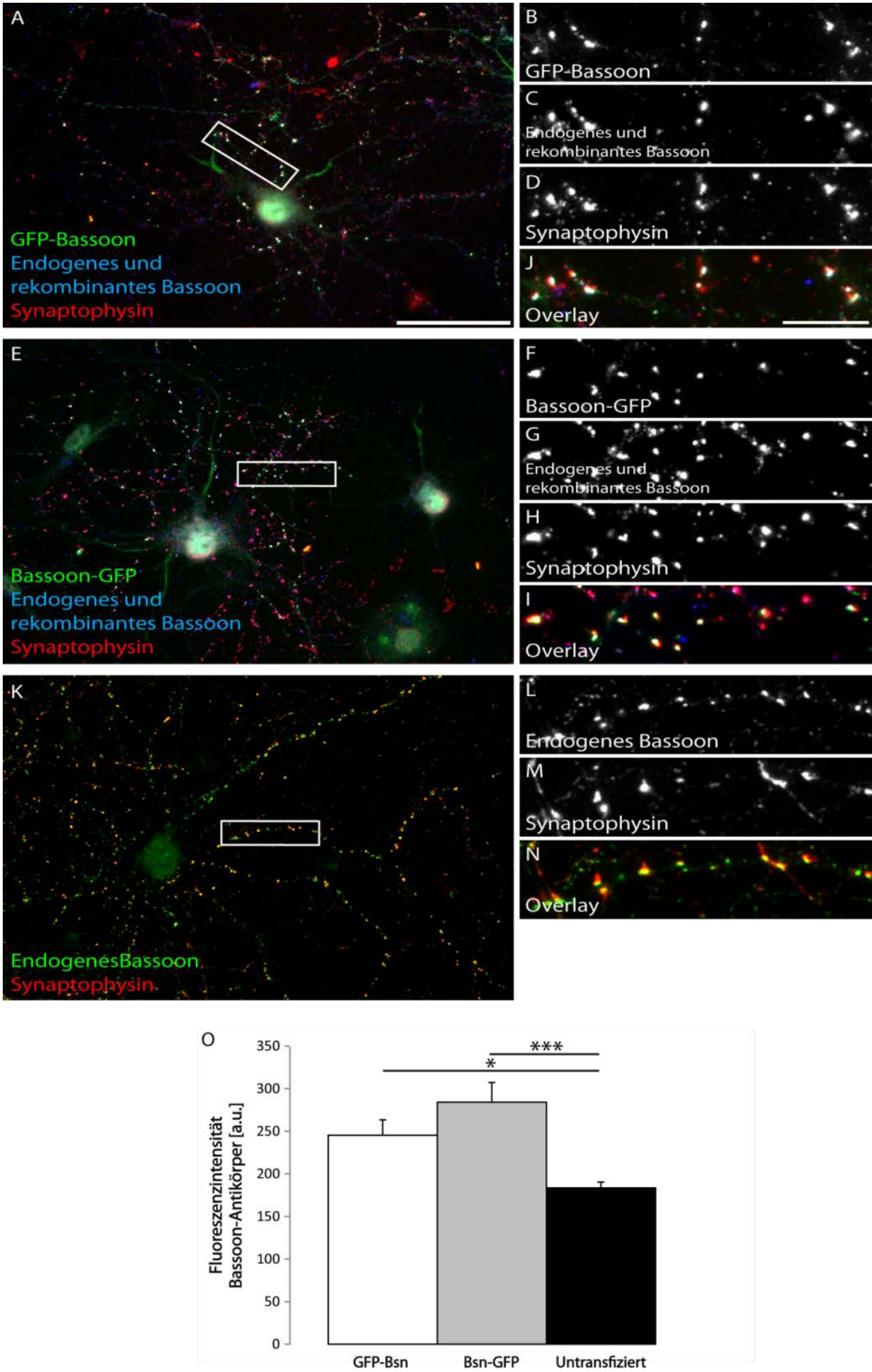

Abbildung 6: Gesamt-Bassoonmenge einer Präsynapse. (A) und (F) zeigen mit rekombinantem Bassoon transfizierte Zellen bei 40 -facher Vergrößerung. Zusätzlich wurde ein Bassoonantikörper (in Blau), welcher sowohl das rekombinante als auch das endogene Bassoon erkennt, und ein Synptophysinantikörper verwendet (in Rot). (K) gibt eine typische Färbung von endogenem Bassoon und Synaptophysin in einer untransfizierten Kultur wieder. (B)-(E), (G)-(J) und (L)-(N) bilden die verschiedenen Kanäle der Ausschnitte aus den Übersichtsbildern bei einer Vergrößerung von 63x ab. Eine Colokalisation der gefärbten Proteine stellt sich in (E) und (J) in Weiß dar, in (N) in Gelb. Maßstäbe: (A) $50 \mu \mathrm{m},(\mathrm{E}) 10 \mu \mathrm{m}$. Das Säulendiagramm $(\mathrm{O})$ lässt erkennen, dass die Gesamtbassoonmengen in den überprüften Synapsen transfizierter und untransfizierter Neurone signifikant voneinander abwich. Abkürzungen: GFP-Bsn: GFP-Bassoon; Bsn-GFP: BassoonGFP. 


\subsubsection{Gesamt-Bassoonmengen in starken Überexprimierern}

Neben der Expression von rekombinanten Proteinen, bei der es zu einer gleichmäßigen präsynaptischen Anreicherung in funktionsfähigen Synapsen kommt, können gelegentlich neuronale Fortsätze erkannt werden, in denen es augenscheinlich zu einer massiven Anreicherung der Proteine kommt. Diese Ansammlungen lassen sich besonders einfach mithilfe der Lipofektion erzeugen, sobald die Neurone etwas länger als üblich mit den Vektoren inkubiert werden. Um eine Einschätzung geben zu können inwieweit eine solche Überexpression von den oben beschriebenen Verhältnissen abweichen kann, wurde die mittlere Fluoreszenzintensität von Bassoon in Fortsätzen solcher Zellen stichpunktartig, also lediglich aus jeweils 10 Regionen zweier Präparationen, ermittelt. Die mittleren Intensitäten der Autofluoreszenzen der exprimierten Bassoon-Konstrukte waren dabei im Vergleich zu denen in Fortsätzen gleichmäßig transfizierter Zellen deutlich erhöht. Zusätzlich wurde auch in diesem Experiment ein Bassoon-Antikörper, welcher also neben dem rekombinanten auch das endogene Bassoon erkennt, verwendet. Dabei konnte erneut eine vielfache Erhöhung des Fluoreszenzsignals für Bassoon festgestellt werden (GFP-Bassoon: von 245,40 \pm 17,97 auf 2333,27 \pm 415,35; Bassoon-GFP: von 284,14 \pm 23,01 auf 2116,75 \pm 183,00).

Eine Signifikanz ist sowohl im Falle von GFP-Bassoon als auch Bassoon-GFP gegeben $(\mathrm{P}<0,001)$. Daher ist für diese Bereiche eine höhere Gesamtmenge an Bassoon anzunehmen.

Dieses Experiment zeigt, dass es in Abhängigkeit von der Transfektionsart zu einer massiven, bis zu 10-fachen Erhöhung der Bassoonmenge kommen kann (Abbildung 7). 


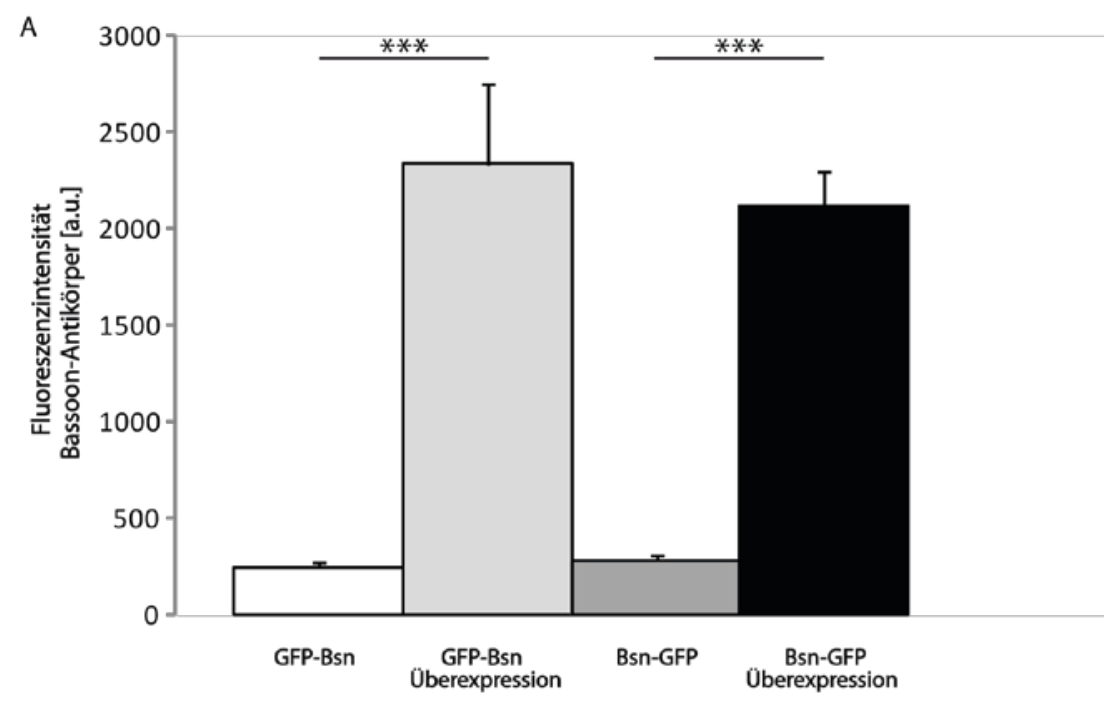

Abbildung 7: Gesamt-Bassoonmengen in starken Überexprimierern. Aus dem Säulendiagramm wird ersichtlich, dass die Gesamtmenge des Proteins Bassoon innerhalb der Kulturen signifikant unterschiedlich ausfallen kann. In den beiden Versuchsansätzen wurden punktförmige Bereiche überprüft, die neben dem endogenen Protein auch die jeweilige rekombinante Form aufwiesen. Der Vergleich erfolgte hierbei zwischen Regionen mit gleichmäßig synaptisch verteiltem Protein und Bereichen massiver Proteinansammlungen, hier als „Überexpression“ bezeichnet. Im Falle beider Proteinkonstrukte kam es zu hochgradigen Anreicherungen ( $\mathrm{P}<0,001)$. Abkürzungen: GFP-Bsn: GFP-Bassoon; Bsn-GFP: Bassoon-GFP.

\subsection{Rekrutierung von Mover}

In vorausgegangenen Untersuchungen konnten einerseits im Hefe-Zwei-Hybrid-System eine Bindung von Mover an einen C-terminalen Abschnitt von Bassoon, andererseits eine Co-Aggregation von Mover- und Bassoon-Konstrukten in HEK293-Zellen gezeigt werden (Kremer et al. 2007).

Um zu überprüfen, ob es unter der Überexpression von Bassoon-Konstrukten zu einer Moverrekrutierung kommt, wurden hippocampale Neurone mittels Calcium-PhosphatPräzipitation am DIV 3 mit verschiedenen Vektoren transfiziert und am DIV 6 sowie in anderen Ansätzen am DIV 10 fixiert. Die transfizierten Deckgläser wurden mit Antikörpern für Mover, im Falle junger Neurone zusätzlich mit einem TGN38-Antikörper, im Falle adulter mit einem Synaptophysin-Antikörper gefärbt. Neben den Bassoon-Konstrukten wurde als Negativkontrolle m-GFP und GFP-VAMP gewählt, wobei m-GFP aufgrund seiner nicht-punktförmigen Verteilung nur in jungen Zellen als Vergleich genutzt wurde. 


\subsubsection{Anreicherung endogenen Movers in den Somata junger trans- fizierter Neurone}

Die Verteilung des Proteins Mover im Vergleich zu den entsprechenden rekombinanten Proteinen am Golgi-Apparat ist in Abbildung 8 dargestellt. Um eine mögliche Rekrutierung endogenen Movers nachzuweisen, wurde die in 2.10 beschriebene helligkeitsbasierte Analyse durchgeführt. Dazu wurde in transfizierten Zellen die Moverintensität bestimmt. Als Maske wurde hierbei die gesamte Fläche, die von den äußeren Begrenzungen der TGN38 positiven Bereichen eingeschlossen wurde, verwendet. Bewusst wurden nicht nur die sich scharf abzeichnenden Lamellen des Golgi-Apparats gewählt, da der Moverantikörper auch zwischen und neben diesen färbt. Es erfolgte die quantitative Analyse von jeweils 30 transfizierten Neuronen aus 3 Präparationen. Zwischen den betrachteten Intensitäten der Proteine bestanden keine signifikanten Unterschiede. m-GFP-transfizierte Zellen zeigten eine durchschnittliche Moverfluoreszenzintensität von 25,07 \pm 23. Für GFPVAMP, GFP-Bassoon und Bassoon-GFP lagen die Werte bei 23,76 \pm 0,91, 21,23 \pm 1,49 und 19,35 \pm 0,84. Die berechneten Fluoreszenzintensitäten unterscheiden sich nicht signifikant voneinander. In den Somata junger transfizierter Neurone ließ sich also keine Rekrutierung von Mover nachweisen. 

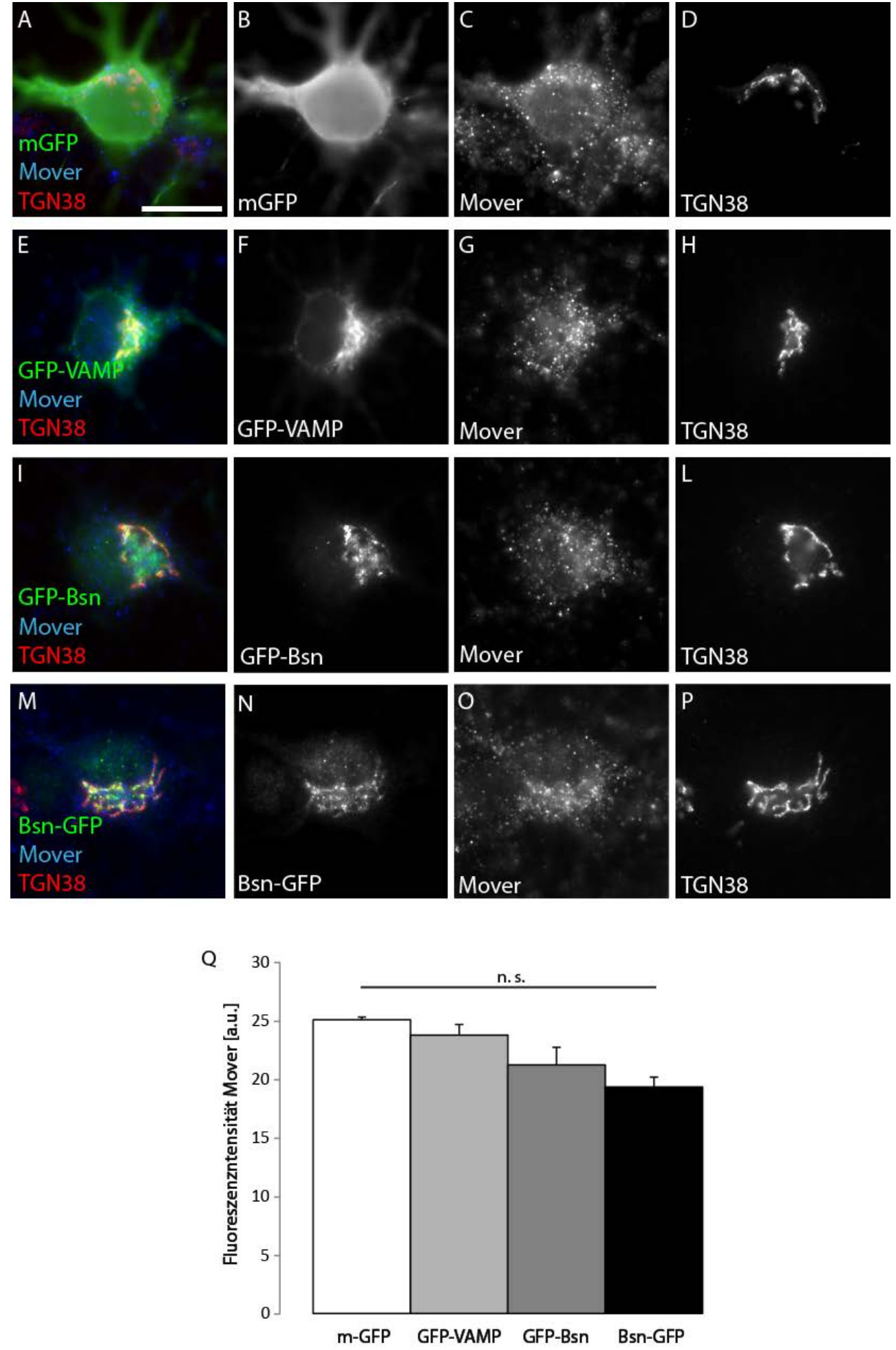

Abbildung 8: Endogenes Mover in den Somata junger transfizierter Neurone. In jungen transfizierten Neuronen finden sich in der Nähe des entsprechenden Soma nachweisbare Mengen des jeweiligen rekombinanten Proteins. (A), (E), (I) und (M) zeigen die Proteine im Verhältnis zu TGN38 und Mover in Form von Abbildungen, welche alle drei Kanäle überlappt enthalten. Die folgenden Spalten zeigen die einzelnen Kanäle, also die rekombinanten Proteine (m-GFP in (B), GFP-VAMP in (F), GFP-Bassoon in (I), Bassoon-GFP in (M)), Mover ((C), (G), (K), (O)) und TGN38 ((D), (H), (L), (P)) getrennt voneinander. Abkürzungen: GFP-Bsn: GFP-Bassoon, Bsn-GFP: Bassoon-GFP. Die MoverFluoreszenzintensitäten, welche stellvertretend für die Movermengen erhoben wurden, wichen nicht signifikant voneinander ab (Q). Maßstab: $10 \mu \mathrm{m}$. 


\subsubsection{Anreicherung endogenen Movers in adulten transfizierten Neuronen}

Nach der Transfektion mittels Calcium-Phosphat-Präzipitation am DIV 3 und der Fixation am DIV 10 wurde zunächst die Verteilung von endogenem Mover in den transfizierten Zellen begutachtet. Wie auch in untransfizerten Zellen kommt es zu einer punktförmigen Anreicherung entlang neuronaler Fortsätze. Es fällt auf, dass die Moverfärbung sehr feine Signale ergibt. In den Axonen transfizierter Zellen kommt es zu einer teilweisen Colokalisation von Mover mit den getesteten rekombinanten Proteinen (Abbildung 9)

Die Analyse der Intensitäten in adulten Neuronen erfolgte entsprechend der in 2.10 beschriebenen Methode, also unter Zuhilfenahme von OpenView und Microsoft Excel. Die in Abbildung 9 dargestellten Ergebnisse ergaben sich aus der Analyse von jeweils 30 aus 3 Präparationen stammenden Regionen. Die Fluoreszenzintensitäten von Mover in transfizierten und untransfizierten Zellen wichen nicht signifikant voneinander ab. Die mittlere Fluoreszenzintensität von Mover in untransfizierten Kulturen lag bei 616,38 $\pm 62,56$. In aufsteigender Reihe folgen die Werte, die für die transfizierten Kulturen erhoben wurden: 409,82 \pm 16,91 (GFP-VAMP), 577,46 \pm 76,07 (Bassoon-GFP) und 622,16 \pm 15,56 (GFPBassoon).

Damit ließ sich auch in den Fortsätzen adulter transfizierter Neurone keine Rekrutierung des Proteins Mover nachweisen. 

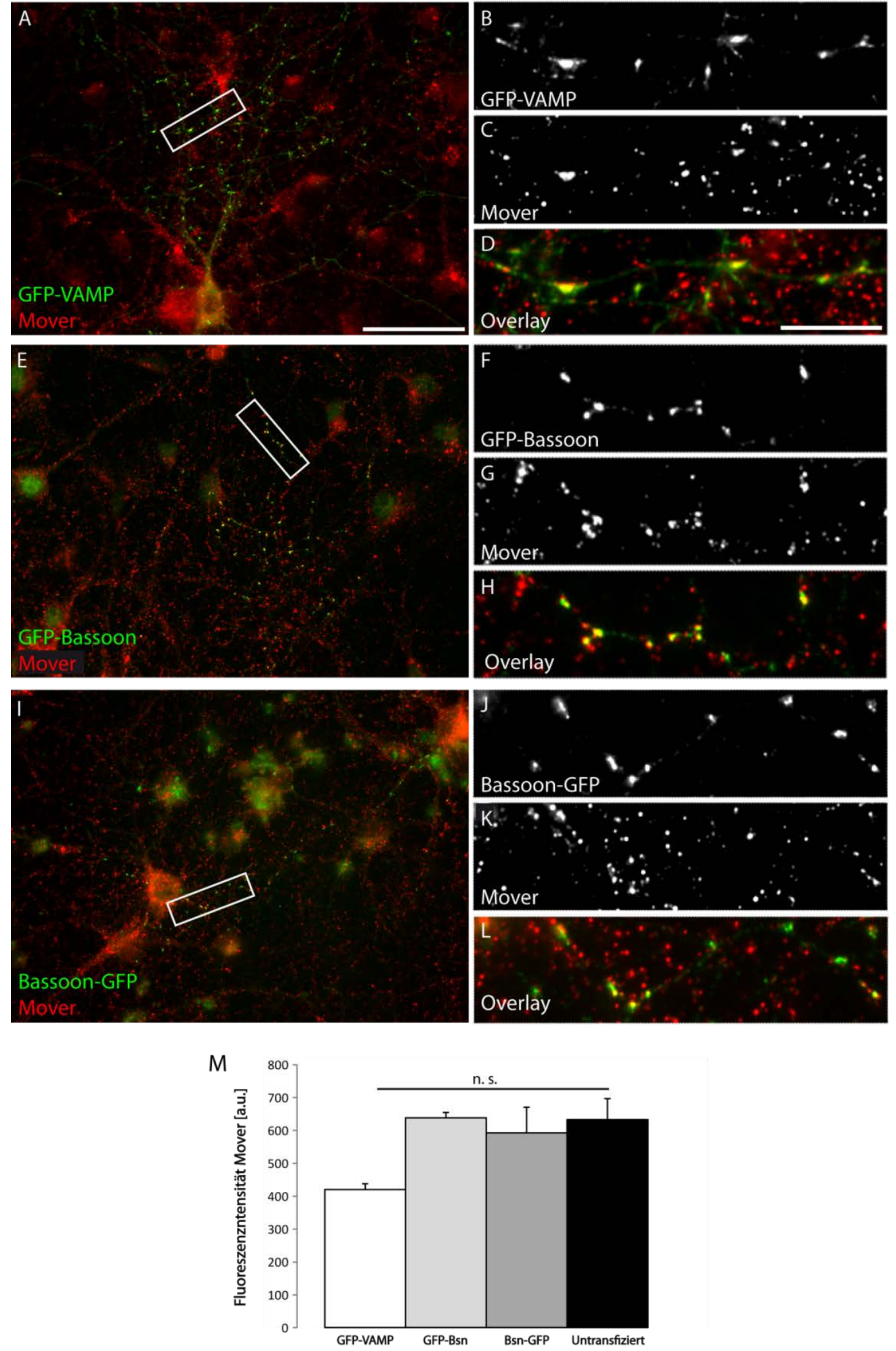

Abbildung 9: Anreicherung endogenen Movers in adulten transfizierten Neuronen. (A), (E) und (I) geben bei 40-facher Vergrößerung einen Überblick über die Verteilung der rekombinanten Proteine (GFP-VAMP, GFP-Bassoon und Bassoon-GFP) im Vergleich zu endogenem Mover in den Fortsätzen adulter transfizierter Zellen. (B)-(D), (F)-(H) und $(\mathrm{J})-(\mathrm{L})$ zeigen jeweils das entsprechende rekombinante Protein, endogenes Mover sowie deren Überlagerungen. Das Säulendiagramm (M) gibt die Fluoreszenzintensitäten des Mover-Antikörpers in den transfizierten Neuronen wieder. Es waren keine signifikanten Unterschiede zwischen den Ansätzen erkennbar. Abkürzungen: GFP-Bsn: GFP-Bassoon; BsnGFP: Bassoon-GFP. Maßstäbe: (A) $50 \mu \mathrm{m}$, (D) $10 \mu \mathrm{m}$. 


\subsubsection{Mover unter massiver Expression zweier Bassoon-Kontrukte}

Die vorangegangenen Untersuchungen lieferten keine Hinweise auf eine Bassoonabhängige Rekrutierung von Mover. Sollte es dennoch zu einer Rekrutierung kommen, so müsste diese zumindest erkennbar sein, wenn eine deutlich höhere Bassoonmenge vorhanden ist. Gelegentlich finden sich in transfizierten Kulturen Fortsätze, welche außerordentlich hohe Mengen an rekombinantem Protein enthalten (s.o.). Dabei kommt es zur Ausbildung ungewöhnlich großer und intensiv fluoreszierender Strukturen, bei denen es sich um Aggregate der entsprechenden rekombinanten Proteine handeln könnte. Daher wurden in diesem Teilexperiment gezielt solche Areale ausgewählt und nach dem oben beschriebenen Verfahren analysiert. Der Vergleich der Fluoreszenzintensitäten des MoverAntikörpers zwischen den Expressionsarten des jeweiligen Proteins (in Abbildung 10 dargestellt) lieferte auch in diesen Zellen keine signifikant erhöhten Werte (Bassoon-GFP: 632,10 und Bassoon-GFP Überexpression: 577,46, P = 0,92; GFP-Bassoon: 597,48 und GFP-Bassoon Überexpression: 681,16, P = 0,991). Insgesamt liegen damit keine Hinweise vor, dass es unter der Überexpression von Bassoon in adulten Zellen zu einer Rekrutierung des Proteins Mover kommt.

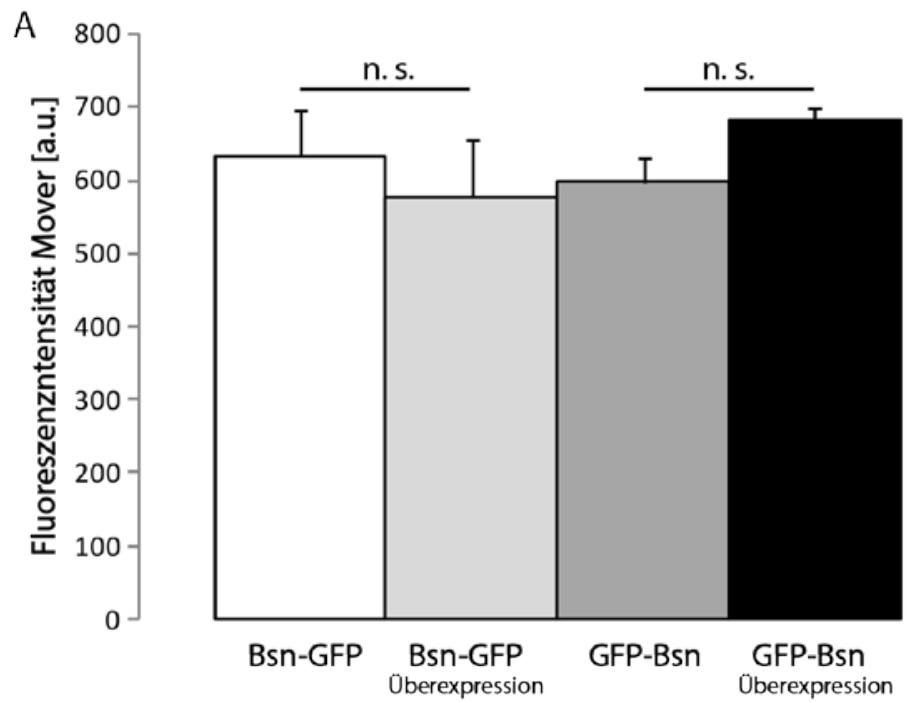

Abbildung 10: Mover-Anreicherung unter massiver Expression zweier Bassoon-Kontrukte. Zur Klärung der Fragestellung, ob es im Falle erhöhter Bassoonmengen auch zu einer verstärkten Mo-veranreicherung kommt, wurde die jeweilige Fluoreszenzintensität des Moverantikörpers unter verschiedenen Ansätzen bestimmt. Dazu wurden jeweils Bereiche mit einer gleichmäßigen und durchschnittlichen Anreicherung der rekombinanten Bassoonformen mit solchen verglichen, in denen es zu einer massiven Expression von Bassoon-GFP bzw. GFP-Bassoon gekommen ist. Im Falle keines der beiden rekombinanten Proteine konnte eine Moverrekrutierung unter der verstärkten Bassoonanreicherung nachgewiesen werden. Abkürzungen: Bsn-GFP: Bassoon-GFP; GFP-Bsn: GFP-Bassoon. 


\subsection{Charakterisierung von GFP-Rogdi}

Im Anschluss an den Nachweis des 287 Aminosäuren messenden Proteins Rogdi in einer synaptischen Vesikelfraktion (Boyken et al. 2013) und der Herstellung des N-terminal markierten GFP-Rogdi, welches für das verwendete Rogdi-Konstrukt codiert, sollen nun dessen Eigenschaften charakterisiert werden. Das Protein Rogdi wurde bisher ausschließlich in Zusammenhang mit dem Kohlschütter-Tönz-Syndrom, einer Erkrankung, bei welcher die Mutation des Rogdi-Gens Amelogenesis imperfecta, Epilepsie sowie psychomotorische Einschränkungen verursacht, untersucht (Schossig et al. 2012). Die im Folgenden beschriebenen Untersuchungen in hippocampalen Neuronen stellen daher die ersten ihrer Art dar. Da nach der erstmaligen Transfektion der Neurone mit GFP-Rogdi sehr schwache, mit dem Auge und der Kamera kaum wahrzunehmende, grüne Signale erkennbar waren, wurden die Folgenden Untersuchungen durch die Zuhilfenahme von GFP- und RogdiAntikörpern erleichtert.

\subsubsection{GFP-Rogdi in jungen Neuronen}

Die Verteilung von GFP-Rogdi in jungen Neuronen (Calcium-Phosphat-Präzipitation am DIV 3, PFA-Fixation am DIV 6) ist in Abbildung 11 veranschaulicht. Neben der schwach ausfallenden Akkumulation im Bereich des Golgi-Apparates (dargestellt durch TGN38) fiel die diffuse Verteilung innerhalb des Soma, jedoch nicht im Nucleus auf. Diese diffuse Verteilung konnte auch in HEK293T-Zellen nachgewiesen werden. Neben der Anreicherung im Soma fielen teilweise bereits in Fortsätzen auftretende Rogdi-Signale auf, deren Form und Distribution an präsynaptisch verteilte Proteine erinnerten.
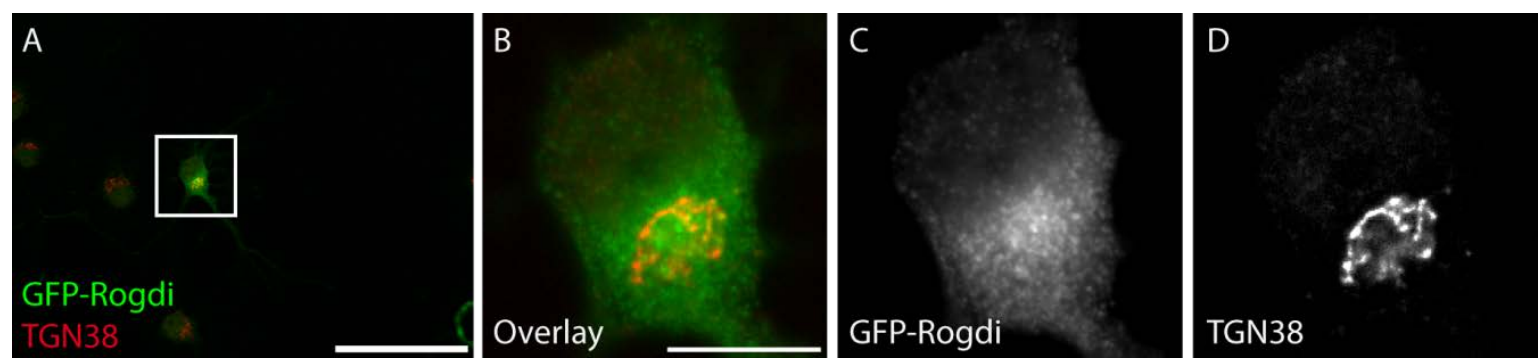

Abbildung 11: Rekombinantes Rogdi in jungen Neuronen. In (A) fällt das mit GFP-Rogdi transfizierte Neuron in 40facher Vergrößerung bereits auf. Neben dem rekombinanten Protein ist der Golgi-Apparat aufgrund der Färbung mit einem TGN38-Antikörper ersichtlich. In (B)-(D) ist das Zellsoma bei 63-facher Vergrößerung zunächst bei überlagerten, dann in aufgetrennten Kanälen dargestellt. Innerhalb des Soma zeigte GFP-Rogdi eine diffuse Verteilung mit Aussparung des Nucleus. Auch in den sich entwickelnden Fortsätzen befanden sich bereits GFP-Rogdi -positive Bereiche. Maßstäbe: (A) $50 \mu \mathrm{m}$, (B) $10 \mu \mathrm{m}$. 


\subsubsection{Untersuchung der Lokalisation des rekombinanten Rogdi}

Um eine bestmögliche Charakterisierung des rekombinanten Proteins hinsichtlich seiner subzellulären Verteilung zu ermöglichen, werden zunächst stellvertretend je ein bereits bekanntes diffus verteiltes, ein präsynaptisch und ein postsynaptisch angereichertes Protein dargestellt und beschrieben. Dazu wurde zur Unterscheidung der neuronalen Fortsätze mit dem Dendritenmarker MAP2 gefärbt. Alle folgenden Abbildungen entstammen Kulturen, welche am DIV 3 mittels Calcium-Phosphat-Präzipitation transfiziert und am DIV 10 fixiert wurden.

Abbildung 12 zeigt m-GFP, welches ein typischer Vertreter der diffus verteilten Proteine ist. Gut erkennbar war das Vorkommen im Zellsoma (hierbei sogar innerhalb des Nucleus) und darüber hinaus sowohl im Axon als auch den Dendriten. Dabei war die Anreicherung in allen Abschnitten des Neurons in etwa gleich stark.
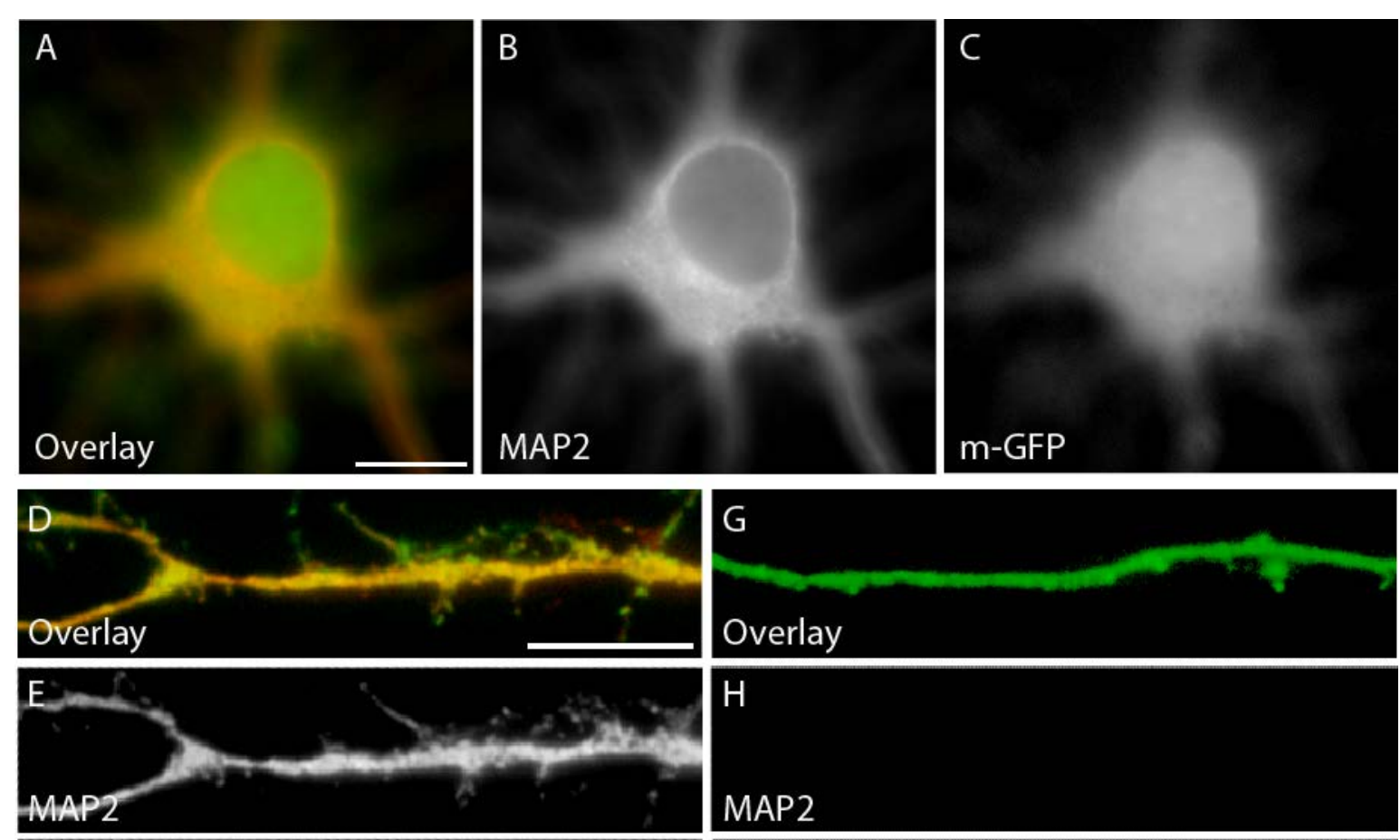

$\mathrm{H}$

\section{MAP2}
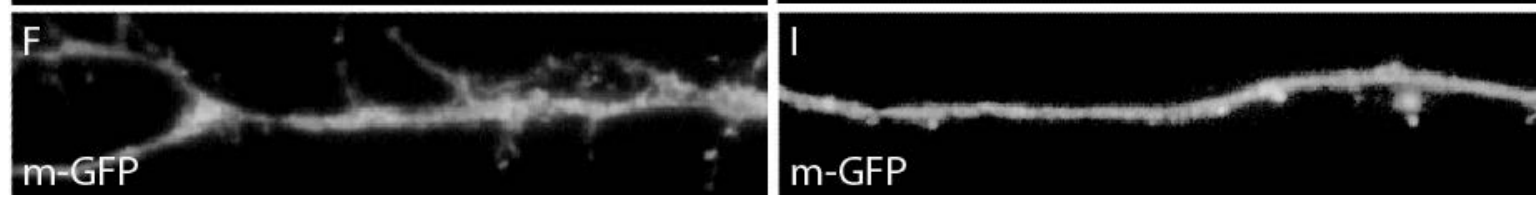

Abbildung 12: Subzelluläre Verteilung des monomeren GFP (m-GFP). (A)-(C): Soma, (D)-(F): Dendrit, (G)-(I): Axon. Die Verteilung von m-GFP erfolgte innerhalb aller Abschnitte des Neurons. Es war innerhalb des Nucleus, des Soma, des Axons und auch innerhalb der Dendriten nachweisbar. Die Verteilung innerhalb der subzellulären Kompartimente ist in 63-facher Vergrößerung dargestellt. Maßstab: $10 \mu \mathrm{m}$. 
Ein typisch präsynaptisch angereichertes rekombinantes Protein, nämlich GFP-VAMP, ist in Abbildung 13 dargestellt. Es wies eine Akkumulation im Bereich des Soma sowie punktförmige Anreicherungen im Axon auf, jedoch keine innerhalb von MAP2-positiven Fortsätzen, also Dendriten. VAMP, das vesikelassoziierte Membranprotein, ist ein bekannter Vertreter präsynaptischer Proteine und kann daher als Synapsenmarker verwendet werden.
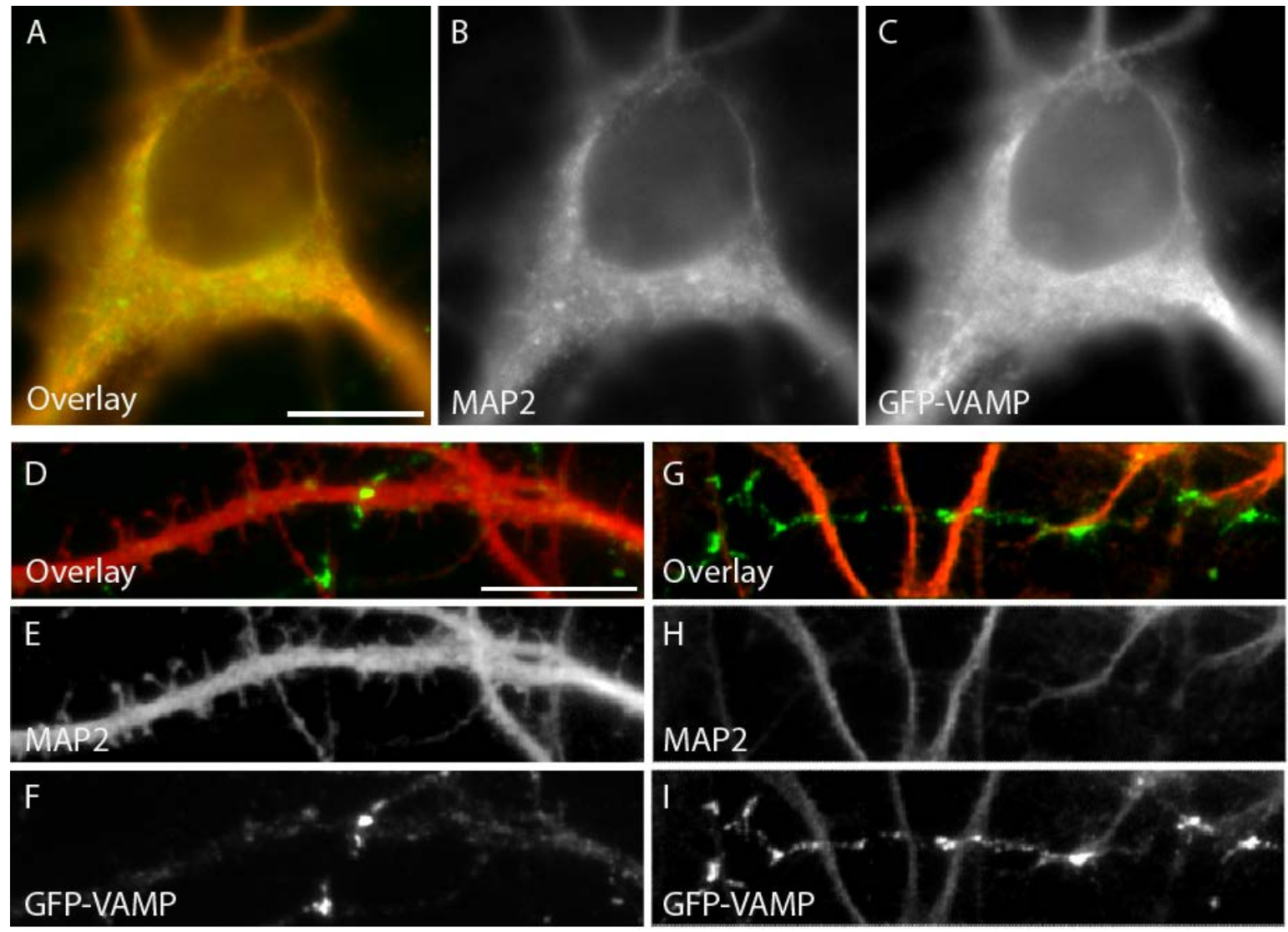

Abbildung 13: Subzelluläre Verteilung des rekombinanten GFP-VAMP. Als Vertreter präsynaptisch angereicherter Proteine ist GFP-VAMP bei 63-facher Vergrößerung dargestellt. Neben der somatischen Akkumulation, (A)-(C), kam es auch punktförmig angereichert im Axon vor ((G)-(I)), jedoch nur an und nicht in MAP2-positiven Fortsätzen, was in (D)(F) erkennbar ist. Maßstab: $10 \mu \mathrm{m}$. 
Ein exklusiv in der postsynaptischen Dichte vorkommendes Protein ist PSD-95, welches zur Gruppe der membranassoziierten Guanylat-Kinasen gehört. Das rekombinante PSD95GFP zeigte aufgrund seiner postsynaptischen Anreicherung ein gänzlich anderes Muster als die zuvor vorgestellten Proteine. Es fielen die zahlreichen an MAP2-positiven Fortsätzen vorkommenden PSD95-GFP-Signale auf (Abbildung 14).
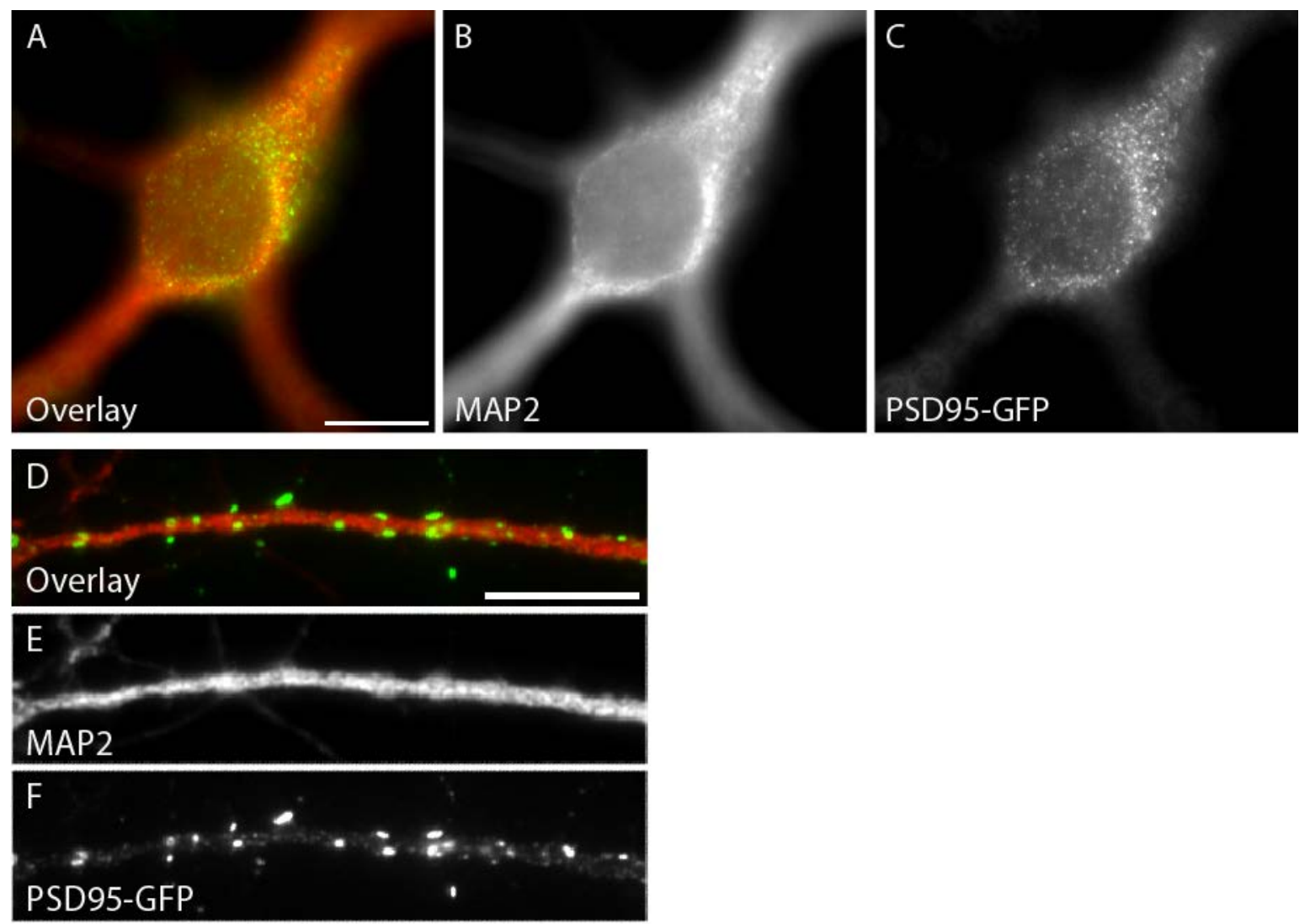

Abbildung 14: Subzelluläre Verteilung des rekombinanten PSD95-GFP. Als postsynaptischer Bestandteil reichert sich PSD95-GFP punktförmig in Dendriten, gekennzeichnet durch deren Gehalt an MAP2, an. Die subzellulären Verteilungen von PSD95-GFP im Soma und in einem Dendriten werden in (A)-(C) und (E)-(G) ersichtlich. Maßstab: $10 \mu \mathrm{m}$. 
Mit diesem Hilfsmittel kann eine vergleichende Betrachtung sowohl von dem endogenen Rogdi als auch dem rekombinanten GFP-Rogdi erfolgen.

Am DIV 10 konnte Rogdi in untransfizierten Kulturen mithilfe eines Rogdi-Antikörpers nachgewiesen werden. Neben der eher diffusen Verteilung innerhalb des Soma fiel die Antikörperfärbung in den verschiedenen Fortsätzen auf. Neben winzigen Punkten in den Dendriten sind punktförmige Anreicherungen in den Axonen der Neurone erkennbar, welche an synaptische Proteine erinnern (Abbildung 15).

Entsprechend verhält sich das rekombinante GFP-Rogdi (Abbildung 16).
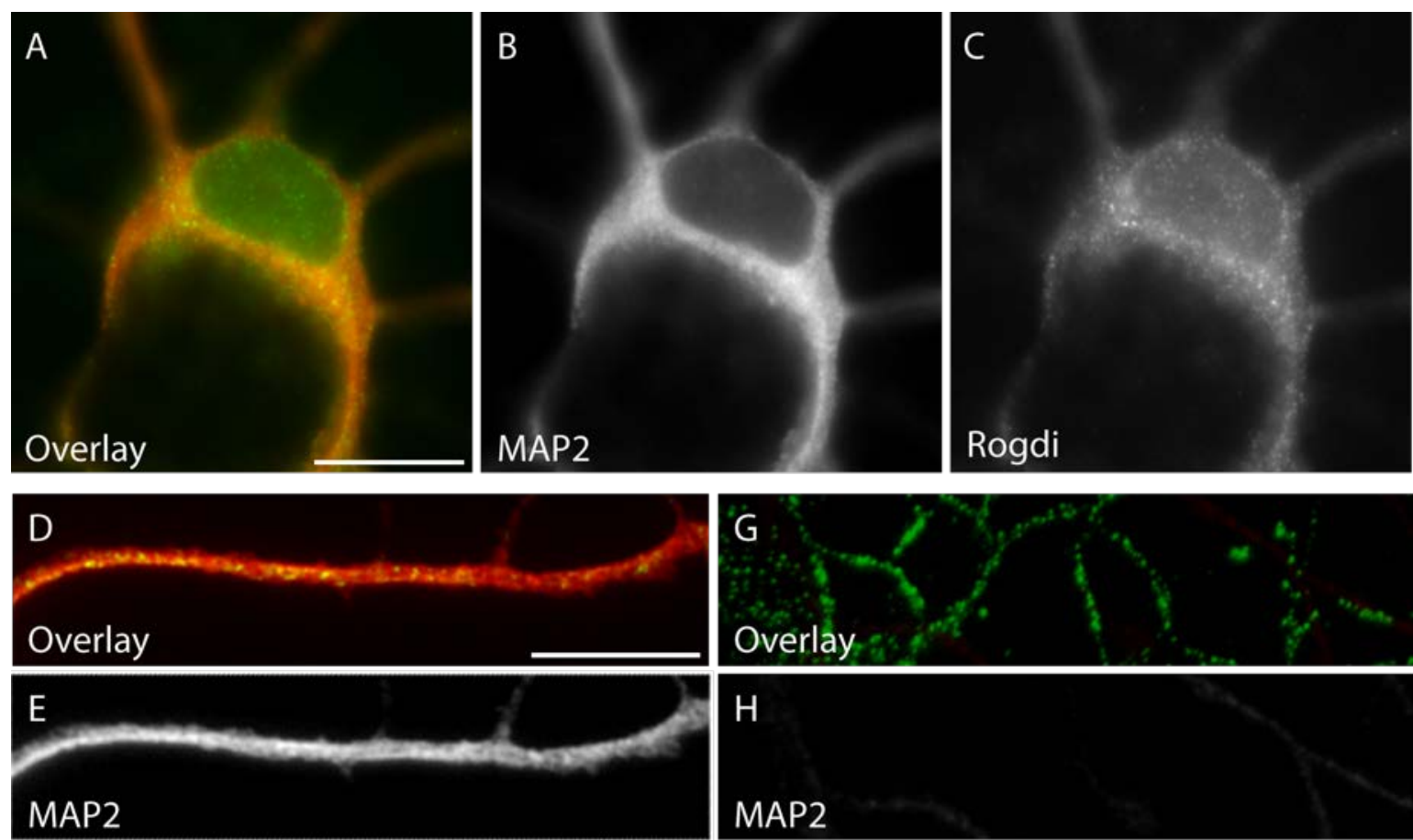

$\mathrm{H}$

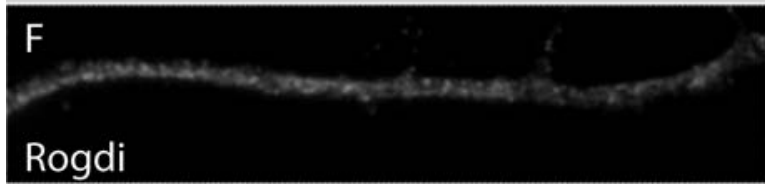

MAP2

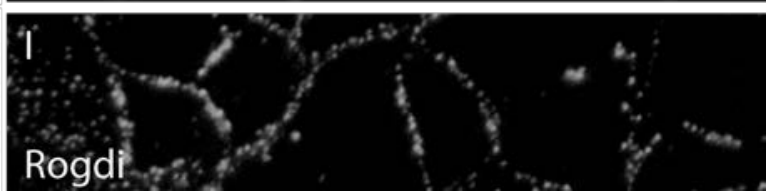

Abbildung 15: Subzelluläre Verteilung des endogenen Rogdi. Endogenes Rogdi ist am DIV 10 mittels Rogdi-Antikörper in Neuronen untransfizierter Kulturen nachweisbar. Bei 63-facher Vergrößerung zeigte sich das Protein im Soma diffus verteilt ((B)-(D)) und im Axon punktförmig angereichert ((H)-(J)). Auch in Dendriten fiel die Färbung positiv aus, wenn auch deutlich geringer. Maßstab: $10 \mu \mathrm{m}$. 

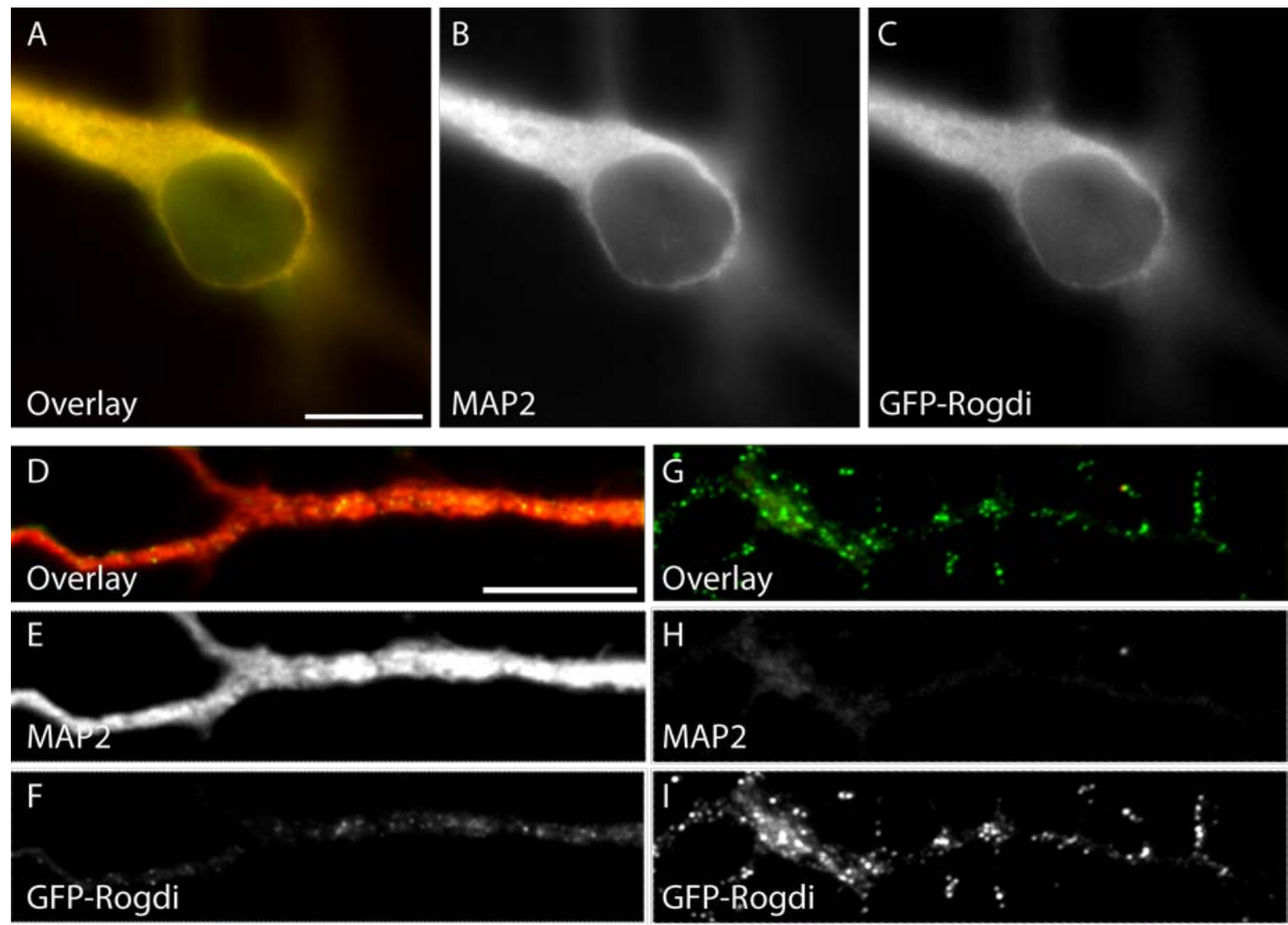

Abbildung 16: Subzelluläre Verteilung des rekombinanten GFP-Rogdi. Das rekombinante GFP-Rogdi war in adulten Zellen sowohl im Soma als auch in Fortsätzen erkennbar. Während es im Soma diffus verteilt war ((B)-(D)), lag es im Axon punktförmig angereichert vor ((H)-(J)). Maßstab: $10 \mu \mathrm{m}$.

\subsubsection{Biochemischer Nachweis von Rogdi}

Der oben beschriebene Nachweis von endogenem als auch rekombinantem Rogdi erfolgte ausschließlich mittels Immunfluoreszenz. Ein erster Indikator für die spezifische Bindung der GFP- und Rogdi-Antikörper an Rogdi lieferten diese selbst, da sie identischen Färbungen von GFP-Rogdi in transfizierten hippocampalen Neuronen und HEK293T-Zellen erzeugten (Daten nicht gezeigt). Dennoch war der biochemische Nachweis des Vorhandenseins von Rogdi in den Kulturen und auch der Spezifität des verwendeten RogdiAntikörpers von großer Bedeutung. Dazu wurden einerseits untransfizierte hippocampale Neurone, andererseits untransfizierte cortikale Neurone (exklusiv der hippocampalen Zellen) kultiviert und am DIV 10 weiterverarbeitet. Nach der Auftrennung der Proteine mittels Gelelektrophorese und Übertragung auf eine PVDF-Membran (Western Blot), konnte Rogdi mithilfe eines Antikörpers sowohl in den hippocampalen Zellen als auch den kortikalen Neuronen nachgewiesen werden. Die entsprechenden Banden konnten in allen Proben bei einer Höhe von ca. $30 \mathrm{kDa}$ gezeigt werden (Abbildung 17). Dieser biochemische Nachweis von Rogdi in hippocampelen Primärkulturen unterstütz eine Metaanalyse von genomweiten Expressionsstudien (Kapushesky et al. 2012). 


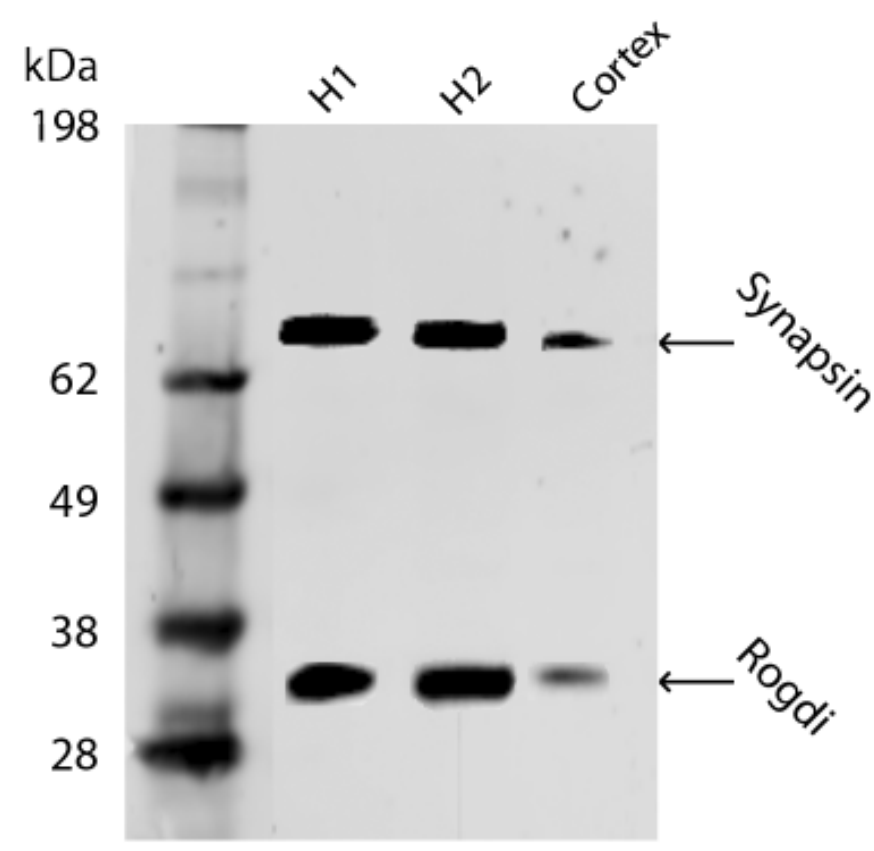

Abbildung 17: Biochemischer Nachweis von Rogdi. Im Western Blot fiel die Färbung mit dem polyklonalen RogdiAntikörper positiv aus und ergab Banden im Bereich von $30 \mathrm{kDa}$. Von link nach rechts wurden neben den dazwischen liegenden Leerwerten der Marker (SeeBlue Pre-stained Protein Standard), zwei Proben aus hippocampalen Neuronen, die mittels unterschiedlicher Puffer gewonnen wurden (H1: Homogenisationspuffer; H2: SDS-Puffer) und eine weitere aus cortikalen Neuronen extrahierte (Cortex) aufgetragen. Als Positivkontrolle wurde zusätzlich mit einem monoklonalen Synapsin-Antikörper gefärbt, welcher in allen Fällen zu nachweisbaren Banden im Bereich von 80 kDa führte.

\subsubsection{Synaptisches Targeting in adulten Neuronen}

Aufgrund der oben beschriebenen subzellulären Verteilung von GFP-Rogdi, die eine Ähnlichkeit zu derer von GFP-VAMP aufwies, wurden anschließend quantitative Analysen durchgeführt.

Es galt die Fragestellung zu klären, ob und in welchem Ausmaß GFP-Rogdi mit endogenen Synapsenmarkern colokalisiert. Zu diesem Zweck wurden wie in den anderen Teilversuchen jeweils 30 Regionen aus drei Präparationen miteinander verglichen. Es wurde die Lokalisation von GFP-Rogdi einerseits im Vergleich zu Synapsin, Synaptophysin und VAMP-2 als synaptische Vesikelproteine, andererseits zu Bassoon als Protein der Zytomatrix der aktiven Zone ausgewertet. Darüber hinaus wurde auch überprüft, ob eine Colokalisation mit Mover nachweisbar ist. Eine Colokalisation wurde als positiv bewertet, sobald GFP-Rogdi an einem Punkt lag, welcher zusätzlich ein Signal des jeweiligen Vergleichsproteins zeigte, welches wiederum die 1,33-fache Fluoreszezintensität des Hintergrundes aufwies (vergleiche „Material und Methoden“).

Mit den synaptischen Markerproteinen lag eine Colokalisationsrate von 91,24 \pm 1,54 \% (Synapsin), 74,08 \pm 2,04 \% (Synaptophysin) und 92,53 \pm 1,35 \% (VAMP2), mit Bassoon eine von 66,26 4,30 \%, mit Mover 44,13 \pm 4,04 \% vor (Abbildungen 18 und 19). Es fiel auf, dass die Analyse einen signifikant geringeren Wert für Synaptophysin als für Synapsin 
und VAMP2 ergibt $(\mathrm{P}<0,001)$. Die gesondert betrachteten Prozentsätze für Bassoon und Mover unterschieden sich signifikant voneinander und auch von denen der anderen synaptischen Proteine $(\mathrm{P} \leq 0,001)$. Es wurde, wie auch für alle weiteren Colokalisationsanalysen ein Chi-Quadrat-Test durchgeführt, wobei den beiden Zuständen „positive Colokalisation“ und „negative Colokalisation“ die Werte 1 und 0 zugeordnet wurden.

Die Untersuchung zum Targeting des rekombinanten Rogdi zeigte eine klare synaptische Anreicherung des Proteins. Interessant sind die teilweise enormen Colokalisationsraten von GFP-Rogdi mit den getesteten Markerproteinen. 

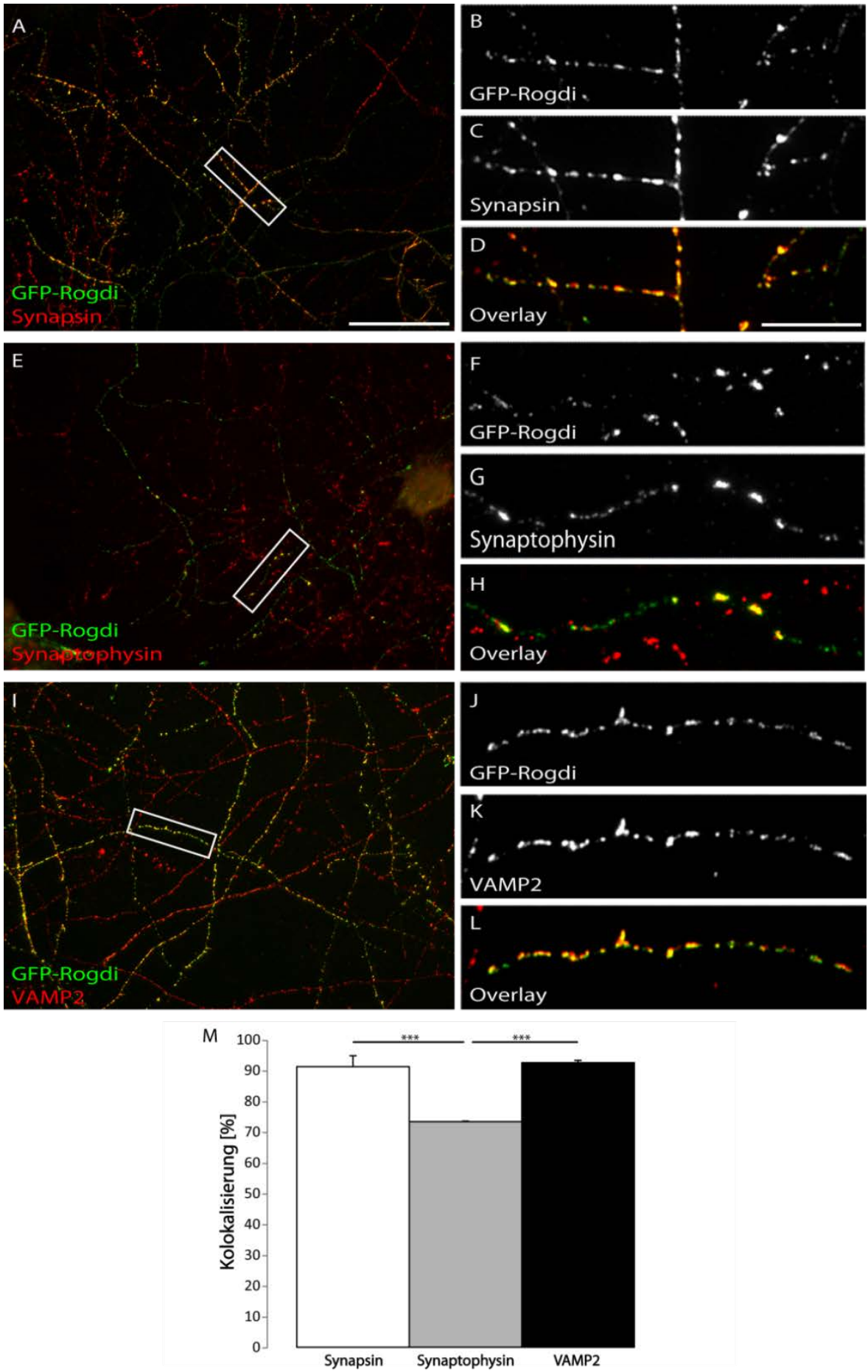

Abbildung 18: Colokalisation von GFP-Rogdi mit Synapsenmarkern. (A), (E) und (I) stellen GFP-Rogdi in Fortsätzen adulter Neurone (DIV 10) im Vergleich zu dem jeweiligen Synapsenmarker bei einer Vergrößerung von 40x dar. Die Teilabbildungen zeigen GFP-Rogdi in Grün, das Vergleichsprotein in Rot. Bereits bei 40-facher Magnifikation fallen Bereiche auf, welche einen hohen Colokalisationsgrad aufzuweisen scheinen. Die Felder (B)-(D), (F)- $(\mathrm{H})$ und $(\mathrm{J})-(\mathrm{L})$ zeigen die Ausschnitte aus den 40x-Übersichtsbildern bei 63-facher Vergrößerung und veranschaulichen die Colokalisation der rekombinanten Proteine mit dem endogenen Synapsenmarkern. Die Kanäle werden voneinander getrennt und jeweils darunter überlagert gezeigt (Overlay). Das rekombinante Protein colokalisierte sowohl mit Synapsin, als auch mit Synaptophysin und VAMP2, welches durch die Gelbfärbung vieler Punkte erkennbar ist. Maßstäbe: $10 \mu \mathrm{m}$. (M) zeigt das das Resultat der Colokalisationsanalyse in Form eines Säulendiagramms. Mit den drei Vergleichsproteinen bestand ein hoher Colokalisationsgrad von ca. 74 \% (Synaptophysin), 91 \% (Synapsin) und 93 \% (VAMP2), wobei dieser für Synapsin und VAMP2 signifikant höher als für Synaptophysin ausfiel. Maßstab: A) $50 \mu \mathrm{m}$, D) $10 \mu \mathrm{m}$. 

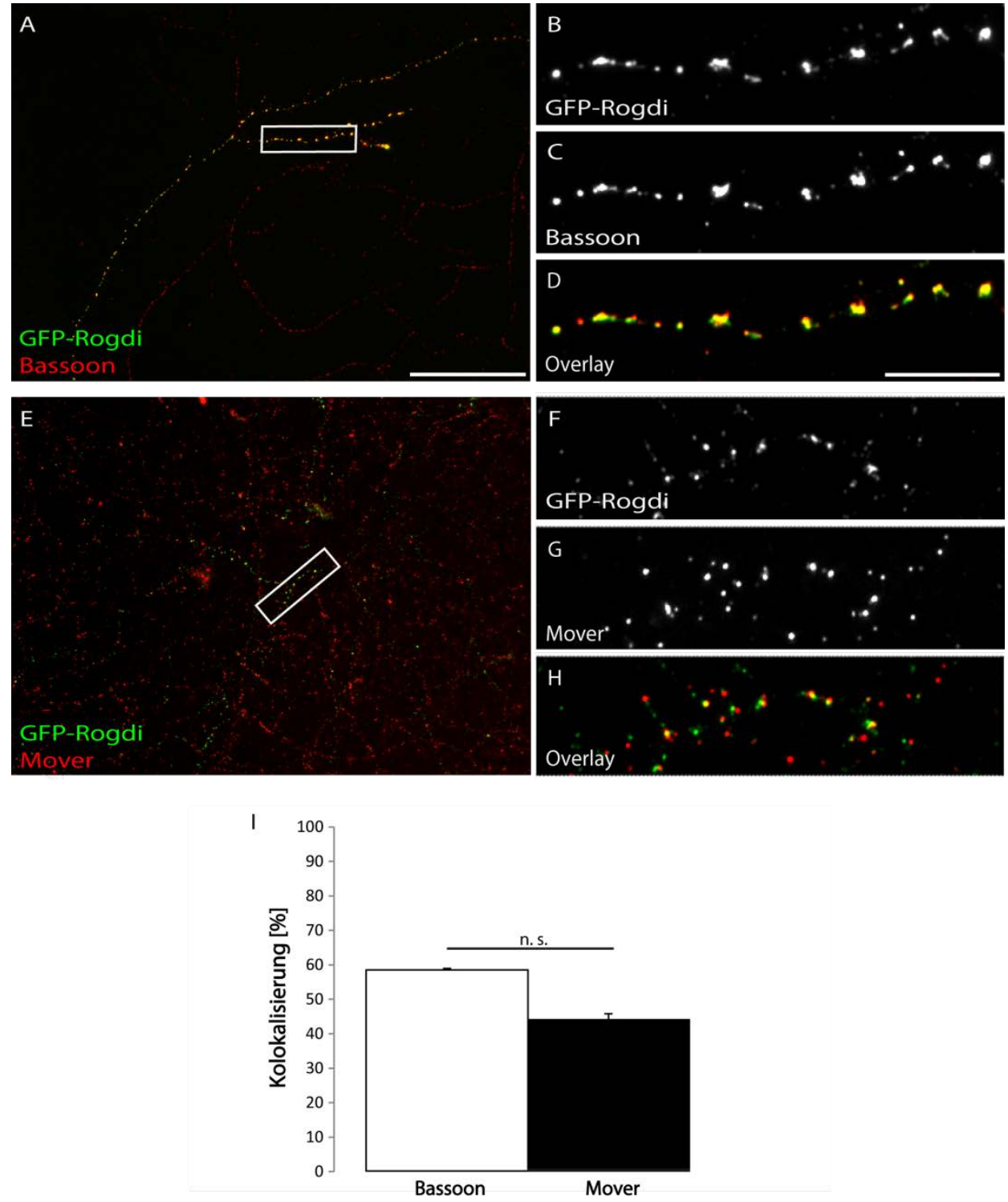

Abbildung 19: Colokalisation von GFP-Rogdi mit Synapsenmarkern II. (A) und (E) zeigen in Fortsätzen adulter Neurone die Verteilung von GFP-Rogdi im Vergleich zu endogenem Bassoon und Mover bei einer Vergrößerung von 40x. Während das rekombinante Protein in Grün dargestellt ist, sind die Vergleichsproteine in Rot gezeigt. (B)-(D) und (F)$(\mathrm{H})$ geben zunächst die jeweiligen Proteine bei einer 63-fachen Vergrößerung getrennt, dann überlagert (Overlay) wieder. Maßstäbe: $10 \mu \mathrm{m}$. In (I) ist der Colokalisationsgrad der Proteine in quantitativer Form abgebildet. Das Ausmaß der Überlagerung unterschied sich nicht signifikant. Maßstab: A) $50 \mu \mathrm{m}$, D) $10 \mu \mathrm{m}$. 


\subsubsection{Synaptotagmin-1-Uptake}

Die bisher beschriebenen Ergebnisse weisen darauf hin, dass es sich bei GFP-Rogdi um ein neues rekombinantes Protein handelt, welches eine (prä-)synaptische Anreicherung erfährt. Nach dem Transport durch das Soma und anschließend entlang von Fortsätzen kann es schließlich zusammen mit bekannten präsynaptischen Proteinen nachgewiesen werden. Um zu bestimmen, ob es sich bei diesen Bereichen tatsächlich um funktionsfähige Synapsen handelt, wurde an adulten hippocampalen Zellen (DIV 10) ein Wiederaufnahmeversuch mit Synaptotagmin-1 durchgeführt. Bei diesem Verfahren wird zunächst künstlich eine Vesikelentleerung herbeigeführt, indem ein sogenannter Depolarisationspuffer auf die noch vitalen Zellen gegeben wird. Der verdünnt im Puffer vorliegende Synaptotagmin-1Antikörper bindet daraufhin mit seiner luminalen Domäne an die Innenseite der mit der präsynaptischen Membran temporär verschmolzenen Vesikel. Im Rahmen des sich anschließenden Vesikelrecyclings werden daher auch Synaptotagmin-1-Antikörper in die präsynaptische Endigung aufgenommen. Diese können später nach Fixierung der Zellen mithilfe eines sekundären Antikörpers nachgewiesen werden. Die Fluoreszenzintensität dieses sekundären Antikörpers dient dann als Maß für die Verschmelzung und die Wiederaufnahme der Vesikel, also die Aktivität der Präsynapse. Nach diesem Prinzip wurde der Versuch am DIV 10 für Zellen durchgeführt, die mittels Calcium-Phosphat-Präzipitation am DIV 3 mit GFP-Rogdi und als Vergleich mit m-GFP transfiziert wurden. Für die Analyse wurden jeweils 30 Regionen aus drei Präparationen miteinander verglichen. Dazu wurden OpenView und Mi-crosoft Excel unter Beachtung der oben genannten Vorgehensweise genutzt. Die Auswertung zeigt keine signifikanten Unterschiede der Fluoreszenzintensitäten von Synaptotagmin-1 in den beiden Ansätzen. Die mittlere Fluoreszenzintensität von Synaptotagmin in m-GFP-transfizierten Zellen lag mit 153,62 \pm 8,84 etwas unter derer in GFP-Rogdi-transfizierten Zellen mit 183,76 \pm 23,37. Die ermittelten Werte wichen nicht signifikant voneinander ab $(\mathrm{P}=0,23)$.

Somit zeigten Neurone, die mit GFP-Rogdi transfiziert wurden, eine in etwa gleiche Aktivität wie die Kontrollzellen. Von den in die Analyse einbezogenen 3978 GFP-Rogdipositiven Punkten wiesen 57,63 \% eine positive Färbung für Synaptotagmin-1 auf. 

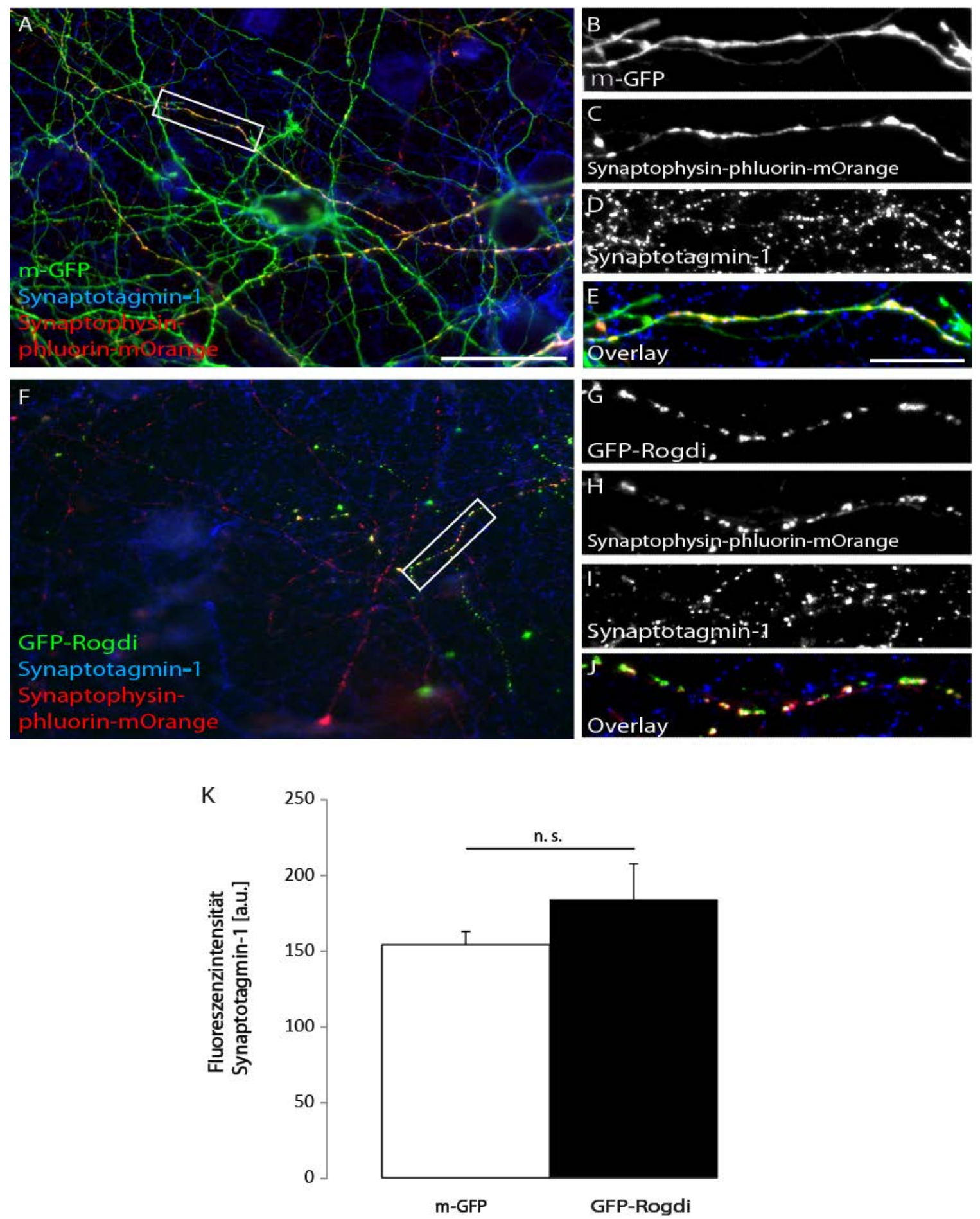

Abbildung 20: Synaptotagmin-1-Uptake in m-GFP- und GFP-Rogdi-transfizierten Neuronen. In (A) und (F) sind bei 40facher Vergrößerung neben m-GFP bzw. GFP-Rogdi (in Grün) die Antikörperfärbungen von Synaptotagmin-1 in Blau und Synaptophysin-phluorin-mOrange in Rot dargestellt. Rechts sind bei 63-facher Vergrößerung in (B) m-GFP und in (G) GFP-Rogdi, darunter jeweils Synaptophysin-phluorin-mOrange, Synaptotagmin-1 und die überlagerten Kanäle zu erkennen. Bei einer Überlagerung aller dreier Kanäle ergeben sich weiße Bereiche. Die Nachweisbarkeit von Synaptotagmin-1 in beiden Fällen spricht für die Funktionsfähigkeit der untersuchten Sy-napsen. Maßstäbe: (A): 50 m, (E): $10 \mu \mathrm{m}$. 


\subsection{GFP-RIBEYE}

\subsubsection{Expression von GFP-RIBEYE in jungen Kulturen}

Im Rahmen des gain-of-function-Experiments sollte zunächst überprüft werden, ob eine Expression des sonst in sensorischen Zellen vorkommenden Proteins auch in hippocampalen Neuronen möglich ist. Dazu wurde am DIV 3 die Calcium-Phosphat-Präzipitation genutzt, um die Kulturen zu transfizieren. Nach der Fixation am DIV 6 wurden die Kulturen mit dem Golgi-Marker TGN38 gefärbt und begutachtet. Es fielen eine große Anzahl an Aggregaten im Bereich des Soma sowie bereits einige punktförmige Areale in den sich entwickelnden Fortsätzen auf. Eine charakteristische transfizierte Zelle ist in Abbildung 21 dargestellt.
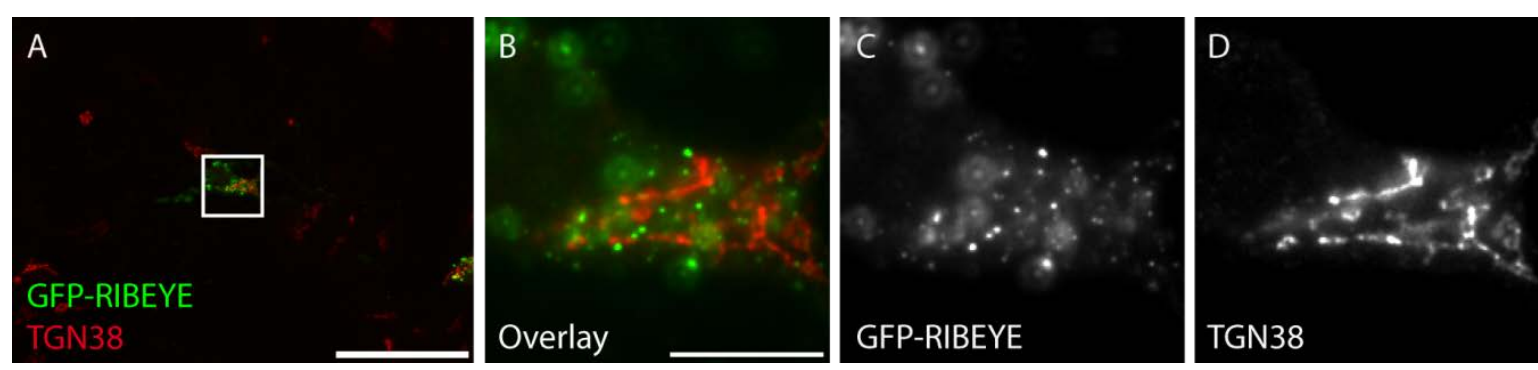

Abbildung 21: Rekombinantes RIBEYE in jungen Neuronen. (A) zeigt das mit GFP-RIBEYE transfizierte Neuron in 40-facher Vergrößerung. Neben dem rekombinanten Protein ist der Golgi-Apparat aufgrund der Färbung mit einem TGN38-Antikörper erkennbar. In (B)-(D) sind die Proteine im Zellsoma bei 63-facher Vergrößerung zunächst bei überlagerten (Overlay), dann in aufgetrennten Kanälen dargestellt. Es fielen zum Teil größere GFP-RIBEYE-Aggregate auf. Maßstäbe: $10 \mu \mathrm{m}$.

\subsubsection{Rekombinantes RIBEYE in adulten Neuronen - qualitative und quantitative Analyse}

Die am DIV 3 mittels Calcium-Phosphat-Präzipitation transfizierten Neurone wurden am DIV 10 fixiert, anschließend gefärbt und untersucht. Zunächst galt es die Frage zu klären, ob GFP-RIBEYE in der Lage ist, das Soma posttranslational zu verlassen. Tatsächlich war eine große Anzahl punktförmiger GFP-RIBEYE Signale in den Fortsätzen nachweisbar. Um deren Lokalisation genauer zu bestimmen, wurde wie in 3.3.2 und 3.3.4 verfahren. Dazu wurden Neurone transfiziert, am DIV 10 fixiert und mit dem Dendritenmarker MAP2 gefärbt. Abbildung 22 zeigt die subzelluläre Lokalisation der GFP-RIBEYEpositiven Punkte bei unterschiedlicher Vergrößerung in adulten Neuronen. 

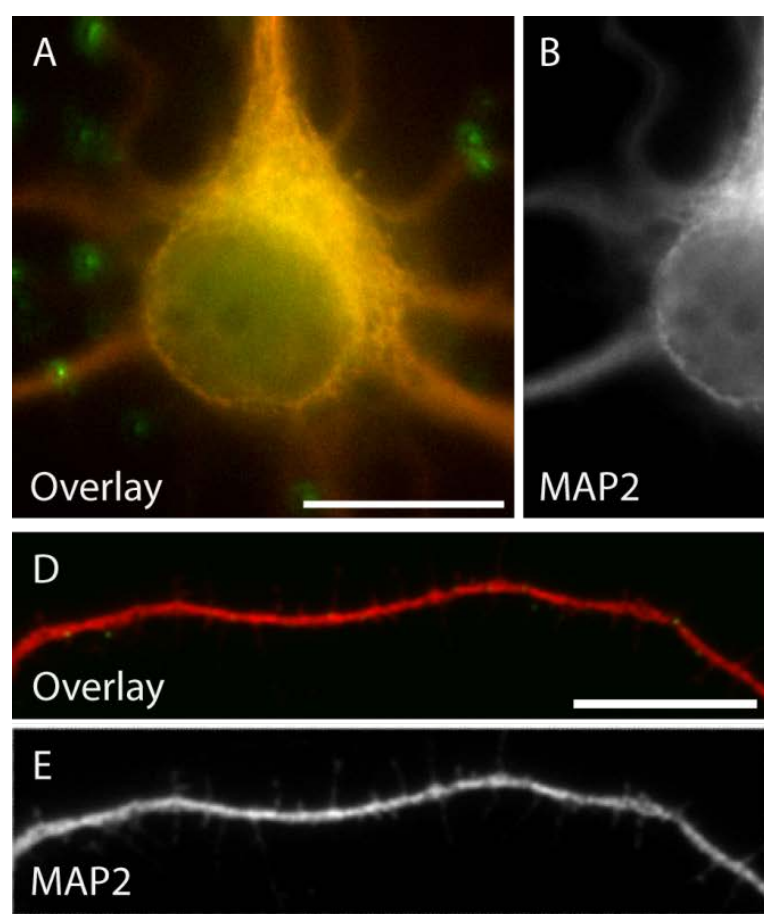

$\mathrm{F}$

GFP-RIBEYE
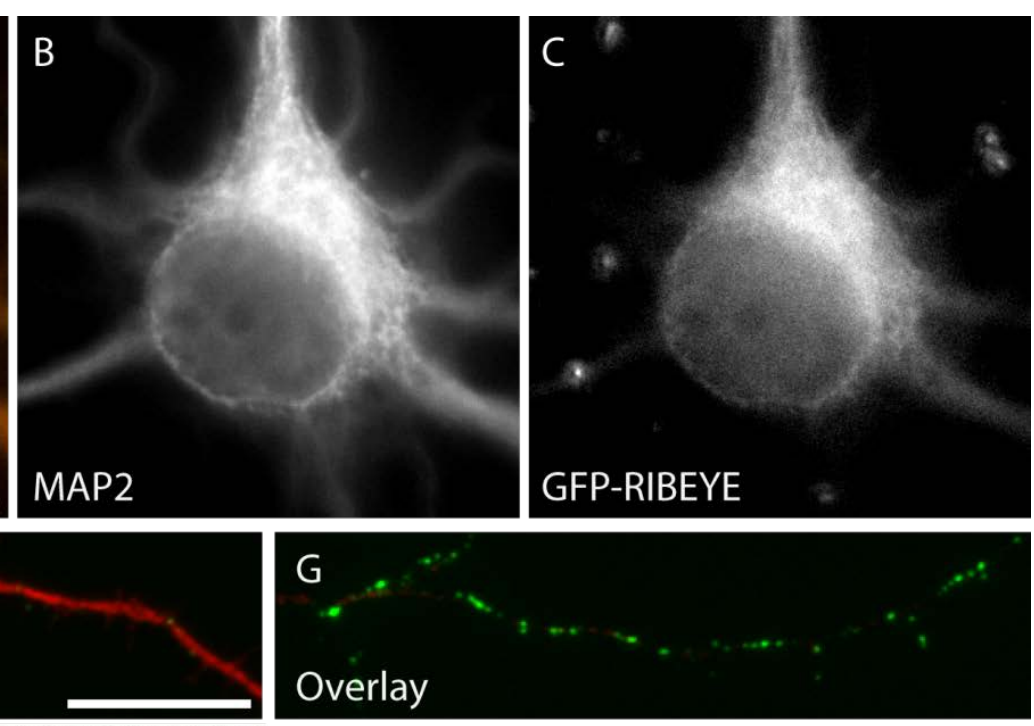

$\mathrm{H}$

\section{MAP2}

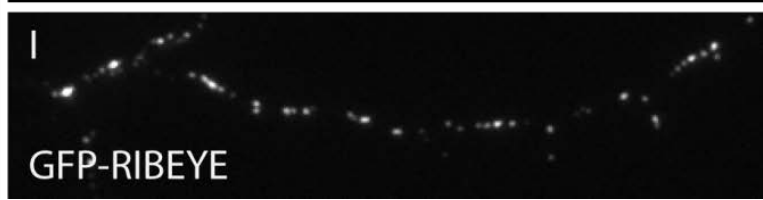

Abbildung 22: Rekombinantes RIBEYE in adulten Neuronen. GFP-RIBEYE entsprach in seiner Verteilung dem präsynaptisch angereicherten GFP-VAMP. (A)-(C) zeigen die Verteilung des rekombinanten Proteins im Vergleich zu MAP2 innerhalb des Soma eines transfizierten adulten Neurons (DIV 10) zunächst überlappend, dann in getrennten Kanälen. Anders als in jungen Neuronen lagen im Soma keine punktförmigen Anreicherungen, sondern eine eher gleichmäßige und weniger intensive Autofluoreszenz des Proteins vor. Dafür war es in Form intensiv fluoreszierender punktförmiger Signale innerhalb von Axonen nachweisbar, was in (G)-(I) zunächst überlagert, dann in den getrennten Kanälen veranschaulicht wird. (D)-(F) weisen auf das Abhandensein des Proteins innerhalb von Dendriten hin. Maßstäbe: $10 \mu \mathrm{m}$.

Zur weiteren Analyse der möglichen synaptischen Anreicherung des Proteins wurde dessen Colokalisationsverhalten mit synaptischen Markerproteinen überprüft. Dazu wurden am DIV 3 transfizierte und am DIV 10 fixierte Neurone mit den entsprechenden Antikörpern gegen Synapsin, Synaptophysin und VAMP2 gefärbt. Um den Grad der Colokalisierung von GFP-RIBEYE mit dem jeweiligen Protein zu erhalten, wurden, wie oben beschrieben, OpenView und Microsoft Excel verwendet. Zur Überprüfung des Vorliegens möglicher signifikanter Abweichungen zwischen den erhaltenen Prozentsätzen wurde das Programm IBM SPSS Statistics 21 verwendet. Es wurde dabei der Chi-Quadrat-Test gewählt.

In allen Fällen konnten hohe Prozentsätze ermittelt werden, die jedoch unterschiedlich stark ausfielen: während der jeweilige Colokalisationsgrad von GFP-RIBEYE mit Synapsin und VAMP2 bei 87,61 \pm 2,81 \% und 92,28 \pm 1,48 \% lag, fiel er mit Synaptophysin signifikant geringer aus $(57,09 \pm 3,90 \%$; $<0,001)$. Diese Ergebnisse sind in Abbildung 23 dargestellt. 

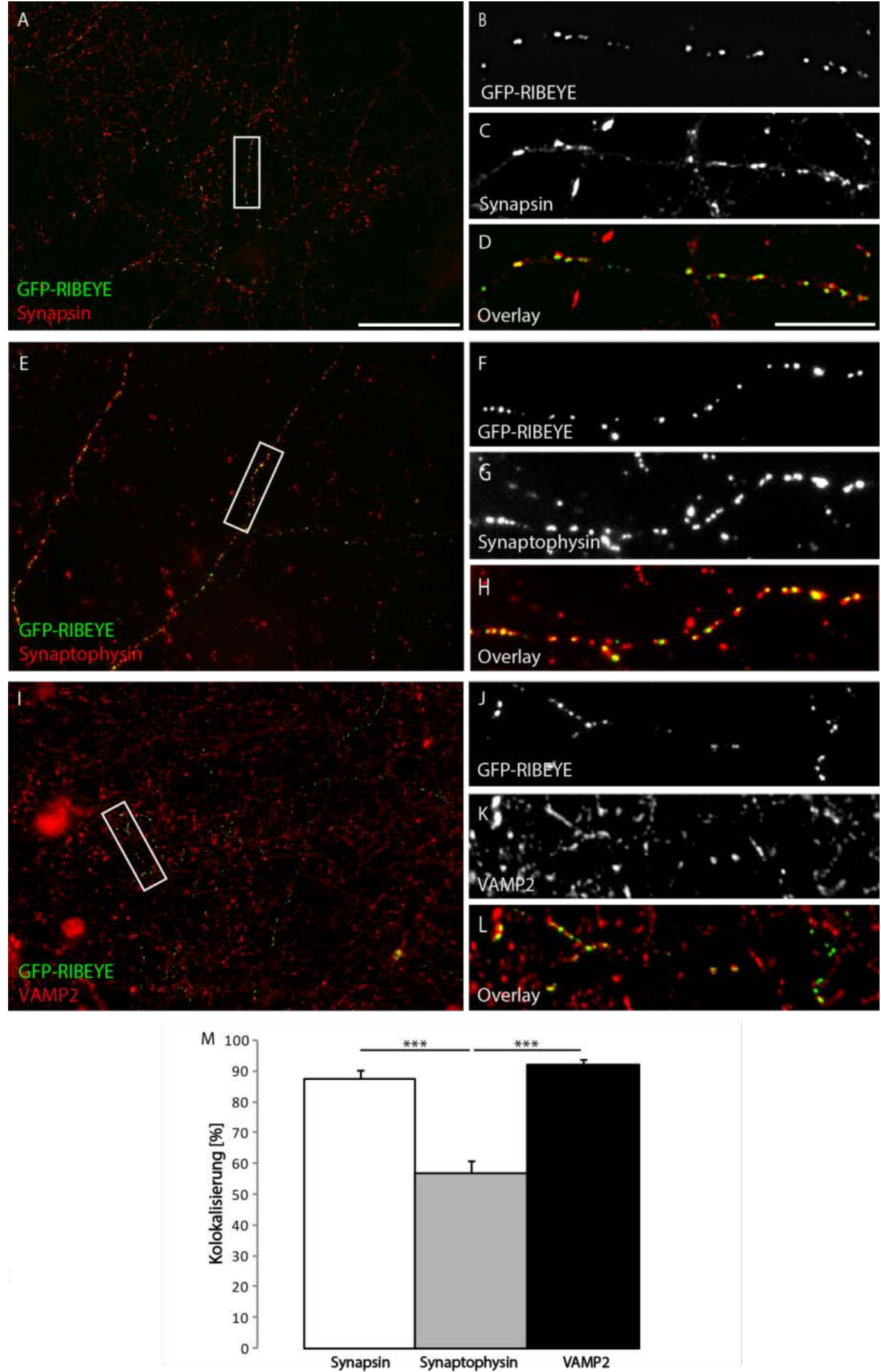

Abbildung 23: Colokalisation von GFP-RIBEYE mit Synapsenmarkern I. (A), (E) und (I) zeigen das rekombinante GFP-RIBEYE in Fortsätzen adulter Neurone (DIV 10). Bei 40-facher Vergrößerung erfolgt der Vergleich von GFPRIBEYE und den Synapsenmarkern Synapsin, Synaptophysin und VAMP2 in der Übersicht. GFP-RIBEYE ist in Grün, das jeweilige Vergleichsprotein in Rot dargestellt. Die in den Übersichtsbildern markierten Ausschnitte sind in (B)-(D), (F)-(H) und (J)-(L) bei 63-facher Vergrößerung zu sehen. Zunächst werden die Proteine in den einzelnen Kanälen, darunter überlagert gezeigt (Overlay). GFP-RIBEYE colokalisierte sowohl mit Synapsin als auch mit Synaptophysin und VAMP2. Das Ausmaß der Colokalisation ist an der Gelbfärbung im Overlay erkennbar. Maßstäbe: (A) $50 \mu \mathrm{m}$, (D) $10 \mu \mathrm{m}$. (M) gibt das Ergebnis der quantitativen Analyse wieder. Bei einem durchgängig hohen Colokalisationsgrad fiel auf, dass GFP-RIBEYE signifikant stärker mit Synapsin und VAMP2 als mit Synaptophysin überlagerte. 
Bei dem Vergleich mit weiteren Proteinen (Abbildung 24) fiel auf, dass das rekombinante RIBEYE signifikant stärker mit Bassoon als mit dessen Bindungspartner Mover colokalisierte. Für die Auswertung mit Bassoon lag der Wert bei 75,93 \pm 3,75 \%, während er für Mover mit 63,65 \% \pm 4,24 \% deutlich geringer ausfiel $(\mathrm{P}<0,001)$.
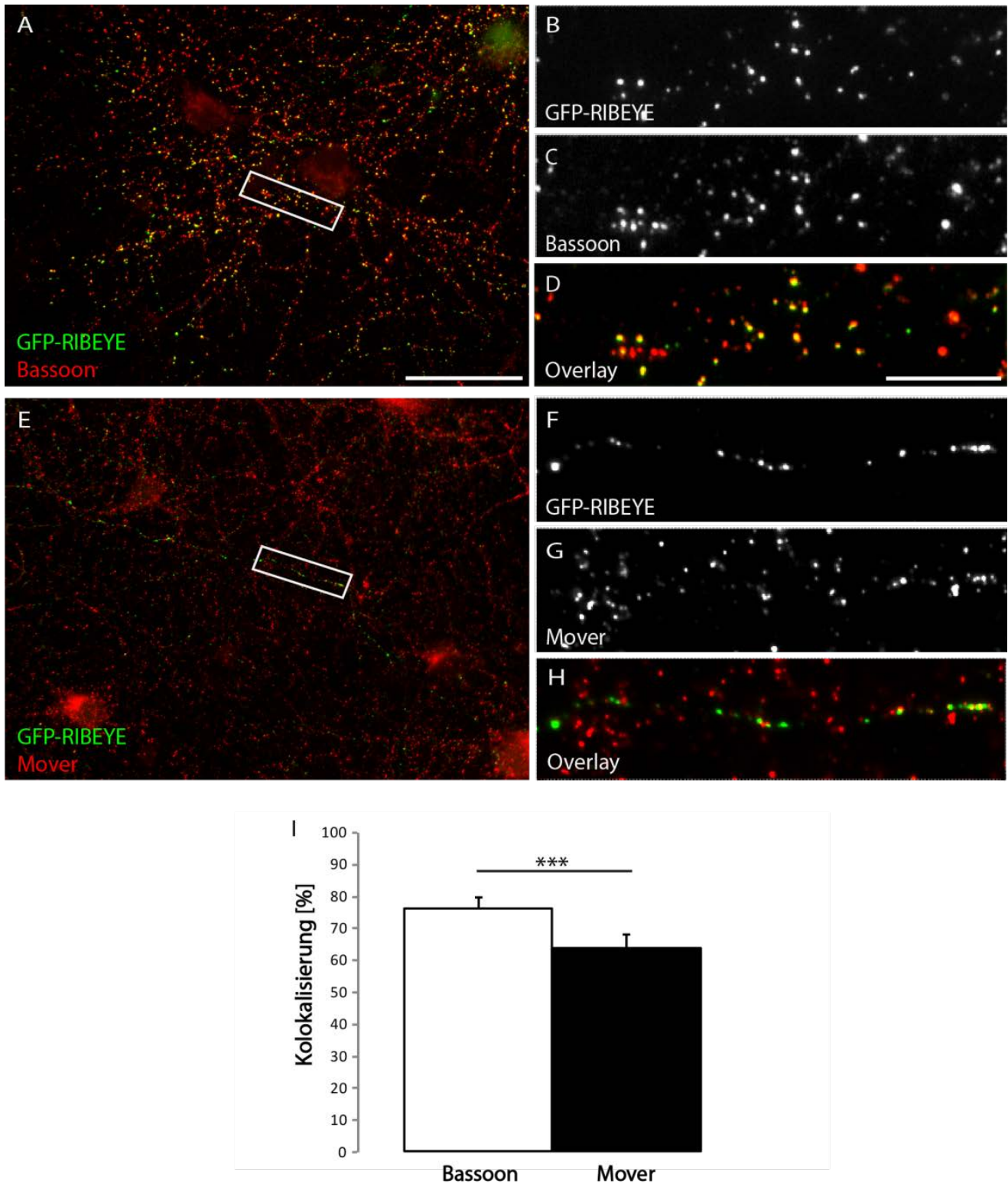

Abbildung 24: Colokalisation von GFP-RIBEYE mit Synapsenmarkern II. Bei einer Vergrößerung von 40x ist das punktförmig angereicherte GFP-RIBEYE bereits erkennbar und im Vergleich zu Bassoon (A) und Mover (E) in Fortsätzen adulter Neurone dargestellt. Das rekombinante Protein zeigt sich in Grün, wohingegen Bassoon und Mover in Rot gezeigt werden. In (B)-(D) und (F)-(H) sind die Proteine getrennt, dann überlagert (Overlay) abgebildet. Maßstäbe: $10 \mu \mathrm{m}$. Der jeweilige Grad der Colokalisation von GFP-RIBEYE mit Bassoon einerseits und Mover andererseits unterschied sich signifikant voneinander (I). 


\section{DISKUSSSION}

In dieser Arbeit sollten die Eigenschaften von drei Proteinen mithilfe der Expression von rekombinanten Versionen dieser Proteine untersucht werden. Dazu wurden deren subzelluläre Verteilungen in neuronalen Primärkulturen aus dem Hippocampus an zwei Entwicklungsstadien untersucht. In jungen Neuronen wurde das Augenmerk dabei auf den GolgiApparat gelegt, in adulten Zellen auf die präsynaptischen Terminalien.

Mittels Immunfluoreszenz wurden zwei rekombinante Varianten von Bassoon sowie eine von RIBEYE untersucht. Bassoon ist als nahezu ubiquitäre Komponente aktiver Zonen von Vertebraten bekannt, während das Protein RIBEYE als spezifischer Bestandteil von Bandsynapsen in Sinneszellen nachgewiesen wurde.

Während die Eigenschaften der Bassoon-Varianten direkt miteinander verglichen werden sollten, war bei RIBEYE interessant, ob es über Regionen verfügt, die eine Anreicherung an Synapsen erlauben, an denen es normalerweise nicht vorkommt.

Umfassender, also mittels Immunfluoreszenz und auch biochemisch, wurde die Eigenschaften des in Primärkulturen bisher nicht beschriebenen Proteins Rogdi untersucht.

Dabei ergaben sich drei Beobachtungen von besonderer Bedeutung:

1) Es konnte nachgewiesen werden, dass das Protein GFP-Bassoon, welches die erste Bassoon-Variante mit einem intramolekularen GFP-Tag darstellt, vergleichbar gute Eigenschaften in Bezug auf dessen subzelluläre Verteilung und Fluoreszenzintensität wie das C-Terminal getagte Bassoon-GFP aufweist.

2) Die durchgeführte Charakterisierung von Rogdi ergab gleich mehrere Ergebnisse, die nahe legen, dass es sich dabei um eine neue Komponente der präsynaptischen Endigungen handeln muss.

3) Die Untersuchungen von RIBEYE ergaben, dass eine Expression und synaptische Anreicherung des Proteins in hippocampalen Primärkulturen tatsächlich möglich ist.

Entsprechend der Vorgehensweise in den Experimenten erfolgt die Gliederung der Diskussion: Zunächst werden die Eigenschaften der rekombinanten Bassoon-Varianten, dann die der rekombinanten Proteine GFP-RIBEYE und GFP-Rogdi beschrieben und diskutiert. Dabei werden jeweils zuerst die aus den jungen Neuronen gezogenen Erkenntnisse, anschließend die aus den adulten diskutiert. 


\subsection{Bassoon: rekombinante Varianten und deren Einfluss auf die Mover-Rekrutierung}

\subsubsection{Subzelluläre Verteilung beider Bassoon-Varianten am Golgi- Apparat junger Neurone}

Bei der Analyse der Bassoon-Konstrukte in transfizierten Nervenzellen wurden diese einerseits miteinander und andererseits mit mGFP - als Beispiel für ein komplett homogen verteiltes Protein - und mit GFP-VAMP - als Beispiel für ein in synaptischen Vesikeln angereichertes Protein - verglichen. Zu erwarten war, dass sich GFP-VAMP (mit Nterminalem GFP-Tag) und Bassoon-GFP (mit C-terminalem GFP-Tag) sowohl am GolgiApparat als auch an Synapsen anreichern (Ahmari et al. 2000; Dresbach et al. 2006). Es galt zu testen, ob der intramolekulare GFP-Tag in GFP-Bassoon die korrekte subzelluläre Verteilung des Konstrukts behindert. Das hier untersuchte Konstrukt GFP-Bassoon ist die erste rekombinante Bassoon-Variante mit intramolekularem Tag. In allen bisher veröffentlichten Studien wurden N- oder C-terminal getagte Konstrukte beschrieben (unter anderem Dresbach et al. 2003; Dresbach et al. 2006)

Bei allen N-terminal getagten Bassoon-Konstrukten wird notwendigerweise die Konsensusstelle für die N-Myristoylierung (MGNEASL) blockiert (Dresbach et al. 2003; Dresbach et al. 2006), sodass zu erwarten ist, dass bei diesen Konstrukten keine NMyristoylierung erfolgt.

Im Vergleich dazu ist die Myristoylierungsstelle in GFP-Bassoon aufgrund der intramolekularen Positionierung des GFP-Tags prinzipiell frei. Ob der Tag aber den Transport von Bassoon - zum Beispiel durch die Verhinderung der korrekten Faltung - stört, war zu klären. Die im Folgenden diskutierten Untersuchungen erfolgten in jungen und in adulten Neuronen.

Bei dem Vergleich in jungen Neuronen stellen sich die untersuchten rekombinanten Proteine, mit Ausnahme des diffus verteilten m-GFP, hinsichtlich ihrer Lokalisation am GolgiApparat gleich dar. Sowohl GFP-Bassoon als auch Bassoon-GFP und GFP-VAMP colokalisieren mit dem Golgi-Marker TGN38. Die Anreicherung von Bassoon am Golgi-Apparat ist daher für die unterschiedlich gatagten Bassoon-Konstrukte vergleichbar. Daher scheint der intramolekulare GFP-Tag in GFP-Bassoon kein prinzipielles Hindernis für den Transport von GFP-Bassoon zum Golgi-Apparat darzustellen (Dresbach 2006). Bei der Betrachtung der rekombinanten Proteine im Fluoreszenzmikroskop fällt auf, dass einige heller als andere fluoreszieren. Die Überlagerung von TGN38 mit den zu vergleichenden Proteinen 
(mit Ausnahme von m-GFP) konnte für die anschließende quantitative Auswertung der Intensitäten genutzt werden. Bereits nach der Auswertung weniger Zellen fiel eine außerordentlich hohe Varianz der errechneten Fluoreszenzintensitäten auf, welche auf ein bestehendes Hintergrundsignal zurückzuführen war. Um diesen Fehler zu korrigieren, wurde stellvertretend für die Hintergrundintensität ein 50 x 50 Pixel großes Feld erstellt. Dieses wurde stets innerhalb des jeweiligen Nucleus platziert, um in derselben Fokusebene zu bleiben.

Die Analyse der Fluoreszenzintensitäten nach Abzug der Hintergrundfluoreszenz ergab signifikante Unterschiede zwischen allen getesteten Proteinen. Von besonderem Interesse ist dabei die signifikant höhere Helligkeit des GFP-Bassoon im Vergleich zu BassoonGFP. Die jeweils gering ausfallende Standardabweichung von Mittelwert kann für die Genauigkeit der angewendeten Methode sprechen. GFP-Bassoon wird also entweder besser exprimiert oder effizienter am Golgi-Apparat verankert. Beides passt zu der Annahme, dass N-Myristoylierung zum Targeting von Bassoon beiträgt (Dresbach et al. 2003; Dresbach et al. 2006) und in Falle dieses Konstrukts möglich ist. GFP-VAMP zeigt eine signifikant höhere Fluoreszenzintensität als die anderen rekombinanten Proteine.

Die signifikant unterschiedlich ausfallende Fluoreszenzintensität der beiden BassoonKonstrukte ließe sich mit besserer Faltung des helleren Konstrukts erklären. Hier könnte die native Konformation des gesamten rekombinanten Proteins in Abhängigkeit von der Posi-tion des Tags ungleich ausfallen, sodass es zu mehreren verschieden günstigen Faltungen käme. Dagegen sind Unterschiede in der Expressionseffizienz der beiden BassoonKonstrukte eher unwahrscheinlich, denn beide werden im gleichen Vektor und vom gleichen Promotor aus exprimiert. Wahrscheinlich ist daher, dass entweder der GFP-Tag selbst in GFP-Bassoon günstiger gefaltet ist als in Bassoon-GFP oder dass die intramolekulare Lage des Tags in GFP-Bassoon für die Faltung des Gesamtkonstrukts tatsächlich ideal ist: dieses Bassoon-Konstrukt besitzt sowohl einen freien N-Terminus als auch einen CTerminus. Möglicherweise müssen beide frei sein, um ein optimales Targeting des Konstrukts zu ermöglichen. GFP-Bassoon würde sich dann an Synapsen besser anreichern als Bassoon-GFP und somit zu einer stärkeren Fluoreszenz führen.

Grundsätzlich besteht auch die Möglichkeit, dass es zu einer teilweisen Abspaltung des Cterminal angebrachten GFP-Tags kommen kann. Eine solche Möglichkeit wurde in Dresbach et al. 2003 für Bassoon-GFP diskutiert. Auch dieser Effekt wäre bei GFP-Bassoon ausgeschlossen. 
Bei der Betrachtung synaptischer Endigungen adulter transfizierter Neurone fielen viele Bassoon-GFP-, GFP-Bassoon- und GFP-VAMP-positive Punkte auf, welche mit dem Synapsenmarker Synaptophysin colokalisieren. Dieses ist als Zeichen einer synaptischen Anreicherung der rekombinanten Proteine aufzufassen. Eine technische Hürde bestand in der Tatsache, dass sich präsynaptische Anreicherungen an aktiven Zonen immer in Form von Fluoreszenzsignalen von maximal 1 Mikrometer Durchmesser (entsprechend der Größe einer aktiven Zone) zeigten. Bei 50.000 plattierten Zellen pro 12 mm-Deckglas kann man lediglich von einigen Dutzend transfizierten Zellen ausgehen. Entsprechend schwierig ist damit das Auffinden der aktiven Zonen dieser transfizierten Neurone. Um die punktförmigen Signale der GFP-getagten Protein-Varianten leichter finden zu können, wurde ein Anti-GFP-Antikörper eingesetzt und mit indirekter Immunfluoreszenz mittels Rotfluoreszenz (Cy3) detektiert. Durch den Amplifikationseffekt waren transfizierte Axone auch bei kleiner Vergrößerung leicht aufzufinden.

Für die anschließenden quantitativen Analysen wurden dann die GFP-Autofluoreszenzen der rekombinanten Proteine miteinander verglichen.

Auch in adulten transfizierten Neuronen lag die Intensität des Vergleichsproteins GFPVAMP deutlich über derer der rekombinanten Bassoon-Varianten.

Die etwa 5-fach so hoch ausfallende Intensität von GFP-VAMP ist höchstwahrscheinlich auf die höhere Anzahl von Kopien pro Synapse zurückzuführen. Während man von ca. 80 Kopien Bassoon pro Bouton ausgeht, findet man allein ca. 70 Kopien VAMP2 in jedem Vesikel (Takamori et al. 2006; Wilhelm et al. 2014). Bei durchschnittlich ca. 400 Vesikeln pro Synaptosom ergibt sich eine Differenz, die dem Faktor 350 entspricht. Es ist unerwartet, dass trotz dieses enormen Unterschieds „lediglich“ eine etwa 5-fach so hohe Fluoreszenzintensität von GFP-VAMP gegenüber den rekombinanten Bassoon-Varianten ermittelt werden konnte. Möglicherweise kommt es zu einer ungünstigen Faltung von GFP-VAMP, die zu einer verringerten Autofluoreszenz des GFP-Tags führt. Denkbar ist auch, dass bei gleicher Expressionsstärke von GFP-VAMP und den GFP-gatagten Bassoon-Konstrukten ein großer Teil der 80 Kopien endogenen Bassoons an der Synapse durch rekombinantes Bassoon ersetzt wird, aber nur ein vergleichsweise kleiner Anteil der 28.000 Kopien endogenen VAMPs. In jedem Fall ist die höhere Fluoreszenzintensität von GFP-VAMP gegenüber der von GFP-Bassoon durch die Kopienzahl der Proteine an der Synapse ein erwartetes Ergebnis.

Interessanterweise konnte in adulten Neuronen zwischen den Autofluoreszenzen der rekombinanten Bassoon-Varianten kein signifikanter Unterschied mehr festgestellt werden. 
Beide Konstrukte fluoreszieren an den Synapsen adulter hippocampaler Neurone gleich hell.

Damit konnte gezeigt werden, dass der intramolekulare Tag zu keiner Behinderung der Anreicherung an Synapsen führt.

Warum kommt es dagegen in jungen Neuronen am Golgi-Apparat zu hellerer Fluoreszenz des GFP-Bassoon?

Es lässt sich mutmaßen, dass GFP-Bassoon durchschnittlich eine günstigere Faltung besitzt, die für die Anreicherung am Golgi-Apparat oder golginah gelegenen Transportintermediaten relevant ist. Es ist denkbar, dass die beiden Konstrukte zu einem unterschiedlich großen Anteil optimal gefalteter Moleküle führen.

Im Falle der Synapsen adulter Neurone könnte die Art der Faltung für den Verbleib des Moleküls entscheidend sein: Geht man davon aus, dass nur optimal gefaltete Moleküle auf Transportintermediate geladen werden und ungünstig gefaltete erst gar nicht aus dem Bereich des Golgi-Apparats abtransportiert werden, so würde im Falle beider BassoonKonstrukte nur das optimal gefaltete Protein zu den Synapsen transportiert werden und dort zu einer Sättigung aller Bindungsstellen führen. Damit würden Unterschiede in den Fluoreszenzintensitäten dieser rekombinanten Proteine nur in jungen Neuronen evident sein, während es in adulten aufgrund des oben beschriebenen Selektionsmechanismus zu keinen unterschiedlichen Fluoreszenzintensitäten an Synapsen käme.

Hervorzuheben ist jedoch, dass sich GFP-Bassoon mit seinem intramolekularen Tag in reifen Neuronen genauso gut an Synapsen anreichert wie Bassoon-GFP. Das neue Konstrukt ist also in jungen Neuronen zur Markierung des Golgi-Apparats bzw. golginah gelegener Transportintermediate besser geeignet und in reifen Neuronen genauso gut wie BassoonGFP einsetzbar, um Synapsen zu markieren. Da seine beiden Termini frei zugänglich sind, dürfte es für zukünftige funktionelle Studien das besser geeignete Konstrukt sein.

Zusätzlich wurde überprüft, wie stark die Bassoon-Menge innerhalb der Synapsen transfizierter Zellen von derer in untransfizierten Neuronen abweichen kann. Die Analyse der Anreicherung der rekombinanten Bassoon-Varianten in Synapsen zeigte, dass es lediglich zu einer geringfügigen Erhöhung der Bassoon-Mengen in transfizierten Zellen gegenüber untransfizierten kam (vergleiche 3.1.3).

Die verwendete Transfektionsmethode (Calcium-Phosphat-Präzipitation) scheint daher zu einer sehr homogenen Aufnahme und Expression der rekombinanten Proteine zu führen, ohne eine massive Erhöhung der Bassoonmenge hervorzurufen. Eine enorme Abweichung von den physiologischen Verhältnissen ist damit nahezu auszuschließen. 
Andererseits kann eine unphysiologisch starke Überexpression als Technik für gain-offunction-Ansätze eingesetzt werden. Dazu wurden mittels Lipofektion starke Überexprimierer erzeugt und die gesamten Bassoonmengen bestimmt.

Die sich signifikant voneinander unterscheidenden Fluoreszenzintensitäten zeigen, dass es unter dem Einfluss der Transfektion je nach Methode zu einer Umgestaltung der Zusammensetzung der Synapsen kommen kann (vergleiche 3.1.3 und 3.1.4). Abgesehen von der gewählten Transfektionsmethode sind auch die Menge der zugegebenen DNA, die Inkubationszeit sowie weitere Faktoren entscheidend für die Anzahl transfizierter Zellen.

Zusammenfassend kann also festgehalten werden, dass GFP-Bassoon als optimiertes Bassoon-Konstrukt für zukünftige Untersuchungen geeignet zu sein scheint.

In Hinblick auf den weiteren Einsatz der Konstrukte konnte festgestellt werden, dass deren Expression im Anschluss an die $\mathrm{CaPO}_{4}$-Transfektion die Lokalisation des Golgi-Apparats, von Transportintermediaten und reifen Synapsen in lebenden Zellen ermöglicht. Ist aufgrund der Frage-stellung eine deutliche Überexpression gewünscht, so kann diese mit anderen Techniken, wie z.B. der Lipofektion, problemlos erreicht werden.

Diese Beobachtungen sind gleichzeitig der Ausgangspunkt für weitere Verbesserungen der Bassoon-Konstrukte: Mit der Entwicklung des enhanced green fluorescent Proteins erfolgte bereits eine deutliche Optimierung des ursprünglichen GFP. Dennoch ist dieser Tag nicht ausreichend hell, um dessen Autofluoreszenz (innerhalb des GFP-Bassoon) zuverlässig und schnell im Mikroskop erkennen zu können.

Das hellste momentan verfügbare grün fluoreszierende Protein ist das sogenannte Emerald (Tsien 1998), welches jedoch schneller ausbleicht.

Denkbar wäre daher z.B. das Anhängen eines zweiten EGFP an das schon vorhandene. Ob ein solches Fusionsprotein exprimiert und im Falle einer Expression eine optimale Faltung aufweist, gilt es zu testen.

Im gelben Bereich gelten das mCitrine (Heikal et al. 2000), enhanced yellow fluorescent protein (EYFP) und Venus (Nagai et al. 2002) als besonders hell. Die Herstellung z.B. eines Venus-getagten Bassoon-Konstrukts mit anschließender Transfektion in den verwendeten Primärkulturen würde Klarheit darüber schaffen, ob dieser gelbe Tag besser geeignet ist. 


\subsubsection{Mover: Bassoon als regulierender Faktor?}

Bei Mover handelt es sich um ein vertebratenspezifisches Phosphoprotein der synaptischen Endigungen. Dabei nimmt es zumindest in der Held'schen Calyx unter anderem einen negativen regulatorischen Einfluss auf die Vesikelentleerung. Interessanterweise bindet Mover im Hefe-2-Hybrid-System an einen C-terminalen Anteil des präsynaptischen Proteins Bassoon (Kremer et al. 2007; Ahmed et al. 2013; Körber et al. 2015).

Zur Überprüfung einer möglichen Bindung von Bassoon und Mover wurde zunächst die Verteilung von Mover in den Somata junger Neurone, die Bassoon überexprimieten, überprüft. Dazu wurde die Verteilung von Mover mit derer der transfizierten rekombinanten Proteine m-GFP, GFP-VAMP, GFP-Bassoon und Bassoon-GFP am Golgi-Apparat verglichen. Stellvertretend für den Golgi-Apparat wurde das TGN gefärbt.

In jungen Kulturen lässt sich keine Rekrutierung von Mover unter der Überexpression von rekombinantem Bassoon nachweisen. Die Fluoreszenzintensitäten von Mover in den getesteten transfizierten Kulturen wichen nicht signifikant voneinander ab. Daher konnte die 2007 im Hefe-2-Hybrid-System identifizierte Protein-Protein-Interaktion von Mover mit einem C-terminalen Abschnitt von Bassoon (Kremer et al. 2007) nicht verifiziert werden.

Hinsichtlich der verwendeten Methode fällt auf, dass keine eindeutige Colokalisation von Mover und TGN bestand. Teilweise ließen sich einige Mover-positive Punkte unmittelbar im Bereich der äußeren Zisterne des Golgi-Apparats und zwischen den Lamellen finden. Dennoch war ein Anteil der Signale in einiger Entfernung vom Zellorganell nachweisbar. Mit der gewählten Methode, nämlich die äußersten Grenzen des TGNs als Umriss der zu erstellenden Maske zu verwenden, können somit nicht alle Mover-positiven Punkte zuverlässig in die Analyse einbezogen werden. Jedoch kann ein Vergleich der MoverFluoreszenzintensitäten unter der Annahme, dass mit zunehmender räumlicher Nähe zu dem TGN die Mover-Dichte steigt, erfolgen.

Dennoch bleibt die Schlussfolgerung gültig, dass eine erhöhte Konzentration von Bassoon im mittels TGN38 markierten Bereich des Golgi-Apparats keine Anreicherung von Mover verursacht.

Bei der Betrachtung der Mover-Signale im Rahmen der Antikörperfärbung fiel subjektiv deren geringe Größe auf (Durchmesser nicht ausgewertet). Für diese Beobachtung kommen verschiedene mögliche Erklärungen in Frage: 
1) Nur eine Subpopulation der synaptischen Vesikel weist tatsächlich das Protein Mover auf. Elektronenmikroskopische Untersuchungen ergaben, dass das Protein nur in 16,4 \% untersuchter synaptischer Vesikel nachweisbar war (Ahmed et al. 2013). Damit könnte dessen Funktion lediglich unter bestimmten Bedingungen zum Tragen kommen.

Betrachtet man diesen vergleichsweise geringen Anteil von etwa $16 \%$, so stellt sich die Frage, welche Funktion diese synaptischen Vesikel erfüllen.

Sind sie beispielsweise charakteristisch für einen der Vesikelpools? Alabi und Tsien (2012) schlagen eine Zugehörigkeit der synaptischen Vesikel zu drei Pools vor, nämlich dem readily releasable pool, dem recycling pool und dem resting pool. Die Vesikel der beiden erstgenannten Pools sind freisetzungsbereit und werden zum sogenannten total recycling pool zusammengefasst, welcher in etwa $15 \%$ aller Vesikel beinhaltet (Harata et al. 2001).

Sowohl die Beobachtung aus der Immunogoldanalyse (Ahmed et al. 2013) als auch weitere Abschätzungen (Wilhelm et al. 2014) ergaben, dass sich Mover auf gerade einmal 20 \% der Vesikel aufhält und sprechen daher ebenfalls dafür, dass das Protein mit einem vergleichsweise kleinen Pool synaptischer Vesikel assoziiert ist. Damit könnte es sich bei Mover um ein Markerprotein für eben diesen Vesikelpool handeln.

Diskutiert wird auch das Vorhandensein eines sogenannten Superprimings.

Dieses beschreibt die Zugehörigkeit von synaptischen Vesikeln zu einem weiteren, innerhalb des readily releasable pools gelegenen, Pool, dessen Freisetzungswahrscheinlichkeit erhöht ist (Schlüter et al. 2006; Taschenberger et al. 2016).

Nimmt man nun an, dass ein Teil der Vesikel innerhalb des readily releasable pools eine niedrige Freisetzungswahrscheinlichkeit besitzt und der andere eine erhöhte, so könnte Mover in diesem Szenario als Inhibitor des Superprimings agieren. Vesikel, die intaktes Mover enthalten, würden dabei eine verringerte Freisetzungswahrscheinlichkeit aufweisen als solche, die kein Mover besitzen. Ein Mover-Knock-down oder -Knock-out könnte aufgrund des fehlenden negativen regulatorischen Einflusses von Mover auch in der ersten Gruppe zu einer erhöhten Freisetzungswahrscheinlichkeit führen.

Dazu passt auch die Beobachtung, dass es in Knock-down-Versuchen zwar weder zu einer strukturellen Veränderung noch zu einer veränderten Anzahl von freisetz- 
baren Vesikeln kam, die Freisetzungswahrscheinlichkeit der Vesikel insgesamt jedoch erhöht war (Körber et al. 2015).

Dieses könnte erklären, warum Mover nur in einem Teil der synaptischen Vesikel nachweisbar ist. Gleichzeitig könnte Mover daher als Charakteristikum zur Identifikation eben dieser speziellen Vesikel dienen.

2) Bei Mover handelt es sich um ein exklusiv an der aktiven Zone angereichertes Protein.

3) Die Antikörperfärbung ist nicht ausreichend spezifisch und führt zu vielen kleinen Signalen. Diese Möglichkeit ist aufgrund der zwischenzeitlich erfolgten unpublizierten Antikörperfärbungen auf Zellkulturen aus Mover-Knock-out-Mäusen auszuschließen (M. Arndt., A.K. Akula., T. Dresbach). Für die Spezifität des MoverAntikörpers spricht auch, dass die in der vorliegenden Arbeit beobachteten kleinen Mover-Fluoreszenzsignale mit Synapsenmarkern colokalisierten.

In adulten Neuronen zeigt die Färbung endogenen Movers ein Vorhandensein des Proteins in Punkten, welche auch rekombinantes Bassoon (sowohl Bassoon-GFP als auch GFPBassoon) und VAMP (GFP-VAMP) enthalten. Diese sowie vorherige Untersuchungen (Ahmed et al. 2013; Kremer et al. 2007) belegen, dass Mover in Synapsen nachweisbar ist. Daher wurden auch diese Bereiche auf eine vermehrte Anreicherung von Mover unter der Expression dieser Proteine überprüft.

Die Auswertung der Fluoreszenzintensitäten von Mover führte zu keiner Verifizierung einer möglichen Rekrutierung. Diese ist aber nicht vollständig auszuschließen, da die durchgeführte Transfektion nachweisbar zu keiner massiven Überexpression des rekombinanten Bassoons führt. Aufgrund der geringen Bassoon-Mengen könnte eine Rekrutierung von Mover daher zwar vorhanden, jedoch nicht nachweisbar sein bzw. unterhalb einer signifikanten Schwelle liegen.

Andererseits hat aber eine signifikante Erhöhung der Bassoon-Menge keine nachweisbare Erhöhung der Mover-Menge zur Folge (vergleiche 3.2).

Sollte tatsächlich eine Rekrutierung von Mover durch Bassoon bestehen, so müsste diese zumindest bei einer massiven Anreicherung von Bassoon nachweisbar sein. Daher wurden mittels Lipofektion - dieses Verfahren führt vermehrt zur stärkeren Überexpression als die Calcium-Phosphat-Präzipitation- Kulturen transfiziert und nach der Fixierung und Färbung ausschließlich Bereiche analysiert, in denen außergewöhnlich starke Anreicherungen von 
rekombinanten Proteinen vorlagen. Die rekombinanten Proteine liegen dabei in sehr großen, oft runden, an Aggregate erinnernden, Gebilden vor (siehe oben).

Erneut konnten keine erhöhten Werte nachgewiesen werden, weshalb eine Rekrutierung zunehmend unwahrscheinlich scheint. Die untersuchten punktierten Bassoon-Signale wurden jedoch nicht weitergehend untersucht. Eine elektronenmikroskopische Analyse wäre sinnvoll, um zu bestimmen, ob es sich bei den Aggregaten um präzipitiertes, zur Bindung unfähiges Protein, oder um synaptisch angereichertes Bassoon handelt.

Es kann ausgeschlossen werden, dass es sich um abgespaltene GFP-Tags handelt, da eine 10-fach erhöhte Gesamtbassoon-Menge nachgewiesen wurde (vergleiche 3.1.4). Dennoch ist z.B. eine Oligomerisierung mit resultierender sterischer Hemmung der Moverbindung denkbar.

Insgesamt zeigt sich, dass mittels des Überexpressions-Assays kein Hinweis auf eine Bindung von Bassoon und Mover in neuronalen Primärkulturen gefunden werden konnte. Insbesondere die Tatsache, dass das neu charakterisierte, optimierte Konstrukt GFPBassoon auch bei signifikanter Überexpression keine Anreicherung von Mover verursachte, spricht dafür, dass Bassoon und Mover keine konstitutive (d.h. permanent existierende) Interaktion ausüben.

Als nächstes wäre die Hypothese zu testen, ob Bassoon und Mover zu bestimmten Zeitpunkten akut aneinander binden, z.B. nur während der Exozytose oder während der Endozytose synaptischer Vesikel. Beide Proteine werden phosphoryliert, wobei Bassoon nachweislich an einer Vielzahl von Stellen (30) phosphoryliert wird (Collins et al. 2005). Die für die Interaktion notwendigen Bedingungen könnten im Hefe-2-Hybrid-Assay zufällig gegeben sein, z.B. durch ein Muster der Phosphorylierung von Bassoon und Mover, das in Neuronen vielleicht konstitutiv durch Phosphatasen verhindert und nur akut ermöglicht wird.

Die hier vorgestellten Beobachtungen stehen im Einklang mit der Tatsache, dass es in vivo zu einer 22\%igen Reduktion der Immunfluoreszenz für Mover in Bassoon-defizienten Mäusen kommt (Mendoza Schulz et al. 2014). Dabei wurden Held'sche Endkolben, also erregende präsynaptische Terminalien im Nucleus cochlearis, von Wildtyp-Mäusen und Mäusen mit mutiertem Bassoon verglichen. Die Tatsache, dass etwas 80 \% der Immunfluoreszenz für Mover auch in Abwesenheit von funktionstüchtigem Bassoon noch an Synapsen vorlag, zeigt, dass Bassoon nicht absolut essentiell für die Anreicherung von Mover in vivo ist. Die geringfügige, aber nicht signifikante Reduktion von Mover legt aber nahe, 
dass Bassoon und Mover in einer noch zu analysierenden Weise doch miteinander interagieren.

\subsection{Rogdi: eine neue präsynaptische Komponente?}

Das Protein rückte erstmalig aufgrund verschiedener zu dem Kohlschütter-Tönz-Syndrom führender Mutationen in das Interesse der Forschung. Bisher identifiziert wurden eine Frameshift-Mutation, die zu einer Veränderung des Leserasters des Gens führt, eine zum Abbruch der Proteinsynthese führende Nonsense-Mutation sowie eine zu einem inkorrekt ablaufendem Spleißen der RNA führenden Spleiß-Mutation. Die zu der Erkrankung zählenden und neurologisch bedeutsamen Symptome sind Epilepsie und psychomotorische Regression. Darüber hinaus kommt es auch zur Amelogenesis imperfecta, einer erblich bedingten Dysplasie des Zahnschmelzes (Schossig et al. 2012).

In diesem Zusammenhang ist interessant, dass Rogdi biochemisch in einer synaptischen Vesikelfraktion nachgewiesen wurde, was für die oben genannten neurologischen Symptome bedeutsam sein könnte (Boyken et al. 2013).

Um zu testen, ob es sich um eine Kontamination handeln könnte, oder ob Rogdi tatsächlich eine bisher unbekannten Komponente der präsynaptischen Endigung sein könnte, wurde das Verhalten des rekombinanten GFP-Rogdi in Neuronen analysiert.

Erste Transfektionen mit dem rekombinanten GFP-Rogdi ergaben eine hinreichend effiziente Expression des Proteins, sodass dessen subzelluläre Verteilung anschließend zunächst in jungen, dann in adulten Neuronen begutachtet werden konnte. Da die Eigenfluoreszenz des GFP-Tags oftmals schwer vom Hintergrund abzugrenzen war, wurden fortan vor allem GFP-Antikörper und auch ein Rogdi-Antikörper verwendet. Neben der rekombinanten Version konnte mithilfe des Rogdi-Antikörpers auch endogenes Rogdi in untransfizierten Kulturen nachgewiesen werden. In jungen Kulturen zeigten sich sowohl das endogene als auch das rekombinante Rogdi innerhalb der Somata wie auch in HEK-Zellen ohne Bereiche klarer Anreicherung, wobei die Dichte in der Nähe des TGN erhöht zu sein schien. Bereits in jungen Neuronen fiel die Rogdi-Färbung innerhalb der Fortsätze positiv aus. Diese punktförmige, an die Verteilung präsynaptischer Proteine erinnernde Anreicherung entlang der Fortsätze konnte anschließend auch in adulten Zellen beobachtet werden. Um den Transport und die Verteilung von Rogdi und GFP-Rogdi möglichst genau charakterisieren zu können, wurden zunächst die Eigenschaften bekannter rekombinanter Proteine begutachtet. Bei dem direkten Vergleich der unbekannten Proteine mit dem diffus verteilten mGFP, dem präsynaptisch angereicherten GFP-VAMP und dem postsynaptischen PSD95- 
GFP stellt sich die Verteilung des zu charakterisierenden Proteins wie folgt dar: innerhalb MAP-2-negativer Fortsätze, also höchstwahrscheinlich der Axone, kam es zu einer punktförmigen Anreicherung. Diese konnte nicht in den MAP2-positiven Dendriten nachgewiesen werden und liefert daher einen ersten Hinweis darauf, dass es sich bei Rogdi um eine bisher unbekannte präsynaptische Komponente handeln könnte. Hinsichtlich der durchgeführten Differenzierung von Dendriten und Axonen mittels MAP-2-Färbung ist zu berücksichtigen, dass das Fehlen des Dendritenmarkers nicht nur für Axone, sondern auch für Gliazellen charakteristisch ist. Durch zusätzliche Färbungen mit dem Axonmarkerprotein Tau (Kosik und Finch 1987) oder smi312 (Ulfig et al. 1998) kann die Arbeitshypothese, dass Rogdi sich in Axonen punktförmig anreichert, zusätzlich getestet werden. Der hier verwendete Transfektionsansatz bietet jedoch einen wichtigen Vorteil gegenüber der Immunfluoreszenzfärbung von endogenem Rogdi: die gesamte transfizierte Zelle ist sichtbar. Deshalb können Gliazellen aufgrund ihrer Morphologie von Neuronen unterschieden werden. In transfizierten Neuronen dient MAP2 dann als Marker für die Dendriten des Neurons. Der MAP2-freie Fortsatz konnte deshalb eindeutig als Axon identifiziert werden. Die Tatsache, dass nur in diesen Fortsätzen punktförmige Fluoreszenzsignale für GFP-Rogdi auftraten, spricht dafür, dass sich rekombinantes Rogdi in präsynaptischen Spezialisierungen anreichert.

Innerhalb der Dendriten waren sowohl bei der Färbung mit dem GFP- als auch dem RogdiAntikörper stets kleinste Punkte erkennbar, die sich in ihrer Größe nicht von Signalen unterschieden, die in Kontrollexperimenten auch vom sekundären Antikörper alleine verursacht wurden.

Ob es sich dabei um eine unspezifische Antikörperfärbung, zelluläre Autofluoreszenz oder tatsächlich um sehr schwache Rogdi- bzw. GFP-Rogdi-positive Punkte handelte, kann nicht sicher bestimmt werden.

Hier kann in Zukunft nur die Analyse von Rogdi-Knock-out-Neuronen Klarheit schaffen. Ebenfalls könnte in Zukunft ein präsynaptischer Anreicherungsfaktor quantitativ bestimmt werden. Dabei handelt es sich um ein helligkeitsbasiertes Verfahren, bei dem die Quotienten der Fluoreszenzintensität der subzellulären Komponenten gebildet und miteinander verglichen werden. Sind die mittlere Fluoreszenzintensität wie bei m-GFP in allen Bereichen des Neurons identisch und damit die Quotienten gleich 1, so spricht dies für eine diffuse Verteilung. Liegt der Quotient deutlich über oder unter eins, so spricht dies für eine Anreicherung des untersuchten Proteins in einem bestimmten Abschnitt des Neurons. 
Der kommerziell erworbene Rogdi-Antikörper musste - soweit ohne Knock-out-Mäuse möglich - auf Spezifität untersucht werden. Sowohl die Antikörperfärbungen in Kulturen als auch die biochemischen Untersuchungen deuten darauf hin, dass der Antikörper das Protein Rogdi erkennt: mit GFP-Rogdi transfizierte Neurone und HEK-Zellen wurden mit Immunfluoreszenz für GFP und für Rogdi gefärbt. Der Rogdi-Antikörper detektierte die gleichen Strukturen wie der GFP-Antikörper, war also in der Lage, rekombinantes Rogdi zu erkennen.

Die biochemischen Untersuchungen zeigten außerdem, dass das knapp 300 Aminosäuren messende endogene Rogdi sowohl in hippocampalen Zellen als auch in cortikalen Neuronen nachweisbar ist. Im Western Blot zeigten sich in beiden Fällen wie erwartet Banden im Bereich von $30 \mathrm{kDa}$. Als Positivkontrolle wurde ein Synapsin-Antikörper verwendet, welcher zu klaren Banden im Bereich von 70 kDa führte.

Zusätzlich sollten die durchgeführten Versuche an Knock-out-Tieren wiederholt werden, um eine Negativkontrolle zu erhalten. Damit könnte die Bedeutung der oben genannten Ergebnisse gestärkt werden. Zu diesem Zweck könnte als schnelle und kostengünstige Variante das CRISPR/Cas (Clustered Regularly Interspaced Short Palindromic Repeats/ CRISPR-associated )-System verwendet werden, wodurch gezielt die für Rogdi codierende DNA-Sequenz entfernt werden könnte (Charpentier und Doudna 2013).

Um zu testen, ob die punktförmigen axonalen Signale einer Anreicherung von Rogdi an präsynaptischen Spezialisierungen entsprechen, wurden Kulturen am DIV 3 mit GFPRogdi transfiziert, am DIV 10 fixiert und daraufhin mit einem anti-GFP-Antikörper und diversen Antikörpern für synaptische Markerproteine gefärbt und die Colokalisationen analysiert. Das Vorgehen entspricht grundsätzlich dem für GFP-Bassoon schon beschriebenen. Dabei wurde der Schwellenwert so gelegt, dass nur ein Subtyp der Rogdi-positiven Punkte ausgewertet wurde. Es scheinen zwei Gruppen zu bestehen: neben der ersten, die sich aus sehr kleinen Punkten zusammensetzt und deutlich weniger häufig mit synaptischen Proteinen zu colokalisieren scheint, findet sich eine zweite mit deutlich größeren und synaptisch wirkenden Punkten. Bei den kleinen Signalen könnte es sich beispielsweise um GFP-Rogdi-Moleküle auf Transportvesikeln oder einfach um eine unspezifische Antikörperfärbung handeln. Mit den getesteten und gut bekannten Membranproteinen der Vesikel, nämlich Synapsin (z.B. (Kennedy und Greengard 1981), Synaptophysin (z.B. Wiedenmann und Franke 1985) und VAMP2 (Baumert et al. 1989; Elferink et al. 1989) bestanden im Falle der zweiten Gruppe sehr hohe Colokalisationsraten von ca. 74 \% (für Synaptophysin) bis 93 \% (für VAMP2), wobei sich der niedrigste und der höchste Wert signifikant vonei- 
nander unterscheiden. Dieses Ergebnis scheint aber dem Eindruck zu widersprechen, den man bei der reinen Betrachtung der Originalaufnahmen erhält. GFP-Rogdi scheint mit allen Vesikelproteinen gleich stark zu colokalisieren. Die Signifikanz ergibt sich wahrscheinlich aufgrund folgenden Einflusses: Es scheint eine deutlich höhere Anzahl ausreichend großer und heller Synapsin- und VAMP2-Punkte vorzuliegen. Bereiche, in denen augenscheinlich eine Colokalisation von GFP-Rogdi und Synaptophysin vorliegt, werden mittels der gewählten Methode als nicht-colokalisierend wahrgenommen. Insgesamt scheint es daher eher zu einer Unterschätzung der Colokalisationsrate mit Synaptophysin zu kommen. Anhand dieses Beispiels lässt sich erneut der große Einfluss der bestimmten Schwellenwerte verdeutlichen. Wird ein kleinerer Faktor gewählt, so steigt die Wahrscheinlichkeit eines falsch positiven Ergebnisses. Liegt der Wert darüber, so kommt es zunehmend zu falsch negativen Auswertungen, wodurch Information verloren geht.

Die Colokalisationsrate mit Bassoon liegt bei etwa $66 \%$, die mit Mover bereits unter 45 \%. Bei der Coexpression von GFP-Rogdi und rekombinanten Versionen von Bassoon und Mover in HEK-Zellen kam es zu keiner Coaggregation. Hinweise für spezifische Bindungen dieser Proteine bestehen daher bisher nicht, wenn auch Rogdi wie Bassoon und Mover regelmäßig in synaptischen Endigungen nachweisbar war. Jedoch kann auch jede Veränderung eines Proteins beispielsweise durch das Anhängen eines Tags möglicherweise zu einer sterischen Hemmung der Bindung führen (Snapp 2005).

Insgesamt scheint es sich daher bei Rogdi um ein synaptisch angereichertes Protein zu handeln. Die außerordentlich hoch ausfallenden Colokalisationsraten des rekombinanten Proteins mit den untersuchten Synapsenmarkern sprechen für ein regelmäßiges Vorkommen des Proteins innerhalb von synaptischen Endigungen. Daher ist eine allgemeine Funktion (im Sinne einer Funktion, die überall erfüllt sein muss) von Rogdi für die Struktur oder Funktionalität der Synapsen denkbar

Um zu überprüfen, ob es nicht nur zu einer reinen Anreicherung an synaptischen Endigungen kommt, sondern diese auch noch aktiv sind, wurde ein Synaptotagmin-1 (Syt-1)Wiederaufnahmeversuch durchgeführt. Dazu wurden nach der künstlichen Vesikelentleerung und der Aufnahme des Syt-1-Antikörpers mit luminaler Domäne die Fluoreszenzintensitäten von Syt-1 bestimmt. Diese wurden für m-GFP und GFP-Rogdi transfizierte Zellen erhoben und verglichen. m-GFP sollte dabei keinen Einfluss auf die synaptische Aktivität nehmen, weshalb es als Standard angesehen wird. Die Analyse ergab keine signifikanten Unterschiede, weshalb GFP-Rogdi keinen Einfluss auf die synaptische Aktivität zu nehmen scheint. 
Aufgrund der Untersuchungen ist davon auszugehen, dass es sich bei dem sowohl im Cortex als auch in aktiven synaptischen Endigungen des Hippocampus nachgewiesenen Protein Rogdi um eine bisher unbekannte Komponente der Präsynapse handelt. Aufgrund seines reichlichen Vorkommens zusammen mit synaptischen Vesikelproteinen könnte es eine allgemeine Funktion als Vesikelprotein/vesikelassoziiertes Protein oder Komponente der Präsynapse bzw. aktiven Zone sein. Eine genauere Überprüfung des Vorhandenseins des Proteins in den verschiedenen Gebieten des Gehirns könnte aufschlussreich sein. Dieses bessere Verständnis könnte auch mithilfe von Knock-down- oder Knock-out-Tieren gewonnen werden. Die mit dem Kohlschütter-Tönz-Syndrom assoziierte Epilepsie deutet ebenfalls auf eine bedeutende Rolle von Rogdi im Rahmen der neuronalen Informationsverarbeitung hin (Schossig et al. 2012).

\subsection{RIBEYE als Bestandteil neuronaler Synapsen}

Im Rahmen eines gain-of-function-Experiments wurde das rekombinante GFP-RIBEYE am DIV 3 mittels Calcium-Phosphat-Präzipitation in hippocampale Kulturen transfiziert und dessen Eigenschaften in jungen und alten Kulturen untersucht. Hierbei wurden ebenfalls die oben beschriebenen Methoden verwendet.

Zunächst sollte geklärt werden, ob GFP-RIBEYE überhaupt exprimiert wird. Anschließend wurde dessen subzelluläre Verteilung qualitativ und z.T. auch quantitativ bestimmt. Das Vorgehen entsprach weitestgehend dem für die Untersuchungen von Rogdi-GFP.

Interessanterweise findet man in den Somata immaturer Neurone eine große Anzahl intensiv leuchtender punktförmiger Bereiche. Eine starke Assoziation mit einem bestimmten Zellorganell scheint unwahrscheinlich, wenn auch nur für TGN gefärbt wurde. Die grünfluoreszierenden Punkte scheinen bei eher heterogener Größe im ganzen Soma gleichmäßig verteilt zu sein. Teilweise lässt deren Form an eine Aggregation erinnern. Diese Annahme ergibt sich auch aufgrund der Struktur von RIBEYE: es besteht aus zwei Domänen, von denen eine identisch mit CtBP2, einem Transkriptionsrepressor, ist (Schmitz et al. 2000). Dieses wiederum ist zur Ausbildung von Homodimeren fähig (Thio et al. 2004). Mittlerweile wurden verschiedene RIBEYE-RIBEYE-Interaktionen nachgewiesen (Magupalli et al. 2008). Darüber lässt sich die beobachtete Aggregatbildung innerhalb der Somata junger hippocampaler Neurone erklären. Denkbar ist aber auch die Aggregation von nicht verankerten RIBEYE-haltigen Bandstrukturen, welche von Bassoon-Mausmutanten bekannt sind. Es konnte nämlich gezeigt werden, dass es bei einer gestörten Interaktion von RIBEYE und Bassoon zu sogenannten free-floating 
ribbons, also nicht synaptisch verankerten, sondern frei im Zytoplasma nachweisbaren Bandstrukturen kommt (Dick et al. 2003). Daher könnte es sich bei den in den Somata junger Neurone beobachteten intensiv fluoreszierenden Signalen auch um aggregierte Bandstrukturen handeln, denen eine fehlerhafte synaptische Transmission zugrunde liegt.

In MAP2-negativen Fortsätzen adulter Zellen, den Axonen, waren GFP-RIBEYE-positive punktförmige Signale nachweisbar. Dabei fielen sowohl deren geringe Größe als auch deren Lage im Vergleich zu den Vesikelmarkern Synapsin, Synaptophysin und VAMP2 auf. Bei genauer Betrachtung scheint GFP-RIBEYE grundsätzlich am Rand der Vesikelmarker zu liegen. Eine mögliche Erklärung könnte das exklusive Vorhandensein des Proteins in der aktiven Zone sein. Aufgrund der Überlagerung von GFP-RIBEYE mit den Vesikelmarkern wurde das Ausmaß der Colokalisation ermittelt. Mit den Vesikelmarkern colokalisierte das rekombinante Protein zu etwa $57 \%$, $88 \%$ und $92 \%$, mit Bassoon und Mover zu etwa $76 \%$ und $64 \%$. Es fiel dabei die relativ genaue Übereinstimmung von GFPRIBEYE und endogenem Bassoon auf, was ebenfalls für die Lage des rekombinanten Proteins in der aktiven Zone spricht. Darüber hinaus ist eine Bindung der beiden Proteine, welche für die Verankerung der Bandsynapsen essentiell ist, bekannt (Dick et al. 2003; tom Dieck et al. 2005).

Ob es sich bei den untersuchten Bereichen um aktive synaptische Endigungen handelte, ließe sich mithilfe eines Synaptotagmin-1-Uptakes feststellen (vergleiche Kapitel 3.3.5).

Von größtem Interesse bleibt die Frage, welchen Einfluss das rekombinante Protein auf die Morphologie der hippocampalen Neurone nehmen kann. Führt allein die Expression von GFP-RIBEYE zur Ausbildung von Bandsynapsen?

Zur Klärung dieser Frage wurde ein Protokoll entwickelt, welches erlaubt, auf gerasterten Deckgläsern befindliche transfizierte Primärkulturen mikroskopisch zu überprüfen und die mit GFP-RIBEYE transfizierten Neurone bei 10-facher Vergrößerung so zu dokumentieren, dass dieselben Areale bei späterer elektronenmikroskopischer Betrachtung problemlos wiedergefunden werden können (D. Riemann und T. Dresbach, unveröffentlichte Daten). Noch nicht publizierte Untersuchungen zeigten zumindest auffällige elektronendichte Bereiche innerhalb der präsynaptischen Endigungen unserer transfizierten Kulturen. Diese konnten jedoch noch nicht eindeutig beschrieben werden. Daher bleibt diese Fragestellung weiterhin spannend. 


\section{ZUSAMMENFASSUNG}

Ein Weg zur Untersuchung von Proteineigenschaften ist die Expression von rekombinanten Varianten dieser Proteine in einem zellulären Umfeld, welches einen korrekten Transport bzw. eine korrekte subzelluläre Verteilung erlaubt. Primärkulturen von hippocampalen Neuronen gelten diesbezüglich als gut etabliertes Modellsystem. Hier wurde dieses Modellsystem genutzt, um die Eigenschaften rekombinanter Varianten dreier Proteine zu untersuchen, nämlich Bassoon, einem Protein aktiver Zonen, Rogdi, dessen Mutationen das Kohlschütter-Tönz-Syndrom hervorrufen können und RIBEYE, einem Bestandteil von Bandsynapsen in Sinneszellen.

Im Vordergrund standen folgende Fragestellungen:

1) Unterscheiden sich zwei unterschiedlich markierte Bassoon-Varianten in ihrer subzellulären Verteilung voneinander und nehmen sie einen Einfluss auf die Rekrutierung des Proteins Mover?

2) Kommt es bei der ektopen Expression des Proteins RIBEYE in hippocampalen Neuronen zur Anreicherung in Synapsen? Reicht die Expression von RIBEYE allein aus, um auch dort Bandsynapsen zu bilden?

3) Handelt es sich bei dem Protein Rogdi um eine bisher unbeschriebene präsynaptische Komponente?

Die vorhandenen Bassoon-Konstrukte gehören zu den am meisten genutzten Reportern. Mit deren Hilfe konnte unter anderem gezeigt werden, dass es mobile Transportvesikel gibt, welche Material für den Aufbau aktiver Zonen transportieren, dass die Größe aktiver Zonen schwankt und Bassoon nicht kontinuierlich, sondern stufenweise in aktiven Zonen angereichert wird.

Die genannten Ergebnisse wurden unter Verwendung von Konstrukten gewonnen, bei denen mindestens ein Terminus blockiert oder deletiert ist. Deshalb kann nicht ausgeschlossen werden, dass diese Konstrukte funktionelle Defizite aufweisen.

Theoretisch ideal wäre ein Bassoon-Konstrukt, welches sowohl einen freien N-Terminus (zwecks N-Myristoylierung) als auch einen freien C-Terminus (um die Bindung an Mover zu ermöglichen) besitzt.

Das in dieser Dissertation untersuchte Bassoon-Konstrukt mit intramolekularem GFP-Tag 
ist das erste, welches diese Voraussetzungen erfüllt. In Hinblick auf weitere Studien sollte dieses verbesserte Konstrukt daher außergewöhnlich gute Bedingungen schaffen.

Mit dieser neuen Generation von Bassoon-Konstrukten ist die Voraussetzung für weitere Optimierungsansätze geschaffen worden: möglich ist jetzt z.B. eine Markierung des Proteins, die zu einer noch höheren Fluoreszenzintensität führt. Es könnten noch intensivere Fluorophore verwendet oder bereits genutzte in Form von Tandemkonfigurationen angeordnet werden.

In der vorliegenden Dissertation wurde nachgewiesen, dass das Protein RIBEYE auch bei ektoper Expression an synaptischen Endigungen hippocampaler Neurone anreichert ist. Diese Beobachtung erlaubt es, in zukünftigen Experimenten erstmals zu untersuchen, ob es (wie auch in sensorischen Zellen) zur Ausbildung von Bandsynapsen kommt.

Falls ja, sollte überprüft werden, ob diese Bandsynapsen den bisher bekannten in Morphologie und Funktionalität entsprechen. Durch die Herstellung mutierter RIBEYE-Varianten könnten daraufhin die dafür erforderlichen Abschnitte des Proteins identifiziert werden.

Die oben beschriebenen Untersuchungen sprechen dafür, dass es sich bei dem zuvor wenig erforschten Rogdi um ein in neuronalen Endigungen vorkommendes Protein handelt. Bedenkt man nun, dass es die Fähigkeit besitzt, sich an präsynaptischen Regionen anzureichern und Mutationen des Rogdi-Gens zu neurologischen (und dentalen) Symptomen führen, so könnten diese Erkenntnisse Ausgangspunkt weitreichender Forschungen sein. So könnte in Humanexperimenten etwa die Expression des Proteins in Gehirnarealen gesunder und erkrankter Probanden verglichen werden.

In Nagern könnten die bisher im Menschen nachgewiesenen Mutationen erzeugt und deren Auswirkungen überprüft werden: Führen etwa dieselben Mutationen auch in anderen Lebewesen zur Epilepsie? Welche Abschnitte des Proteins sind die pathologisch bedeutsamen? 


\section{LITERATURVERZEICHNIS}

Ackley BD, Harrington RJ, Hudson ML, Williams L, Kenyon CJ, Chisholm AD, Jin Y. (2005): The Two Isoforms of the Caenorhabditis elegans Leukocyte-Common Antigen Related Receptor Tyrosine Phosphatase PTP-3 Function Independently in Axon Guidance and Synapse Formation. J Neurosci 25, 7517-7528

Ahmari SE, Buchanan J, Smith SJ (2000): Assembly of presynaptic active zones from cytoplasmic transport packets. Nat Neurosci 3, 445-451

Ahmed S, Wittenmayer N, Kremer T, Hoeber J, Kiran Akula A, Urlaub H, Islinger M, Kirsch J, Dean C, Dresbach T (2013): Mover Is a Homomeric Phospho-Protein Present on Synaptic Vesicles. PLoS ONE 8, e63474

Alabi AA, Tsien RW (2012): Synaptic Vesicle Pools and Dynamics. Cold Spring Harb Perspect Biol 4, a013680-a013680

Altrock WD, Tom Dieck S, Sokolov M, Meyer AC, Sigler A, Brakebusch C, Fässler R, Richter K, Boeckers TM, Potschka H (2003): Functional inactivation of a fraction of excitatory synapses in mice deficient for the active zone protein bassoon. Neuron 37, 787-800

Angenstein F, Hilfert L, Zuschratter W, Altrock WD, Niessen HG, Gundelfinger ED (2008): Morphological and Metabolic Changes in the Cortex of Mice Lacking the Functional Presynaptic Active Zone Protein Bassoon: A Combined 1H-NMR Spectroscopy and Histochemical Study. Cereb Cortex 18, 890-897

Antonini D, Dentice M, Mahtani P, De Rosa L, Della Gatta G, Mandinova A, Salvatore D, Stupka E, Missero C (2008): Tprg, a gene predominantly expressed in skin, is a direct target of the transcription factor p63. J Invest Dermatol 128, 1676-1685

Augustin I, Rosenmund C, Südhof TC, Brose N (1999): Munc13-1 is essential for fusion competence of glutamatergic synaptic vesicles. Nature 400, 457-461

Basu J, Shen N, Dulubova I, Lu J, Guan R, Guryev O, Grishin NV, Rosenmund C, Rizo J (2005): A minimal domain responsible for Munc13 activity. Nat Struct Mol Biol 12, 1017-1018

Baumert M, Maycox PR, Navone F, De Camilli P, Jahn R (1989): Synaptobrevin: an integral membrane protein of 18,000 daltons present in small synaptic vesicles of rat brain. EMBO J 8, 379

Betz A, Thakur P, Junge HJ, Ashery U, Rhee J-S, Scheuss V, Rosenmund C, Rettig J, Brose N (2001): Functional interaction of the active zone proteins Munc13-1 and RIM1 in synaptic vesicle priming. Neuron 30, 183-196 
Bloom O, Evergren E, Tomilin N, Kjaerulff O, Löw P, Brodin L, Pieribone VA, Greengard $\mathrm{P}$, Shupliakov O (2003): Colocalization of synapsin and actin during synaptic vesicle recycling. J Cell Biol 161(4), 737-747

Bonazzi M, Spanò S, Turacchio G, Cericola C, Valente C, Colanzi A, Kweon HS, Hsu VW, Polishchuck EV, Polishchuck RS (2005): CtBP3/BARS drives membrane fission in dynamin-independent transport pathways. Nat Cell Biol. 7(6), 570-580

Boyken J, Grønborg M, Riedel D, Urlaub H, Jahn R, Chua JJE (2013): Molecular Profiling of Synaptic Vesicle Docking Sites Reveals Novel Proteins but Few Differences between Glutamatergic and GABAergic Synapses. Neuron 모, 285-297

Breckenridge LJ Almers W (1987): Currents through the fusion pore that forms during exocytosis of a secretory vesicle. Nature $\underline{328}, 814-817$

Brose N, Hofmann K, Hata Y, Südhof TC (1995): Mammalian homologues of Caenorhabditis elegans unc-13 gene define novel family of C2-domain proteins. J Biol Chem $\underline{270}, 25273-25280$

Brose N, Rosenmund C, Rettig J (2000): Regulation of transmitter release by Unc-13 and its homologues. Curr Opin Neurobiol $\underline{10}$, 303-311

Burns ME, Augustine GJ (1995): Synaptic structure and function: dynamic organization

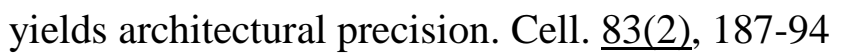

Burré J, Volknandt W (2007): The synaptic vesicle proteome. J Neurochem 101, 14481462

Butz S, Okamoto M, Südhof TC (1998): A tripartite protein complex with the potential to couple synaptic vesicle exocytosis to cell adhesion in brain. Cell $\underline{94}, 773-782$

Cases-Langhoff C, Voss B, Garner AM, Appeltauer U, Takei K, Kindler S, Veh RW, De Camilli P, Gundelfinger ED, Garner CC (1996): Piccolo, a novel 420 kDa protein associated with the presynaptic cytomatrix. Eur J Cell Biol 69, $214-223$

Castillo PE, Schoch S, Schmitz F, Südhof TC, Malenka RC (2002): RIM1 $\alpha$ is required for presynaptic long-term potentiation. Nature $\underline{415}$, 327-330

Ceccarelli B, Hurlbut WP, Mauro A (1972): Depletion of vesicles from frog neuromuscular junctions by prolonged tetanic stimulation. J Cell Biol 54, 30-38

Cesca F, Baldelli P, Valtorta F, Benfenati F (2010): The synapsins: Key actors of synapse function and plasticity. Prog Neurobiol 91, 313-348

Charpentier E, Doudna JA (2013): Biotechnology: Rewriting a genome. Nature $\underline{495}, 50-51$

Chen K, Featherstone DE (2011): Pre and postsynaptic roles for Drosophila CASK. Mol Cell Neurosci $48,171-182$

Chevaleyre V, Heifets BD, Kaeser PS, Südhof TC, Castillo PE (2007): Endocannabinoidmediated long-term plasticity requires cAMP/PKA signaling and RIM1 $\alpha$. Neuron $\underline{54}, 801-812$ 
Collins MO, Yu L, Coba MP, Husi H, Campuzano I, Blackstock WP, Choudhary JS, Grant SGN (2005): Proteomic Analysis of in Vivo Phosphorylated Synaptic Proteins. J Biol Chem 280, 5972-5982

Couteaux R, Pecot-Dechavassine M (1970): Vésicules synaptiques et poches au niveau des „zones actives“ de la jonction neuromusculaire. Comptes Rendus Séances Académie Sci Sér Sci Nat 271, 2346-2349

Dai Y, Taru H, Deken SL, Grill B, Ackley B, Nonet ML, Jin Y (2006): SYD-2 Liprinalpha organizes presynaptic active zone formation through ELKS. Nat Neurosci. $\underline{9(12)}, 1479-1487$

Davydova D, Marini C, King C, Klueva J, Bischof F, Romorini S, Montenegro-Venegas C, Heine M, Schneider R, Schröder MS (2014): Bassoon Specifically Controls Presynaptic P/Q-type Ca2+ Channels via RIM-Binding Protein. Neuron 2, 181-194

Deng L, Kaeser PS, Xu W, Südhof TC. (2011): RIM proteins activate vesicle priming by reversing autoinhibitory homodimerization of Munc13. Neuron 69, 317-331

Denker A, Rizzoli SO (2010): Synaptic vesicle pools: an update. Frontiers in Synaptic Neuroscience $\underline{2}, 135$

Dick O, tom Dieck S, Altrock WD, Ammermüller J, Weiler R, Garner CC, Gundelfinger ED, Brandstätter JH (2003): The Presynaptic Active Zone Protein Bassoon Is Essential for Photoreceptor Ribbon Synapse Formation in the Retina. Neuron 37, 775-786

Dresbach T, Hempelmann A, Spilker C, tom Dieck S, Altrock WD, Zuschratter W, Garner CC, Gundelfinger ED (2003): Functional regions of the presynaptic cytomatrix protein bassoon: significance for synaptic targeting and cytomatrix anchoring. Mol Cell Neurosci 23, 279-291

Dresbach $\mathrm{T}$, Torres V, Wittenmayer N, Altrock WD, Zamorano P, Zuschratter W, Nawrotzki R, Ziv NE, Garner CC, Gundelfinger ED (2006): Assembly of active zone precursor vesicles: obligatory trafficking of presynaptic cytomatrix proteins Bassoon and Piccolo via a trans-Golgi compartment. J Biol Chem 281, 6038-6047

Dulubova I, Lou X, Lu J, Huryeva I, Alam A, Schneggenburger R, Südhof TC, Rizo J. (2005): A Munc13/RIM/Rab3 tripartite complex: from priming to plasticity? EMBO J 24, 2839-2850

Elferink LA, Trimble WS, Scheller RH (1989): Two vesicle-associated membrane protein genes are differentially expressed in the rat central nervous system. J Biol Chem $\underline{264}, 11061-11064$

Fejtova A, Davydova D, Bischof F, Lazarevic V, Altrock WD, Romorini S, Schöne C, Zuschratter W, Kreutz MR, Garner CC (2009): Dynein light chain regulates axonal trafficking and synaptic levels of Bassoon. J Cell Biol 185, 341-355

Fenster SD, Chung WJ, Zhai R, Cases-Langhoff C, Voss B, Garner AM, Kaempf U, Kindler S, Gundelfinger ED, Garner CC (2000): Piccolo, a presynaptic zinc finger protein structurally related to bassoon. Neuron 25, 203-214 
Fisher-Lavie A, Ziv NE (2013): Matching Dynamics of Presynaptic and Postsynaptic Scaffolds. J Neurosci $\underline{33}, 13094-13100$

Fourcaudot E, Gambino F, Humeau Y, Casassus G, Shaban H, Poulain B, Lüthi A (2008): cAMP/PKA signaling and RIM1 $\alpha$ mediate presynaptic LTP in the lateral amygdala. Proc Natl Acad Sci 105, 15130-15135

Frank T, Rutherford MA, Strenzke N, Neef A, Pangršič T, Khimich D, Fejtova A, Gundelfinger ED, Liberman MC, Harke B (2010): Bassoon and the Synaptic Ribbon Organize Ca2+ Channels and Vesicles to Add Release Sites and Promote Refilling. Neuron $\underline{68}$, 724-738

Friedman HV, Bresler T, Garner CC, Ziv NE (2000): Assembly of new individual excitatory synapses: time course and temporal order of synaptic molecule recruitment. Neuron $\underline{27}, 57-69$

Fukuda M (2003): Distinct Rab binding specificity of Rim1, Rim2, rabphilin, and Noc2. Identification of a critical determinant of Rab3A/Rab27A recognition by Rim2. J Biol Chem. 278(17), 15373-15380

Furusawa T, Moribe H, Kondoh H, Higashi Y (1999): Identification of CtBP1 and CtBP2 as corepressors of zinc finger-homeodomain factor $\delta E F 1$. Mol Cell Biol $\underline{19}$, 85818590

Gerber SH, Rah J-C, Min S-W, Liu X, de Wit H, Dulubova I, Meyer AC, Rizo J, Arancillo M, Hammer RE (2008): Conformational switch of syntaxin-1 controls synaptic vesicle fusion. Science $\underline{321}, 1507-1510$

Gracheva EO, Hadwiger G, Nonet ML, Richmond JE (2008): Direct interactions between C. elegans RAB-3 and Rim provide a mechanism to target vesicles to the presynaptic density. Neurosci Lett $\underline{444}, 137-142$

Guan R, Dai H, Rizo J (2008): Binding of the Munc13-1 MUN Domain to MembraneAnchored SNARE Complexes. Biochemistry (Mosc) 느, 1474-1481

Gundelfinger ED, Reissner C, Garner CC (2015): Role of Bassoon and Piccolo in Assembly and Molecular Organization of the Active Zone. Front Synaptic Neurosci 7, 19 (die Verwendung der Abbildung erfolgt entsprechend der Creative CommonsLizenzen mit freundlicher Genehmigung der Frontiers Research Foundation sowie der Autoren Gundelfinger, Reissner und Garner)

Hallermann S, Fejtova A, Schmidt H, Weyhersmüller A, Silver RA, Gundelfinger ED, Eilers J (2010): Bassoon Speeds Vesicle Reloading at a Central Excitatory Synapse. Neuron $\underline{68}, 710-723$

Han Y, Kaeser PS, Südhof TC, Schneggenburger R (2011): RIM Determines Ca2+ Channel Density and Vesicle Docking at the Presynaptic Active Zone. Neuron 69, 304316

Harata N, Pyle JL, Aravanis AM, Mozhayeva M, Kavalali ET, Tsien RW (2001): Limited numbers of recycling vesicles in small CNS nerve terminals: implications for neural signaling and vesicular cycling. Trends Neurosci 24, 637-643 
Hata Y, Butz S, Südhof TC (1996): CASK: a novel dlg/PSD95 homolog with an Nterminal calmodulin-dependent protein kinase domain identified by interaction with neurexins. J Neurosci 16, 2488-2494

Heikal AA, Hess ST, Baird GS, Tsien RY, Webb WW (2000): Molecular spectroscopy and dynamics of intrinsically fluorescent proteins: coral red (dsRed) and yellow (Citrine). Proc Natl Acad Sci 97, 11996-12001

Herculano-Houzel S (2009): The human brain in numbers: a linearly scaled-up primate brain. Front Hum Neurosci $\underline{3}, 31$

Heyden A, Ionescu M-CS, Romorini S, Kracht B, Ghiglieri V, Calabresi P, Seidenbecher C, Angenstein F, Gundelfinger ED (2011): Hippocampal enlargement in Bassoonmutant mice is associated with enhanced neurogenesis, reduced apoptosis, and abnormal BDNF levels. Cell Tissue Res $\underline{346}, 11-26$

Hibino H, Pironkova R, Onwumere O, Vologodskaia M, Hudspeth AJ, Lesage F (2002): RIM binding proteins (RBPs) couple Rab3-interacting molecules (RIMs) to voltage-gated Ca $2+$ channels. Neuron $\underline{34}, 411-423$

Hilfiker S, Schweizer FE, Kao HT, Czernik AJ, Greengard P, Augustine GJ. (1998): Two sites of action for synapsin domain $\mathrm{E}$ in regulating neurotransmitter release. Nat Neurosci $\underline{1}, 29-35$

Hirokawa N, Sobue K, Kanda K, Harada A, Yorifuji H (1989): The cytoskeletal architecture of the presynaptic terminal and molecular structure of synapsin 1 . J Cell Biol $\underline{108}, 111-126$

Hosaka M, Südhof TC (1999): Homo-and heterodimerization of synapsins. J Biol Chem 274, 16747-16753

Hsueh Y-P, Yang F-C, Kharazia V, Naisbitt S, Cohen AR, Weinberg RJ, Sheng M (1998): Direct interaction of CASK/LIN-2 and syndecan heparan sulfate proteoglycan and their overlapping distribution in neuronal synapses. J Cell Biol 142, 139-151

Huang YY, Zakharenko SS, Schoch S, Kaeser PS, Janz R, Südhof TC, Siegelbaum SA, Kandel ER. (2005): Genetic evidence for a protein-kinase-A-mediated presynaptic component in NMDA-receptor-dependent forms of long-term synaptic potentiation. Proc Natl Acad Sci U S A 102, 9365-9370

Hübler D, Rankovic M, Richter K, Lazarevic V, Altrock WD, Fischer K-D, Gundelfinger ED, Fejtova A (2012): Differential Spatial Expression and Subcellular Localization of CtBP Family Members in Rodent Brain. PLoS ONE $\underline{7}$, e39710

Ivanova D, Dirks A, Montenegro-Venegas C, Schöne C, Altrock WD, Marini C, Frischknecht R, Schanze D, Zenker M, Gundelfinger ED (2015): Synaptic activity controls localization and function of CtBP1 via binding to Bassoon and Piccolo. Embo J 34, 1056-1077

Jose M, Nair DK, Altrock WD, Dresbach T, Gundelfinger ED, Zuschratter W (2008): Investigating Interactions Mediated by the Presynaptic Protein Bassoon in Living 
Cells by Foerster's Resonance Energy Transfer and Fluorescence Lifetime Imaging Microscopy. Biophys J 94, 1483-1496

Jordan M, Wurm F (2004): Transfection of adherent and suspended cells by calcium phosphate. Methods. $\underline{33(2)}$, 136-143

Kaech SM, Whitfield CW, Kim SK (1998): The LIN-2/LIN-7/LIN-10 complex mediates basolateral membrane localization of the C. elegans EGF receptor LET-23 in vulval epithelial cells. Cell $\underline{94}$, 761-771

Kaeser PS, Deng L, Wang Y, Dulubova I, Liu X, Rizo J, Südhof TC (2011): RIM proteins tether Ca 2+ channels to presynaptic active zones via a direct PDZ-domain interaction. Cell 144, 282-295

Kapushesky M, Adamusiak T, Burdett T, Culhane A, Farne A, Filippov A, Holloway E, Klebanov A, Kryvych N, Kurbatova N (2012): Gene Expression Atlas update--a value-added database of microarray and sequencing-based functional genomics experiments. Nucleic Acids Res 40, D1077-D1081

Kaufmann N, DeProto J, Ranjan R, Wan H, Van Vactor D (2002): Drosophila Liprin- $\alpha$ and the Receptor Phosphatase Dlar Control Synapse Morphogenesis. Neuron 34, 27-38

Kennedy MB, Greengard P (1981): Two calcium/calmodulin-dependent protein kinases, which are highly concentrated in brain, phosphorylate protein I at distinct sites. Proc Natl Acad Sci 78, 1293-1297

Kittel RJ, Wichmann C, Rasse TM, Fouquet W, Schmidt M, Schmid A, Wagh DA, Pawlu C, Kellner RR, Willig KI (2006): Bruchpilot promotes active zone assembly, Ca2+ channel clustering, and vesicle release. Science 312, 1051-1054

Ko J, Na M, Kim S, Lee J-R, Kim E (2003): Interaction of the ERC Family of RIMbinding Proteins with the Liprin- Family of Multidomain Proteins. J Biol Chem $\underline{278}, 42377-42385$

Koch H, Hofmann K, Brose N (2000): Definition of Munc13-homology-domains and characterization of a novel ubiquitously expressed Munc13 isoform. J Biochem $\underline{349}, 247-53$

Körber C, Horstmann H, Venkataramani V, Herrmannsdörfer F, Kremer T, Kaiser M, Schwenger DB, Ahmed S, Dean C, Dresbach T (2015): Modulation of Presynaptic Release Probability by the Vertebrate-Specific Protein Mover. Neuron 87, 521-533

Kohlschütter A, Chappuis D, Meier C, Tönz O, Vassella F, Herschkowitz N (1974): Familial epilepsy and yellow teeth--a disease of the CNS associated with enamel hypoplasia. Helv Paediatr Acta. 29, 283-294

Kosik KS, Finch EA (1987): MAP2 and tau segregate into dendritic and axonal domains after the elaboration of morphologically distinct neurites: an immunocytochemical study of cultured rat cerebrum. J Neurosci $\underline{7}$, 3142-3153

Koushika SP, Richmond JE, Hadwiger G, Weimer RM, Jorgensen EM, Nonet ML (2001): A post-docking role for active zone protein Rim. Nat Neurosci 4 , 997-1005 
Kremer T, Kempf C, Wittenmayer N, Nawrotzki R, Kuner T, Kirsch J, Dresbach T (2007): Mover is a novel vertebrate-specific presynaptic protein with differential distribution at subsets of CNS synapses. FEBS Lett $\underline{581}$, 4727-4733

Lachamp PM, Liu Y, Liu SJ (2009): Glutamatergic Modulation of Cerebellar Interneuron Activity Is Mediated by an Enhancement of GABA Release and Requires Protein Kinase A/RIM1 Signaling. J Neurosci 29, 381-392

Lenzi D, Runyeon JW, Crum J, Ellisman MH, Roberts WM (1999): Synaptic vesicle populations in saccular hair cells reconstructed by electron tomography. J Neurosci $\underline{19}$, 119-132

Lenzi D, Von Gersdorff H (2001): Structure suggests function: the case for synaptic ribbons as exocytotic nanomachines. Bioessays $\underline{23}$, 831-840

Limbach C, Laue MM, Wang X, Hu B, Thiede N, Hultqvist G, Kilimann MW (2011): Molecular in situ topology of Aczonin/Piccolo and associated proteins at the mammalian neurotransmitter release site. Proc Natl Acad Sci 108, E392-E401

Liu KS, Siebert M, Mertel S, Knoche E, Wegener S, Wichmann C, Matkovic T, Muhammad K, Depner H, Mettke C (2011): RIM-binding protein, a central part of the active zone, is essential for neurotransmitter release. Science 334, 1565-1569

Lu J, Machius M, Dulubova I, Dai H, Südhof TC, Tomchick DR, Rizo J (2006): Structural Basis for a Munc13-1 Homodimer to Munc13-1/RIM Heterodimer Switch. PLoS Biol 4, 192

Lupas A (1996): Coiled coils: new structures and new functions. Trends Biochem Sci 21, 375-382

Lv C, Gould TJ, Bewersdorf J, Zenisek D (2012): High-resolution optical imaging of zebrafish larval ribbon synapse protein RIBEYE, RIM2, and CaV 1.4 by stimulation emission depletion microscopy. Microsc Microanal. 18(4), 745-752

Ma C, Li W, Xu Y, Rizo J (2011): Munc13 mediates the transition from the closed syntaxin-Munc18 complex to the SNARE complex. Nat Struct Mol Biol 18, 542-549

Magupalli VG, Schwarz K, Alpadi K, Natarajan S, Seigel GM, Schmitz F (2008): Multiple RIBEYE-RIBEYE Interactions Create a Dynamic Scaffold for the Formation of Synaptic Ribbons. J Neurosci 28, 7954-7967

Maxeiner S, Luo F, Tan A, Schmitz F, Südhof TC (2016): How to make a synaptic ribbon: RIBEYE deletion abolishes ribbons in retinal synapses and disrupts neurotransmitter release. EMBO J $\underline{35}$, 1098-1114

Mendoza Schulz A, Jing Z, María Sánchez Caro J, Wetzel F, Dresbach T, Strenzke N, Wichmann C, Moser T (2014): Bassoon-disruption slows vesicle replenishment and induces homeostatic plasticity at a CNS synapse. EMBO J n/a-n/a

Miller KE, DeProto J, Kaufmann N, Patel BN, Duckworth A, Van Vactor D (2005): Direct Observation Demonstrates that Liprin- $\alpha$ Is Required for Trafficking of Synaptic Vesicles. Curr Biol 15, 684-689 
Missler M, Südhof TC (1998): Neurexins: Three genes and 1001 products. Trends Genet $\underline{14}, 20-26$

Mittelstaedt T, Schoch S. (2007): Structure and evolution of RIM-BP genes: identification of a novel family member. Gene $\underline{403}, 70-79$

Monier S, Jollivet F, Janoueix-Lerosey I, Johannes L, Goud B (2002): Characterization of novel Rab6-interacting proteins involved in endosome-to-TGN transport. Traffic $\underline{3}$, 289-297

Mukherjee K, Yang X, Gerber SH, Kwon H-B, Ho A, Castillo PE, Liu X, Südhof TC (2010): Piccolo and bassoon maintain synaptic vesicle clustering without directly participating in vesicle exocytosis. Proc Natl Acad Sci 107, 6504-6509

Nagai T, Ibata K, Park ES, Kubota M, Mikoshiba K, Miyawaki A (2002): A variant of yellow fluorescent protein with fast and efficient maturation for cell-biological applications. Nat Biotechnol 20, 87-90

Nakata T, Kitamura Y, Shimizu K, Tanaka S, Fujimori M, Yokoyama S, Ito K, Emi M. (1999): Fusion of a novel gene, ELKS, to RET due to translocation $\mathrm{t}(10 ; 12)(\mathrm{q} 11 ; \mathrm{p} 13)$ in a papillary thyroid carcinoma. Genes Chromosomes Cancer $\underline{25}, 97-103$

Ohtsuka T, Takao-Rikitsu E, Inoue E, Inoue M, Takeuchi M, Matsubara K, DeguchiTawarada M, Satoh K, Morimoto K, Nakanishi H (2002): Cast: a novel protein of the cytomatrix at the active zone of synapses that forms a ternary complex with RIM1 and munc13-1. J Cell Biol 158, 577-590

Okamoto M, Südhof TC (1997): Mints, Munc18-interacting proteins in synaptic vesicle exocytosis. J Biol Chem 272, 31459-31464

Olsen O, Moore KA, Fukata M, Kazuta T, Trinidad JC, Kauer FW, Streuli M, Misawa H, Burlingame AL, Nicoll RA (2005): Neurotransmitter release regulated by a MALS-liprin- $\alpha$ presynaptic complex. J Cell Biol 170, 1127-1134

Pelkey KA, Topolnik L, Yuan XQ, Lacaille JC, McBain CJ. (2008): State-dependent cAMP sensitivity of presynaptic function underlies metaplasticity in a hippocampal feedforward inhibitory circuit. Neuron $\underline{60}$, 980-987

Phillips GR, Huang JK, Wang Y, Tanaka H, Shapiro L, Zhang W, Shan W-S, Arndt K, Frank M, Gordon RE (2001): The presynaptic particle web: ultrastructure, composition, dissolution, and reconstitution. Neuron $\underline{32}, 63-77$

Porton B, Kao HT, Greengard P (1999a): Cloning of cDNAs encoding human synapsins IIa and IIb. DNA Seq. 10(1), 49-54

Porton B, Kao HT, Greengard P (1999b): Characterization of transcripts from the synapsin III gene locus. J Neurochem. 1999 73(6), 2266-71

Reddy PS, Housman DE (1997): The complex pathology of trinucleotide repeats. Curr Opin Cell Biol $\underline{9}$, 364-372 
Rhee JS, Betz A, Pyott S, Reim K, Varoqueaux F, Augustin I, Hesse D, Südhof TC, Takahashi M, Rosenmund C (2002): Beta phorbol ester- and diacylglycerolinduced augmentation of transmitter release is mediated by Munc13s and not by PKCs. Cell 108, 121-133

Richmond JE, Weimer RM, Jorgensen EM (2001): An open form of syntaxin bypasses the requirement for UNC-13 in vesicle priming. Nature $\underline{412}$, 338-341

Richter K, Langnaese K, Kreutz MR, Olias G, Zhai R, Scheich H, Garner CC, Gundelfinger ED. (1999): Presynaptic cytomatrix protein bassoon is localized at both excitatory and inhibitory synapses of rat brain. J Comp Neurol $\underline{408}, 437-448$

Rizzoli SO, Betz WJ (2005): Synaptic vesicle pools. Nat Rev Neurosci $\underline{6}$, 57-69

Rosenmund C, Sigler A, Augustin I, Reim K, Brose N, Rhee J-S (2002): Differential control of vesicle priming and short-term plasticity by Munc13 isoforms. Neuron $\underline{33}$, $411-424$

Ross CA (1997): Intranuclear Neuronal Inclusions: A Common Pathogenic Mechanism for Glutamine-Repeat Neurodegenerative Diseases? Neuron 19, 1147-1150

Sánchez-García I, Rabbitts TH. (1994): The LIM domain: a new structural motif found in zinc-finger-like proteins. Trends Genet $\underline{10}$, 315-320

Schikorski T, Stevens CF (1997): Quantitative ultrastructural analysis of hippocampal excitatory synapses. J Neurosci $\underline{17}$, 5858-5867

Schlüter OM, Basu J, Südhof TC, Rosenmund C. (2006): Rab3 Superprimes Synaptic Vesicles for Release: Implications for Short-Term Synaptic Plasticity. J Neurosci 26, 1239-1246

Schmitz F, Königstorfer A, Südhof TC (2000): RIBEYE, a Component of Synaptic Ribbons: A Protein's Journey through Evolution Provides Insight into Synaptic Ribbon Function. Neuron 28, 857-872

Schoch S, Castillo PE, Jo T, Mukherjee K, Geppert M, Wang Y, Schmitz F, Malenka RC, Südhof TC. (2002): RIM1alpha forms a protein scaffold for regulating neurotransmitter release at the active zone. Nature $\underline{415}, 321-326$

Schoch S, Gundelfinger ED (2006): Molecular organization of the presynaptic active zone. Cell Tissue Res $\underline{326}$, 379-391

Schossig A, Wolf NI, Fischer C, Fischer M, Stocker G, Pabinger S, Dander A, Steiner B, Tönz O, Kotzot D (2012): Mutations in ROGDI Cause Kohlschütter-Tönz Syndrome. Am J Hum Genet 90, 701-707

Serra-Pagès C, Medley QG, Tang M, Hart A, Streuli M (1998): Liprins, a family of LAR transmembrane protein-tyrosine phosphatase-interacting proteins. J Biol Chem $\underline{273}$, 15611-15620

Shapira M, Zhai RG, Dresbach T, Bresler T, Torres VI, Gundelfinger ED, Ziv NE, Garner CC (2003): Unitary assembly of presynaptic active zones from Piccolo-Bassoon transport vesicles. Neuron $\underline{38}$, 237-252 
Sheng M, Hoogenraad CC (2007): The Postsynaptic Architecture of Excitatory Synapses: A More Quantitative View. Annu Rev Biochem 76, 823-847

Siksou L, Rostaing P, Lechaire J-P, Boudier T, Ohtsuka T, Fejtova A, Kao H-T, Greengard P, Gundelfinger ED, Triller A (2007): Three-Dimensional Architecture of Presynaptic Terminal Cytomatrix. J Neurosci 27, 6868-6877

Siksou L, Varoqueaux F, Pascual O, Triller A, Brose N, Marty S (2009): A common molecular basis for membrane docking and functional priming of synaptic vesicles. Eur J Neurosci 30, 49-56

Snapp E: Design and Use of Fluorescent Fusion Proteins in Cell Biology. In: Bonifacino JS, Dasso M, Harford JB, Lippincott-Schwartz J, Yamada KM (Hrsg.) : Current Protocols in Cell Biology. John Wiley \& Sons, Inc., Hoboken 2005

Spangler SA, Hoogenraad CC (2007): Liprin- $\alpha$ proteins: scaffold molecules for synapse maturation. Biochem Soc Trans $\underline{35}, 1278-1282$

Stevens DR, Wu Z-X, Matti U, Junge HJ, Schirra C, Becherer U, Wojcik SM, Brose N, Rettig J (2005): Identification of the Minimal Protein Domain Required for Priming Activity of Munc13-1. Curr Biol 15, 2243-2248

Stryker E, Johnson KG (2007): LAR, liprin $\alpha$ and the regulation of active zone morphogenesis. J Cell Sci 120, 3723-3728

Südhof TC, Czernik AJ, Kao HT, Takei K, Johnston PA, Horiuchi A, Kanazir SD, Wagner MA, Perin MS, De Camilli P (1989): Synapsins: mosaics of shared and individual domains in a family of synaptic vesicle phosphoproteins. Science $\underline{245}, 1474-1480$

Südhof TC (1995): The synaptic vesicle cycle: a cascade of protein-protein interactions. Nature $\underline{375}$, 645-653

Südhof TC (2004): The synaptic vesicle cycle. Annu Rev Neurosci 27, 509-547

Südhof TC (2012): The Presynaptic Active Zone. Neuron 75, 11-25 (die Verwendung der Abbildung erfolgt mit freundlicher Genehmigung des Elsevier Verlags)

Takamori S, Holt M, Stenius K, Lemke EA, Grønborg M, Riedel D, Urlaub H, Schenck S, Brügger B, Ringler P (2006): Molecular Anatomy of a Trafficking Organelle. Cell 127, 831-846

Takao-Rikitsu E, Mochida S, Inoue E, Deguchi-Tawarada M, Inoue M, Ohtsuka T, Takai Y (2004): Physical and functional interaction of the active zone proteins, CAST, RIM1, and Bassoon, in neurotransmitter release. J Cell Biol 164, 301-311

Tarelli FT, Bossi M, Fesce R, Greengard P, Valtorta F (1992): Synapsin I partially dissociates from synaptic vesicles during exocytosis induced by electrical stimulation. Neuron $\underline{9}, 1143-1153$

Taschenberger H, Woehler A, Neher E (2016): Superpriming of synaptic vesicles as a common basis for intersynapse variability and modulation of synaptic strength. Proc Natl Acad Sci 113, E4548-E4557 
Thio SS, Bonventre JV, Hsu SI (2004): The CtBP2 co-repressor is regulated by NADHdependent dimerization and possesses a novel $\mathrm{N}$-terminal repression domain. Nucleic Acids Res 32, 1836-1847

tom Dieck S, Sanmartí-Vila L, Langnaese K, Richter K, Kindler S, Soyke A, Wex H, Smalla K-H, Kämpf U, Fränzer J-T (1998): Bassoon, a novel zinc-finger CAG/glutamine-repeat protein selectively localized at the active zone of presynaptic nerve terminals. J Cell Biol 142, 499-509

tom Dieck S, Altrock WD, Kessels MM, Qualmann B, Regus H, Brauner D, Fejtová A, Bracko O, Gundelfinger ED, Brandstätter JH (2005): Molecular dissection of the photoreceptor ribbon synapse: physical interaction of Bassoon and RIBEYE is essential for the assembly of the ribbon complex. J Cell Biol 168, 825-836

Tsien RY (1998): The green fluorescent protein. Annu Rev Biochem. 67, 509-44

Tsuriel S, Fisher A, Wittenmayer N, Dresbach T, Garner CC, Ziv NE (2009): Exchange and Redistribution Dynamics of the Cytoskeleton of the Active Zone Molecule Bassoon. J Neurosci 29, 351-358

Ulfig N, Nickel J, Bohl J (1998): Monoclonal antibodies SMI 311 and SMI 312 as tools to investigate the maturation of nerve cells and axonal patterns in human fetal brain. Cell Tissue Res 291, 433-443

Von Mollard GF, Mignery GA, Baumert M, Perin MS, Hanson TJ, Burger PM, Jahn R, Südhof TC (1990): rab3 is a small GTP-binding protein exclusively localized to synaptic vesicles. Proc Natl Acad Sci 87, 1988-1992

Wagh DA, Rasse TM, Asan E, Hofbauer A, Schwenkert I, Dürrbeck H, Buchner S, Dabauvalle M-C, Schmidt M, Qin G (2006): Bruchpilot, a Protein with Homology to ELKS/CAST, Is Required for Structural Integrity and Function of Synaptic Active Zones in Drosophila.Neuron 49, 833-844

Wan L, Almers W, Chen W (2005): Two ribeye genes in teleosts: the role of Ribeye in ribbon formation and bipolar cell development. J Neurosci.25(4), 941-9

Wang X, Kibschull M, Laue MM, Lichte B, Petrasch-Parwez E, Kilimann MW (1999): Aczonin, a 550-kD putative scaffolding protein of presynaptic active zones, shares homology regions with Rim and Bassoon and binds profilin. J Cell Biol 147, 151162

Wang X, Hu B, Zieba A, Neumann NG, Kasper-Sonnenberg M, Honsbein A, Hultqvist G, Conze T, Witt W, Limbach C (2009): A Protein Interaction Node at the Neurotransmitter Release Site: Domains of Aczonin/Piccolo, Bassoon, CAST, and Rim Converge on the N-Terminal Domain of Munc13-1. J Neurosci 29, 12584-12596

Wang Y, Okamoto M, Schmitz F, Hofmann K, Südhof TC (1997): Rim is a putative Rab3 effector in regulating synaptic-vesicle fusion. Nature $\underline{388,593-598}$

Wang Y, Sugita S, Südhof TC. (2000): The RIM/NIM Family of Neuronal C2 Domain Proteins. Interactions with Rab3 and a new class of Src homology 3 domain proteins. J Biol Chem 275, 20033-20044 
Wang Y, Liu X, Biederer T, Südhof TC (2002): A family of RIM-binding proteins regulated by alternative splicing: Implications for the genesis of synaptic active zones. Proc Natl Acad Sci 99, 14464-14469

Wiedenmann B, Franke WW (1985): Identification and localization of synaptophysin, an integral membrane glycoprotein of Mr 38,000 characteristic of presynaptic vesicles. Cell $\underline{41}, 1017-1028$

Wilhelm BG, Mandad S, Truckenbrodt S, Kröhnert K, Schäfer C, Rammner B, Koo SJ, Claßen GA, Krauss M, Haucke V (2014): Composition of isolated synaptic boutons reveals the amounts of vesicle trafficking proteins. Science $\underline{344}, 1023-1028$

Winter C, tom Dieck S, Boeckers TM, Bockmann J, Kämpf U, Sanmartí-Vila L, Langnaese K, Altrock W, Stumm M, Soyke A (1999): The Presynaptic Cytomatrix Protein Bassoon: Sequence and Chromosomal Localization of the HumanBSNGene. Genomics 57, 389-397

Zhai R, Olias G, Chung WJ, Lester RAJ, tom Dieck S, Langnaese K, Kreutz MR, Kindler S, Gundelfinger ED, Garner CC (2000): Temporal Appearance of the Presynaptic Cytomatrix Protein Bassoon during Synaptogenesis. Mol Cell Neurosci 15, 417428

Zhai RG (2004): The Architecture of the Active Zone in the Presynaptic Nerve Terminal. Physiology $\underline{19}, 262-270$

Zhai RG, Vardinon-Friedman H, Cases-Langhoff C, Becker B, Gundelfinger ED, Ziv NE, Garner CC (2001): Assembling the presynaptic active zone: a characterization of an active zone precursor vesicle. Neuron $\underline{29}$, 131-143

Zhen M, Jin Y (1999): The liprin protein SYD-2 regulates the differentiation of presynaptic termini in C. elegans. Nature $\underline{401}, 371-375$

Zimmerberg J, Curran M, Cohen FS, Brodwick M. (1987): Simultaneous electrical and optical measurements show that membrane fusion precedes secretory granule swelling during exocytosis of beige mouse mast cells. Proc Natl Acad Sci U S A $\underline{84}$, 15851589 